\author{
Universidade de São Paulo \\ Instituto de Física
}

\title{
Caracterização estrutural e eletrônica da zircônia pura e com defeitos e impurezas
}

\author{
Michel Lacerda Marcondes dos Santos
}

Orientadora: Profa. Dra. Lucy Vitória Credidio Assali

\begin{abstract}
Dissertação apresentada ao Instituto de Física da Universidade de São Paulo para a obtenção do título de Mestre em Ciências
\end{abstract}

Banca Examinadora:

Profa. Dra. Lucy Vitória Credidio Assali (Orientadora) (IFUSP)

Profa. Dra. Euzi Conceição Fernandes da Silva (IFUSP)

Prof. Dr. Ivan Costa da Cunha Lima (UERJ)

São Paulo

2011 
FICHA CATALOGRÁFICA

Preparada pelo Serviço de Biblioteca e Informação do Instituto de Física da Universidade de São Paulo

Santos, Michel Lacerda Marcondes dos

Caracterização estrutural e eletrônica da zircônia pura e com defeitos e impurezas - São Paulo - 2011.

Dissertação (Mestrado) - Universidade de São Paulo. Instituto de Física - Depto. de Física dos Materiais e Mecânica

Orientador: Profa. Dra. Lucy Vitória Credidio Assali Área de Concentração: Física

Unitermos: 1. Física do Estado Sólido; 2. Estrutura dos Sólidos; 3. Propriedade dos Sólidos; 4. Zircônia; 5. Impureza 
Dedico este trabalho ao meu pai. 

"Se você acha que entendeu alguma coisa de mecânica quântica, então é porque você não entendeu nada".

[Richard P. Feynman] 



\section{Agradecimentos}

Os meus agradecimentos:

À minha mãe, à minha irmã e à minha namorada, Tamires, pelo apoio quando mais precisei.

À Profa. Lucy V. C. Assali, pela orientação e oportunidade de trabalho.

À Profa. Marcia C. A. Fantini pelas valiosas discussões e sugestões.

Aos colegas Joelson Cott e Rolando Larico, pelas diversas dicas sobre o uso e instalação do software WIEN2k, além de outras inúmeras ajudas.

Também agradeço:

A todos meus amigos e amigas.

À Sandra, à Marisa e à Rosana, secretárias do Departamento de Física dos Materiais e Mecânica, e ao pessoal da Comissão de Pós-Graduação, Cláudia, Éber, Cristiano e Izabel, pelo suporte na área administrativa.

Ao Laboratório de Computação Científica Avançada (LCCA-USP) e ao Centro Nacional de Processamento de Alto Desempenho de São Paulo (CENAPAD-SP), pelas facilidades computacionais.

Ao $\mathrm{CNPq}$ pelo apoio financeiro. 



\section{Índice}

Resumo iv

Abstract $\quad$ vi

1 Introdução 1

2 Fundamentos teóricos e metodologia 5

2.1 Introdução . . . . . . . . . . . . . . . . . . . . . . . . 5

2.2 Teoria do Funcional da Densidade . . . . . . . . . . . . . . . . 7

2.2.1 Teoremas de Hohenberg e Kohn . . . . . . . . . . . . . . . 7

2.2 .2 Equações de Kohn - Sham . . . . . . . . . . . . . . . 7

2.2.3 Aproximação da Densidade Local - LDA . . . . . . . . . . . 12

2.2.4 Aproximação do Gradiente Generalizado - GGA . . . . . . . 14

2.3 O Método APW . . . . . . . . . . . . . . . . . . . . . 18

2.3.1 Noções Preliminares - Método APW . . . . . . . . . . . 18

2.3.2 Método FP-LAPW . . . . . . . . . . . . . . . . . 21

2.3.3 Método APW+lo . . . . . . . . . . . . . . . . 24

2.3.4 Efeitos Relativísticos no WIEN2k . . . . . . . . . . 25

2.4 O Processo Autoconsistente . . . . . . . . . . . . . . . . . . 29

2.5 Esquema da Supercélula . . . . . . . . . . . . . . . . . 30

3 Cristal de $\mathrm{ZrO}_{2}$

3.1 Introdução . . . . . . . . . . . . . . . . . . . . . . 33

3.2 Cristais Perfeitos de Zircônia . . . . . . . . . . . . . . . . . . . 34 
$3.2 .1 \mathrm{ZrO}_{2}$ Cúbico . . . . . . . . . . . . . . . 35

3.2.2 $\mathrm{ZrO}_{2}$ Tetragonal .................... 43

3.2.3 Cristal de $\mathrm{ZrO}_{2}$ Tetragonal de Corpo Centrado . . . . . . . . 50

3.3 Supercélulas de $\mathrm{ZrO}_{2}$. . . . . . . . . . . . . . . . . . . 58

3.3.1 Supercélula da Zircônia Cúbica . . . . . . . . . . . . . 58

3.3.2 Supercélula da Zircônia Tetragonal . . . . . . . . . . . . . . 59

4 Defeitos e Impurezas no Cristal de $\mathrm{ZrO}_{2}$

4.1 Introdução . . . . . . . . . . . . . . . . . . . . . . . . 63

4.2 Vacância de Oxigênio: $\mathrm{V}_{\mathrm{O}}$. . . . . . . . . . . . . . . . . 64

4.3 Impureza substitucional de $\mathrm{Ce}: \mathrm{ZrO}_{2}: \mathrm{Ce}_{\mathrm{Zr}} \ldots \ldots \ldots . . \ldots 68$

$\begin{array}{lll}5 & \text { Conclusão } & 75\end{array}$

$\begin{array}{lll}\text { A Energia de Formação } & 77\end{array}$

A.1 Energia de Formação da Vacância de Oxigênio: $\mathbf{Z r O}_{2}: \mathbf{V}_{\mathbf{O}}$. . . . . 80

A.2 Energia de Formação da Impureza Substitucional de Ce no sítio do $\mathrm{Zr}: \mathrm{ZrO}_{2}: \mathrm{Ce}_{\mathrm{Zr}} \ldots \ldots \ldots \ldots$

B Cálculo da distância entre primeiros vizinhos na zircônia tetragonal

$\begin{array}{lr}\text { Bibliografia } & 86\end{array}$

$\begin{array}{lr}\text { Referências Bibliográficas } & 86\end{array}$ 


\section{Resumo}

Neste trabalho estudamos as propriedades eletrônicas e as estabilidades estruturais do cristal de $\mathrm{ZrO}_{2}$ e dos defeitos de vacância de oxigênio e impureza substitucional de cério. As investigações foram efetuadas através de simulações computacionais baseadas em métodos de primeiros princípios dentro do formalismo da teoria do funcional da densidade e utilizando o método APW + lo (Aumengted Plane Waves plus local orbitals), implementado no código computacional WIEN2k, dentro do esquema de supercélula, com relaxações atômicas tratadas de modo apropriado.

A zircônia apresenta 3 fases estruturais, dependendo da temperatura. Sua fase mais estável é a monoclínica e, a altas temperaturas, ela apresenta as fases tetragonal e cúbica, sendo estas duas últimas as mais importantes para aplicações tecnológicas. Ela pode ser estabilizada em uma condição metaestável em uma estrutura quase cúbica quando crescida na forma de pós nanocristalinos, com tamanhos menores que um certo tamanho crítico. Outra maneira de se estabilizar as estruturas cúbica e tetragonal, a temperatura ambiente, é através da adição de dopantes, entre eles o cério. Nesses casos, estão sempre presentes vacâncias de oxigênio.

Neste trabalho, para o cristal puro de $\mathrm{ZrO}_{2}$, foram calculadas as propriedades das estruturas cristalinas cúbica e tetragonal, constatando-se que a estrutura quase cúbica, proposta em várias investigações relatadas na literatura, pode ser interpretada como uma estrutura tetragonal de corpo centrado, com pequenos deslocamentos dos átomos de oxigênio na direção $\hat{k}$. Destes resultados, propomos que nas análises dos dados experimentais obtidos por difração de raios-X e EXAFS (Extended X-ray Absorption Fine Structure) sejam utilizadas simulações onde a es- 
trutura tetragonal de corpo centrado seja considerada como uma possível estrutura para o cristal.

Dos estudos da vacância de oxigênio, obtivemos que sua presença quebra a simetria local do sistema e faz com que existam três diferentes distâncias entre um átomo de Zr e os átomos primeiros vizinhos de oxigênio, podendo, também, explicar resultados experimentais de difração de raios-X e EXAFS. Para o centro de impureza substitucional de Ce no sítio do átomo de $\mathrm{Zr}$, nossos resultados apresentam uma possível explicação de porque as impurezas de Ce, em diferentes concentrações, estabilizam o $\mathrm{ZrO}_{2}$ nas estruturas tetragonal e cúbica. 


\section{Abstract}

In this investigation we studied the electronic properties and the structural stabilities of zirconia $\left(\mathrm{ZrO}_{2}\right)$, as well as oxygen vacancy and Ce substitutional impurity. The investigations were carried by computational simulations using ab initio methods, based on the density functional theory and the APW + lo (Aumengted Plane Waves plus local orbitals) method, as implemented in the WIEN2k code, considering the supercell approach and atomic relaxations.

Concerning the $\mathrm{ZrO}_{2}$ bulk, the tetragonal (quasi-cubic) phase is not thermodynamically stable at room temperature, but it can be retained in a metastable condition in nanocrystalline powders with crystallite sizes smaller than a certain critical size, or throught addition of dopants, for example cerium. In this cases, oxygen vacancies are always present.

In this work we have obtained the properties of the cubic and tetragonal phases of $\mathrm{ZrO}_{2}$. From the results, we propose that the quasi-cubic structure presented in many articles can be understood as a body centered tetragonal structure, with small oxygen atoms displacement perpendicular to the $\hat{k}$ direction. Those results suggest that the analysis of the X-ray and EXAFS (Extended X-ray Absorption Fine Structure) data should include in the crystallographic model the body-center tetragonal structure. The results of the structural and electronic properties of the oxygen vacancy suggest that its presence could explain the different models of the Zr first neighbor oxygen shell. For the Ce substitutional impurity, our results present a possible explanation why these impurities, in several concentrations, are able to stabilise the $\mathrm{ZrO}_{2}$ in the tetragonal and cubic phases. 



\section{Capítulo 1}

\section{Introdução}

A zircônia tem sido amplamente estudada devido ao seu grande potencial tecnológico. Contudo, apesar de muitos estudos experimentais, pouco tem sido estudado do ponto de vista teórico sobre propriedades estruturais e impurezas em zircônia. Materiais baseados em zircônia têm sido muito investigados devido às suas grandes aplicações tecnológicas como calalizadores [1], células solares e sensores de oxigênio $[2,3]$. A zircônia apresenta 3 fases estruturais, dependendo da temperatura. Até $1170^{\circ} \mathrm{C}$ sua fase mais estável é a monoclínica, de $1170^{\circ} \mathrm{C}$ até $2370^{\circ} \mathrm{C}$ a fase tetragonal é a mais estável e acima de $2370^{\circ} \mathrm{C}$ até seu ponto de fusão $\left(2780^{\circ} \mathrm{C}\right)$ a estrutura é cúbica [2]. As fases mais importantes para aplicações práticas são a tetragonal e a cúbica.

A fase tetragonal pode ser obtida da estrutura cúbica, através de distorções dos átomos de oxigênio. A zircônia cúbica apresenta uma rede de Bravais de faces centradas, onde o átomo de $\mathrm{Zr}$ tem oito átomos de oxigênio como primeiros vizinhos. Se quatro destes átomos de oxigênio forem deslocados em um sentido e os outro quatro átomos restantes para o outro e, ainda, ocorrer uma pequena elongação na direção $\hat{k}$, obtém-se a zircônia tetragonal. Alguns resultados experimentais [4] sugerem que a instabilidade estrutural da fase cúbica está ligada à esta distorção. Uma rede cúbica de face centrada distorcida em uma determinada direção é equivalente à uma rede tetragonal de corpo centrado. Se considerarmos esta rede como uma estrutura cristalina para a zircônia, com pequenos deslocamentos dos átomos 
de oxigênio, obtém-se a estrutura tetragonal primitiva.

Apesar da zircônia apresentar as fases cúbica e tetragonal apenas em altas temperaturas, é possível estabilizá-la nessas fases com a adição de dopantes. Esses dopantes são impurezas substitucionais que ocupam o lugar de um átomo de zircônio, mas acrescentam vacâncias de oxigênio no cristal de $\mathrm{ZrO}_{2}$. O papel desempenhado por vacâncias de oxigênio na estabilização da fase cúbica ainda não é bem compreendido [5]. Apesar de compostos à base de zircônia serem muito estudados, sua estrutura local ainda não é bem compreendida [6] e restam várias controvérsias sobre como a fase tetragonal é retida com a adição de dopantes. Alguns modelos foram propostos para tentar explicar a estrutura local do $\mathrm{ZrO}_{2}$, baseados em experimentos de EXAFS e raios-X [2]. Porém, ainda não se sabe qual desses modelos melhor representa a estrutura da zircônia. Vários trabalhos experimentais têm sido elaborados para explicar a estabilização da zircônia na fase cúbica $[1,2,7]$, mas pouco foi estudado teoricamente, através de cálculos baseados em métodos de primeiros princípios, sobre o papel dos dopantes, tais como Ce, Ca e Y, na estabilização estrutural da zircônia.

O objetivo deste trabalho é estudar as propriedades estruturais e eletrônicas da zircônia pura e com defeitos usando métodos de primeiros princípios para tentar entender sua estrutura de ordem local e tentar explicar teoricamente alguns resultados experimentais de zircônia dopada com Ce. Fornasiero et al. [1] sugerem que alguns resultados experimentais podem ser explicados se for feita a suposição de que os átomos de oxigênio se desloquem na direção do eixo $\hat{k}$. Entretanto, resultados recentes mostram que também é necessário supor a existência de deslocamentos nas direções dos eixos $\hat{\imath}$ e $\hat{\jmath}$ para explicar os resultados obtidos [2]. Um dos objetivos desse trabalho é calcular os deslocamentos dos átomos de oxigênio e verificar as direções e sentidos em que eles ocorrem.

A introdução de impurezas e/ou defeitos em um sistema cristalino leva à perda da simetria de translação do sistema. Entretanto, ainda é possível estudar o efeito dessas impurezas, dentro de um modelo de estado sólido, se considerarmos que elas se repetem periodicamente no cristal. No nosso estudo da vacância de oxigênio e 
da impureza de Ce utilizamos o esquema de supercélula, que é uma célula formada pela repetição de células primitivas. Em cada supercélula coloca-se a impureza. A supercélula deve ser suficientemente grande para que não haja interação entre as impurezas pertencentes à células adjacentes.

Nosso trabalho está estruturado da seguinte forma: no Capítulo 2 apresentamos os modelos teóricos e a metodologia utilizada em nosso estudo. Nos Capítulos 3 e 4 apresentamos nossos resultados das propriedades físicas da zircônia pura e com defeitos: vacância de oxigênio e cério substitucional. Nossas conclusões estão sumarizadas no Capítulo 5. No Apêndice A apresentamos uma descrição de como calculamos as entalpias e energias de formação dos sistemas, enquanto o Apêndice $\mathrm{B}$ apresenta os valores das distâncias entre primeiros vizinhos da $\mathrm{ZrO}_{2}$ tetragonal. 


\section{Capítulo 2}

\section{Fundamentos teóricos e metodologia}

\subsection{Introdução}

O estudo quântico de um sistema de vários corpos é um problema clássico em física do estado sólido. Todas as propriedades de um sistema cristalino podem ser obtidas resolvendo-se a equação de Schroedinger:

$$
\hat{H} \Psi=E \Psi
$$

onde o hamiltoniano $\hat{H}$ é dado por

$$
\begin{aligned}
\hat{H}= & -\frac{\hbar^{2}}{2} \sum_{i=1}^{N_{n}} \frac{\nabla_{R_{i}}^{2}}{M_{i}}-\frac{\hbar^{2}}{2} \sum_{i=1}^{N_{e}} \frac{\nabla_{r_{j}}^{2}}{m_{e}}-\frac{1}{4 \pi \epsilon_{0}} \sum_{i \neq j} \frac{Z_{i} e^{2}}{\left|\vec{R}_{i}-\vec{r}_{j}\right|}+ \\
& +\frac{1}{8 \pi \epsilon_{0}} \sum_{i \neq j} \frac{e^{2}}{\left|\vec{r}_{i}-\vec{r}_{j}\right|}+\frac{1}{8 \pi \epsilon_{0}} \sum_{i \neq j} \frac{Z_{i} Z_{j} e^{2}}{\left|\vec{R}_{i}-\vec{R}_{j}\right|}
\end{aligned}
$$

onde $\vec{R}_{i}\left(i=1, \ldots N_{n}\right)$ denotam as posições dos núcleos, com números atômicos $Z_{i}$ e massa $M_{i}$, e $\vec{r}_{i}\left(i=1, \ldots N_{e}\right)$ as dos elétrons de massa $m_{e}$. Nesta expressão, os dois primeiros termos representam, respectivamente, os operadores energias cinéticas dos núcleos e dos elétrons. Os outros três termos são, sucessivamente, os operadores energias de interação núcleo-elétron, elétron-elétron e núcleo-núcleo. A primeira 
aproximação que devemos fazer para resolver esta equação, chamada aproximação de Born-Oppenheimer [8,9], se faz notando que, como os núcleos são muito mais pesados que os elétrons, então suas energias cinéticas são muito menores que as dos elétrons. Desse modo, podemos desprezar o termo da energia cinética dos núcleos, assumindo-os em repouso. Com isso, o último termo da expressão (2.2), que corresponde à energia de interação núcleo-núcleo, passa a ser uma constante que podemos considerar, sem perda de generalidade, como sendo nula. Assim o hamiltoniano do sistema se reduz à:

$$
\hat{H}=-\frac{\hbar^{2}}{2} \sum_{i=1} \frac{\nabla_{r_{i}}^{2}}{m_{e}}-\frac{1}{4 \pi \epsilon_{0}} \sum_{i \neq j} \frac{Z_{i} e^{2}}{\left|\vec{R}_{i}-\vec{r}_{j}\right|}+\frac{1}{8 \pi \epsilon_{0}} \sum_{i \neq j} \frac{e^{2}}{\left|\vec{r}_{i}-\vec{r}_{j}\right|},
$$

o qual, no sistema de unidades atômicas em Rydbergs, pode ser escrito como:

$$
\hat{H}=-\sum_{i} \nabla_{r_{i}}^{2}-\sum_{i \neq j} \frac{2 Z_{i}}{\left|\vec{R}_{i}-\vec{r}_{j}\right|}+\sum_{i \neq j} \frac{1}{\left|\vec{r}_{i}-\vec{r}_{j}\right|}
$$

Mesmo com a aproximação de Born-Oppenheimer, ainda ficamos com uma equação de muitas partículas interagentes, sem possibilidade prática de resolução. A teoria do funcional da densidade (DFT) [10,11] é um esquema que permite resolver este problema de muitos corpos utilizando, como o ente principal a ser determinado, a densidade eletrônica do sistema. A primeira teoria a utilizar a densidade eletrônica como variável básica, ao invés da função de onda, estabelecendo uma relação implícita entre o potencial externo e a densidade eletrônica do sistema, foi a do átomo de Thomas-Fermi, em 1937 [12,13]. No entanto, até 1964 o uso da densidade era considerada apenas um modelo, quando Hohenberg e Kohn propuseram um método prático e poderoso para descrever um sistema de elétrons interagentes. Na DFT as partículas são tratadas através do mapeamento de um sistema auxiliar, não interagente, no qual se movem em um potencial efetivo local de partícula única. Os resultados obtidos neste trabalho utilizam um esquema prático para resolver as equações de Kohn-Sham (KS), provenientes da DFT, conhecido com APW + lo (Aumengted Plane Waves plus local orbitals) [14-16], implementado no código computacional WIEN2k [17], e constitue uma poderosa ferramenta na descrição das propriedades físicas de materiais. Esta metodologia está descrita nas próximas seções. 


\subsection{Teoria do Funcional da Densidade}

\subsubsection{Teoremas de Hohenberg e Kohn}

Os teoremas de Hohenberg e Kohn [10] são:

Teorema 1: A energia total de um sistema quântico de vários elétrons é um funcional único do potencial externo.

Teorema 2: A correta densidade eletrônica para o estado fundamental é aquela que minimiza o funcional energia total do sistema.

O primeiro teorema diz que o potencial externo é um funcional único da densidade eletrônica do sistema, estabelecendo uma relação biunívoca entre a densidade eletrônica e o potencial externo. O segundo teorema é o princípio variacional de Rayleight-Ritz aplicado à densidade eletrônica, ao invés de na função de onda, e pode ser considerado como uma maneira formal de tornar exata a teoria de ThomasFermi. Assim, o teorema 1, ao estabelecer que existe uma correspondência única entre a densidade $\rho(\vec{r})$ do estado fundamental de um sistema de muitos elétrons e o potencial externo $V_{\text {ext }}$, ela estabelece que o valor esperado, no estado fundamental, para um observável descrita pelo operador $\hat{O}$, é um funcional único da densidade eletrônica do estado fundamental do sistema, que depende de $V_{\text {ext }}$. Isto leva ao teorema 2, pois se o operador $\hat{O}$ for o hamiltoniano $\hat{H}$, então existe um funcional energia total, do estado fundamental de um sistema de elétrons interagentes, que é um funcional da densidade de carga eletrônica, que depende de $V_{\text {ext }}$.

\subsubsection{Equações de Kohn - Sham}

Utilizando os teoremas de Hohenberg e Kohn (HK), Kohn e Sham (KS) [11] desenvolveram um método eficaz para se calcular as propriedades de um sistema de muitos corpos. Utilizando o primeiro teorema de HK, onde o funcional energia total é escrito como:

$$
E[\rho(\vec{r})]=V_{e x t}[\rho(\vec{r})]+G[\rho(\vec{r})]
$$


com $G[\rho(\vec{r})]$ sendo um funcional universal, independente do sistema considerado, e pode ser escrito em termos do funcional energia cinética e do funcional energia de interação eletrônica do sistema:

$$
G[\rho(\vec{r})]=T[\rho(\vec{r})]+V_{e e}[\rho(\vec{r})] .
$$

A forma analítica do funcional $G$ não é conhecida, mas os teoremas de HK garantem que ele é um funcional da densidade. Em 1965, Kohn e Sham [11] propuseram uma maneira de escrever este funcional, o qual denominamos $F_{K S}[\rho(\vec{r})]$, o qual trata as partículas interagentes do sistema em termos de um sistema efetivo não interagente, com a mesma densidade total do problema de muitos corpos. A expressão proposta para o funcional de KS tem a seguinte forma:

$$
F_{K S}[\rho(\vec{r})]=\iint \frac{\rho(\vec{r}) \rho\left(\vec{r}^{\prime}\right)}{\left|\vec{r}-\vec{r}^{\prime}\right|} d \vec{r} d \vec{r}^{\prime}+T_{s}[\rho(\vec{r})]+E_{x c}[\rho(\vec{r})]
$$

onde o primeiro termo do segundo membro da equação (2.7) define as interações elétron-elétron puramente coulombianas, $T_{s}[\rho(\vec{r})]$ representa o funcional energia cinética de um gás de elétrons não interagentes e $E_{x c}[\rho(\vec{r})]$ corresponde ao funcional energia de troca e correlação e incorpora o termo de troca (devido ao princípio de exclusão de Pauli) e parte do funcional $T[\rho(\vec{r})]$ da equação (2.6), desprezado em $T_{s}[\rho(\vec{r})]$. Assim, o funcional energia total do sistema fica:

$$
E[\rho(\vec{r})]=\int \rho(\vec{r}) V_{e x t}(\vec{r}) d \vec{r}+\iint \frac{\rho(\vec{r}) \rho\left(\vec{r}^{\prime}\right)}{\left|\vec{r}-\vec{r}^{\prime}\right|} d \vec{r} d \vec{r}^{\prime}+T_{s}[\rho(\vec{r})]+E_{x c}[\rho(\vec{r})] .
$$

Utilizando o segundo teorema de HK, temos que a correta densidade para o estado fundamental é a que minimiza o funcional energia total do sistema, dado pela equação (2.8), com a restrição de que o número total de partículas $N$, expresso por

$$
N=\int \rho(\vec{r}) d \vec{r}
$$

deva ser constante. Sendo $\varepsilon$ um multiplicador de Lagrange, a condição de mínimo é obtida por meio de

$$
\delta\{E[\rho(\vec{r})]-\varepsilon N\}=0 .
$$


Substituindo as expressões (2.8) e (2.9) na equação (2.10), obtemos

$\delta\left\{\int \rho(\vec{r}) V_{\text {ext }}(\vec{r}) d \vec{r}+\iint \frac{\rho(\vec{r}) \rho\left(\vec{r}^{\prime}\right)}{\left|\vec{r}-\vec{r}^{\prime}\right|} d \vec{r} d \vec{r}^{\prime}+T_{s}[\rho(\vec{r})]+E_{x c}[\rho(\vec{r})]-\varepsilon \int \rho(\vec{r}) d \vec{r}\right\}=0$.

Explicitando a variação, separadamente, de cada um dos termos da equação (2.11), temos:

$$
\begin{aligned}
\delta\left\{\int \rho(\vec{r}) V_{\text {ext }}(\vec{r}) d \vec{r}\right\} & =\int V_{\text {ext }}(\vec{r}) \delta \rho(\vec{r}) d \vec{r} ; \\
\delta\left\{\iint \frac{\rho(\vec{r}) \rho\left(\vec{r}^{\prime}\right)}{\left|\vec{r}-\vec{r}^{\prime}\right|} d \vec{r} d \vec{r}^{\prime}\right\} & =2 \int \frac{\rho\left(\vec{r}^{\prime}\right)}{\left|\vec{r}-\vec{r}^{\prime}\right|} \delta \rho(\vec{r}) d \vec{r}^{\prime} ; \\
\delta T_{s}[\rho(\vec{r})] & =\int\left[\frac{\delta T_{s}}{\delta \rho}\right] \delta \rho(\vec{r}) d \vec{r} ; \\
\delta E_{x c}[\rho(\vec{r})] & =\int\left[\frac{\delta E_{x c}}{\delta \rho}\right] \delta \rho(\vec{r}) d \vec{r} ; \\
\delta\left\{\int \rho(\vec{r}) d \vec{r}\right\} & =\int \delta \rho(\vec{r}) d \vec{r} .
\end{aligned}
$$

Substituindo as equações (2.12)-(2.16) na equação (2.11) obtemos

$$
\int d \vec{r}\left\{V_{e x t}(\vec{r})+2 \int \frac{\rho\left(\vec{r}^{\prime}\right)}{\left|\vec{r}-\vec{r}^{\prime}\right|} d \vec{r}^{\prime}+\frac{\delta T_{s}}{\delta \rho}+\frac{\delta E_{x c}}{\delta \rho}-\varepsilon\right\} \delta \rho(\vec{r})=0 .
$$

Como a variação $\delta \rho(\vec{r})$ é arbitrária, então a expressão entre parênteses, na equação, acima deve ser nula, levando à equação

$$
V_{e x t}(\vec{r})+2 \int \frac{\rho\left(\vec{r}^{\prime}\right)}{\left|\vec{r}-\vec{r}^{\prime}\right|} d \vec{r}^{\prime}+\frac{\delta T_{s}}{\delta \rho}+\frac{\delta E_{x c}}{\delta \rho}-\varepsilon=0 .
$$

Para encontrarmos as equações de KS devemos, neste ponto, expressar a densidade eletrônica do sistema em termos de um conjunto de $N$ funções ortonormais 
de modo que

$$
\rho(\vec{r})=\sum_{k=1}^{N} \varphi_{k}^{*}(\vec{r}) \varphi_{k}(\vec{r})
$$

Com isso, podemos, no processo variacional anterior, substituir a variação em $\rho(\vec{r})$ por variações nas funções $\varphi_{k}^{*}(\vec{r})$ e $\varphi_{k}(\vec{r})$. Iremos variar $\varphi_{k}^{*}(\vec{r})$ e, portanto $\delta \rho(\vec{r})=\left[\delta \varphi_{k}^{*}(\vec{r})\right] \varphi_{k}(\vec{r})$. No caso considerado de um sistema auxiliar de elétrons não interagentes, o funcional energia cinética também pode ser expresso em termos do conjunto de $N$ funções ortonormais, como

$$
T_{s}[\rho]=\sum_{i=1}^{N} \int \nabla \varphi_{k}^{*}(\vec{r}) \cdot \nabla \varphi_{k}(\vec{r}) d \vec{r}
$$

Desse modo, a variação do funcional energia cinética fica:

$$
\begin{aligned}
\delta T_{s}[\rho(\vec{r})] & =\int \nabla\left[\delta \varphi_{k}^{*}(\vec{r})\right] \cdot \nabla \varphi_{k}(\vec{r}) d \vec{r} \\
& =\int \nabla \cdot\left[\delta \varphi_{k}^{*}(\vec{r}) \nabla \varphi_{k}(\vec{r})\right] d \vec{r}-\int \delta \varphi_{k}^{*}(\vec{r}) \nabla^{2} \varphi_{k}(\vec{r}) d \vec{r} \\
& =\underbrace{\int \delta \varphi_{k}^{*}(\vec{r}) \nabla \varphi_{k}(\vec{r}) d \vec{S}}_{=0}-\int \delta \varphi_{k}^{*}(\vec{r}) \nabla^{2} \varphi_{k}(\vec{r}) d \vec{r}
\end{aligned}
$$

onde a integral de superfície, na equação (2.21), é nula, pois ou $\varphi_{k}$ é nula no infinito ou temos condições periódicas de contorno. Utilizando a definição de derivadas funcionais, temos que a equação (2.21) fica

$$
\frac{\delta T_{s}[\rho]}{\delta \rho}=-\int \delta \varphi_{k}^{*}(\vec{r}) \nabla^{2} \varphi_{k}(\vec{r}) d \vec{r}=-\nabla^{2} \varphi_{k}(\vec{r})
$$

Usando essa expressão na equação (2.18), chegamos às equações de Kohn-Sham:

$$
\left\{-\nabla^{2}+2 \int \frac{\rho(\vec{r})}{\left|\vec{r}-\vec{r}^{\prime}\right|} d \vec{r}^{\prime}+V_{e x t}(\vec{r})+V_{x c}(\vec{r})\right\} \varphi_{k}(\vec{r})=\varepsilon_{k} \varphi_{k}(\vec{r})
$$

onde, por definição, $V_{x c}(\vec{r})=\frac{\delta E_{x c}}{\delta \rho}$ é o potencial de troca e correlação. 
A teoria do funcional da densidade relaciona um sistema de elétrons interagentes com um de elétrons não interagentes que possua a mesma densidade $\rho(\vec{r})$ no estado fundamental. Estas equações são muito semelhantes às equações de Hartree, mas contém o termo $V_{x c}(\vec{r})$, que representa o potencial de troca mais o de correlação, os quais derivam do funcional energia de troca e correlação $E_{x c}[\rho(\vec{r})]$. O termo de troca e correlação contém todos os efeitos de muitos corpos não incorporados na teoria de Hartree. As equações de KS são exatas. No entanto, a atribuição de qualquer significado físico às funções de onda $\varphi_{j}(\vec{r})$ e aos auto-valores $\varepsilon_{j}$ deve ser feita de modo judicioso, pois, em princípio, as auto-funções obtidas pela solução das equações de KS são aquelas utilizadas como base para determinar a densidade eletrônica do estado fundamental do sistema eletrônico. No entanto, todos os $\varepsilon_{j}$ e $\varphi_{j}(\vec{r})$ possuem um valor semi-quantitativo pois contêm os efeitos de troca e correlação e são consistentes com a densidade física exata $\rho(\vec{r})$. Para se obter os estados eletrônicos de um sistema, através da utilização das equações de KS, encontramos dois problemas:

(a) Como o potencial efetivo deste sistema fictício auxiliar depende de um funcional da densidade eletrônica, as equações de KS devem ser resolvidas de maneira autoconsistente;

(b) Deve-se tomar uma forma aproximada para o funcional energia de troca e correlação pois, na prática, para a maior parte das densidades, ele não é conhecido exatamente.

O primeiro destes problemas é superado, hoje em dia, de maneira trivial, até o grau de precisão desejado. Para o segundo problema, a solução não é trivial mas, atualmente, existem várias aproximações para o funcional de troca e correlação. A aproximação mais comum é a chamada aproximação da densidade local (LDA - Local Density Approximation). Nesta aproximação supõe-se que a contribuição de troca-correlação de todo o volume infinitesimal dependa apenas da densidade local daquele volume. Apesar de simples, ela fornece resultados satisfatórios para uma grande variedade de sistemas, sendo amplamente utilizada na física da matéria 
condensada. No entanto, em alguns casos, a aproximação LDA não funciona muito bem e o próximo passo foi melhorar a LDA, fazendo com que a contribuição de troca-correlação de todo o volume infinitesimal não dependesse apenas da densidade local daquele volume, mas também da densidade nos volumes vizinhos, ou seja, incluindo a dependência do gradiente da densidade. Esta aproximação é chamada de aproximação do gradiente generalizado (GGA - Generalized Gradient Approximation) [16]. Aproximações deste tipo vêm sendo amplamente utilizadas na física da matéria condensada e serão discutidas brevemente nas próximas seções.

\subsubsection{Aproximação da Densidade Local - LDA}

A LDA foi a primeira ideia para uma aproximação para o potencial de troca e correlação. Ela foi proposta por Kohn e Sham em 1964 [11]. A ideia da LDA é considerar um volume infinitesimal do sistema e aproximar $E_{x c}$ desse volume pela energia de troca e correlação de um gás de elétrons homogêneo com a mesma densidade local do sistema original e, em seguida, somar as contribuições de cada elemento de volume da seguinte maneira

$$
E_{x c}^{L D A}[\rho(\vec{r})]=\int \rho(\vec{r}) \varepsilon_{x c}^{h o m}(\rho) d \vec{r}
$$

onde a função $\varepsilon_{x c}^{h o m}(\rho)$, não um funcional, é a energia de troca e correlação, por elétron, de um gás homogêneo de elétrons de densidade $\rho$, e pode ser decomposta em duas parcelas, uma relativa à densidade de energia de troca e outra à densidade de energia de correlação:

$$
\varepsilon_{x c}^{h o m}(\rho)=\varepsilon_{x}^{h o m}(\rho)+\varepsilon_{c}^{h o m}(\rho),
$$

onde a parcela relativa à densidade de energia de troca, para um gás de elétrons homogêneo, possui a forma analítica (em unidades atômicas):

$$
\varepsilon_{x}^{h o m}(\rho)=-3\left(\frac{3 \rho}{8 \pi}\right)^{\frac{1}{3}}
$$


enquanto que a parcela relativa ao termo de correlação, para um gás de elétrons homogêneo, foi obtida através de métodos quânticos computacionais de Monte Carlo $[18,19]$.

Em sistemas onde se considera polarização de spin, a densidade de carga $\rho(\vec{r})$ é decomposta em duas densidades de spin, uma densidade $\rho_{\uparrow}(\vec{r})$ para os elétrons com spin up e uma densidade $\rho_{\downarrow}(\vec{r})$ para os elétrons com spin down, tal que a densidade total do sistema é $\rho(\vec{r})=\rho_{\uparrow}(\vec{r})+\rho_{\downarrow}(\vec{r})$ e a densidade de spin do sistema é $\rho_{\text {spin }}(\vec{r})=\rho_{\uparrow}(\vec{r})-\rho_{\downarrow}(\vec{r})$. Neste caso, o teorema de HK é generalizado de maneira que a energia total do sistema passa a ser um funcional das duas densidades de spin, ou seja,

$$
E[\rho(\vec{r})]=E\left[\rho_{\uparrow}(\vec{r}), \rho_{\downarrow}(\vec{r})\right]
$$

e a energia de troca e correlação levando em consideração a polarização de spin (LSDA), será

$$
E_{x c}^{\mathrm{LSDA}}\left[\rho_{\uparrow}(\vec{r}), \rho_{\downarrow}(\vec{r})\right]=\int \rho(\vec{r}) \varepsilon_{x c}^{h o m}\left(\rho_{\uparrow}, \rho_{\downarrow}\right) d \vec{r} .
$$

Como na LDA ou LSDA aproxima-se o sistema, localmente, por um gás de elétrons homogêneo, ela deve, a priori, ser válida para sistemas onde a densidade eletrônica varie muito lentamente. Para sistemas atômicos esta condição é raramente satisfeita sendo, na maior parte das vezes, seriamente violada. Entretanto a experiência mostra que para muitos sistemas cristalinos e moleculares ela fornece resultados extremamente úteis em muitas aplicações, tendo previsto e explicado várias propriedades dos estados fundamentais destes sistemas. Uma explicação plausível para este sucesso está no fato de as ligações entre os átomos, nas moléculas e nos sólidos, ocorrer na região de cauda das funções de onda atômicas, onde a densidade de carga eletrônica varia pouco. No entanto, ela falha na descrição de sistemas que possuem elétrons com caráter $d$ e $f$ bastante localizados, cujas densidades eletrônicas variam bastante e não podem, localmente, serem mapeadas por um sistema equivalente de um gás homogêneo. Por exemplo, utilizando-se a aproximação LSDA, para a obtenção das propriedades estruturais e eletrônicas do metal de Fe, obtém-se que o estado fundamental tem estrutura cúbica de faces centradas 
e é um material não magnético, enquanto que experimentalmente, sua estrutura é cúbica de corpo centrado e o material é magnético. Em geral, a descrição de materiais compostos por elementos da tabela periódica onde os orbitais $d$ e $f$ devem ser descritos como de valência, a aproximação LSDA falha e, portanto, é necessária a utilização de outros níveis de aproximação para a energia de troca e correlação que vão além da LSDA. Neste trabalho utilizamos uma aproximação GGA, devida a Perdew, Burke e Ernzerhof [16], descrita na próxima seção. Vale a pena mencionar que nesta aproximação o metal de Fe é descrito corretamente, ou seja, o estado fundamental é magnético e tem uma estrutura cúbica de corpo centrado.

\subsubsection{Aproximação do Gradiente Generalizado - GGA}

Várias tentativas foram feitas de se usar, além da densidade em um ponto, a taxa de variação da densidade. A primeira tentativa de tal método foi a expansão em gradientes, tal como em uma série de Taylor, mas correções dessa forma raramente aprimoravam os resultados da LDA [20]. No entanto, na década de 80 percebeu-se que as correções não necessariamente precisavam ter a forma de uma expansão em séries, mas podiam ser funções mais gerais da densidade, da forma:

$$
E_{x c}^{\mathrm{GGA}}[\rho]=\int f(\rho(\vec{r}), \nabla \rho(\vec{r})) d \vec{r} .
$$

Essa é a aproximação do gradiente generalizado. Existem vários tipos de GGA, cada um com um tipo de função $f(\rho(\vec{r}), \nabla \rho(\vec{r}))$. O GGA mais popular (que foi utilizado neste trabalho) é o proposto por Perdew, Burke e Ernzerhof, chamado GGA-PBE [16]. Este funcional é baseado no funcional PW91 [21], desenvolvido por Perdew e Wang, que apesar de incorporar efeitos da não homogeneidade do sistema, apresenta diversos problemas. Ao contrário do PW91, que foi construído de tal forma a satisfazer a maior quantidade possível de situações exatas, o PBE foi desenvolvido de forma a satisfazer apenas as condições energéticas mais importantes, resolvendo os problemas do PW91 [21], sendo mais facilmente derivado e usando apenas constantes fundamentais [16]. Assim, nesta aproximação, tem-se que o funcional energia de troca e correlação, considerando a polarização de spin, 
pode ser escrito como:

$$
E_{x c}^{\mathrm{GGA}}\left[\rho_{\uparrow}(\vec{r}), \rho_{\downarrow}(\vec{r})\right]=E_{x}^{\mathrm{GGA}}\left[\rho_{\uparrow}(\vec{r}), \rho_{\downarrow}(\vec{r})\right]+E_{c}^{\mathrm{GGA}}\left[\rho_{\uparrow}(\vec{r}), \rho_{\downarrow}(\vec{r})\right] .
$$

Nesta construção, o funcional energia de correlação é escrito na forma:

$$
E_{c}^{\mathrm{GGA}}\left[\rho_{\uparrow}(\vec{r}), \rho_{\downarrow}(\vec{r})\right]=\int \rho\left[\varepsilon_{c}^{h o m}\left(r_{s}, \zeta\right)+H\left(r_{s}, \zeta, t\right)\right] d \vec{r},
$$

onde $r_{s}$ é o raio local de Seitz $\left(\rho=3 /\left[4 \pi r_{s}^{3}\right]=k_{F}^{3} /\left[3 \pi^{2}\right]\right), \quad \zeta$ é a polarização relativa de $\operatorname{spin}\left(\zeta=\left[\rho_{\uparrow}-\rho_{\downarrow}\right] / \rho\right)$ e $t$ é o gradiente adimensional da densidade $\left(t=|\nabla \rho| / 2 \phi k_{s} \rho\right.$, onde $\phi(\zeta)=\left[(1+\zeta)^{2 / 3}+(1-\zeta)^{2 / 3}\right] / 2$ é o fator de escalonamento de spin [22], $k_{s}=\sqrt{4 k_{F} /\left(\pi a_{0}\right)}$ é o fator de blindagem de Thomas-Fermi e $a_{0}=$ $\hbar^{2} /\left(m e^{2}\right)$ é o raio de Bohr). Como a contribuição do gradiente está incorporado na função $H$, essa função é construída levando-se em conta 3 limites:

1. Variações lentas da densidade: Neste caso, $t \rightarrow 0$ e a função $H$, tende para sua expansão do gradiente em segunda ordem [22]:

$$
H \longrightarrow\left(\frac{e^{2}}{a_{0}}\right) \beta \phi^{3} t^{2}
$$

$\operatorname{com} \beta \simeq 0,066725$. Este é o limite de altas densidades $\left(r_{s} \rightarrow 0\right)$, e a energia de correlação é fracamente dependente de $r_{s}$.

2. Variações rápidas da densidade: Neste caso, $t \rightarrow \infty$ e

$$
H \longrightarrow-\varepsilon_{c}^{h o m}
$$

fazendo com que a energia de correlação, dado pela expressão (2.31), se anule, pois nesse limite a densidade de energia e o potencial de troca dominam sobre a correlação.

3. Sob uma transformação de semelhança uniforme para o limite de altas densidades $\left[\rho(\vec{r}) \rightarrow \lambda^{3} \rho(\lambda \vec{r})\right.$, e $\lambda \rightarrow \infty$, enquanto $r_{s} \rightarrow 0$ com $\lambda^{-1}$ e $t \rightarrow \infty$ com $\left.\lambda^{1 / 2}\right]$, a energia de correlação deve escalar para uma constante. Assim, a função $H$ deve cancelar a singularidade logarítmica de $\varepsilon_{c}^{\text {hom }}$ [21], ou seja,

$$
H \longrightarrow\left(\frac{e^{2}}{a_{0}}\right) \beta \phi^{3} \ln t^{2} .
$$


Essas três condições podem ser satisfeitas pelo ansatz:

$$
\begin{gathered}
H=\left(\frac{e^{2}}{a_{0}}\right) \gamma \phi^{3} \ln \left\{1+\frac{\beta}{\gamma} t^{2}\left[\frac{1+A t^{2}}{1+A t^{2}+A^{2} t^{4}}\right]\right\}, \quad \text { onde } \\
A=\frac{\beta}{\gamma}\left\{\exp \left[-\varepsilon_{c}^{h o m} /\left(\gamma \phi^{3} e^{2} / a_{0}\right)\right]-1\right\}^{-1} .
\end{gathered}
$$

A função $H$ começa em $t=0$, de acordo com a equação (2.32), e cresce monotonicamente para o limite da equação (2.33), para $t \rightarrow \infty$, tal que $E_{c}^{\mathrm{GGA}} \leq 0$.

O funcional energia de troca na aproximação GGA-PBE é construído com base em mais 4 condições:

1. Sobre uma homotetia uniforme da densidade, como descrito no item $\mathbf{3}$ acima, a energia de troca deve escalar $\operatorname{com} \lambda$. Então, para $\zeta=0$ [23] deve-se ter:

$$
E_{x}^{\mathrm{GGA}}[\rho(\vec{r})]=\int \rho\left[\varepsilon_{x}^{h o m}(\rho) F_{x}(s)\right] d \vec{r}
$$

onde $F_{x}(0)=1$ para recuperar o limite correto do gás de elétrons homogêneo, $s=|\nabla \rho| /\left(2 \rho k_{F}\right)$ é outro gradiente adimensional da densidade e $\varepsilon_{x}^{h o m}(\rho)=$ $-3 e^{2} k_{F} /(4 \pi)$, que em unidades atômicas é escrito como a expressão (2.26).

2. A energia de troca exata deve obedecer à relação de escala de spin [24], tal que

$$
E_{x}^{\mathrm{GGA}}\left[\rho_{\uparrow}, \rho_{\downarrow}\right]=\frac{E_{x}\left[2 \rho_{\uparrow}\right]+E_{x}\left[2 \rho_{\downarrow}\right]}{2} .
$$

3. Como a resposta linear de um gás de elétrons homogêneo, sem polarização de spin, para pequenas variações da densidade em torno da densidade uniforme, a LSDA é uma ótima aproximação para e energia de troca e correlação [25,26], enquanto que a expansão do gradiente não o é [27], a resposta linear da LSDA deve ser recuperada. Desse modo, deve-se ter, para $s \rightarrow 0$, que

$$
F_{x}(s) \rightarrow 1+\mu s^{2}
$$


onde $\mu=\beta\left(\pi^{2} / 3\right) \simeq 0,21952$. Essa condição faz com que o coeficiente efetivo do gradiente, para o termo de troca, se cancele com aquele termo de correlação.

4. O limite de Lieb-Oxford [28]

$$
E_{x}\left[\rho_{\uparrow}, \rho_{\downarrow}\right] \geq E_{x c}\left[\rho_{\uparrow}, \rho_{\downarrow}\right] \geq-1,679 e^{2} \int \rho^{4 / 3} d \vec{r}
$$

será satisfeito se o fator de polarização de spin

$$
F_{x}(\zeta=1, s)=2^{1 / 3} F_{x}\left(s / 2^{1 / 3}\right)
$$

crescer gradualmente com $s$ até um valor máximo menor ou igual a 2,273, ou seja, quando $F_{x}(s) \leq 1,804$. Uma expressão simples para a função $F_{x}(s)$ que satisfaz todas essas condições é:

$$
F_{x}(s)=1+\kappa-\frac{\kappa}{1+\mu s^{2} / \kappa}, \quad \text { com } \quad \kappa=0,804 .
$$

Para retratar a não localidade desta aproximação GGA, foi definido um fator de intensificação $F_{x c}$ sobre o termo local de troca, dado por

$$
E_{x c}^{\mathrm{GGA}}\left[\rho_{\uparrow}(\vec{r}), \rho_{\downarrow}(\vec{r})\right]=\int \rho \varepsilon_{x}^{h o m}(\rho) F_{x c}\left(r_{s}, \zeta, s\right) d \vec{r},
$$

que representa exatamente qualquer aproximação GGA quando $\zeta$ é independente de $\vec{r}$ e é sempre aproximadamente válida [16]. A aproximação LSDA é obtida quando toma-se, além de $\zeta$ independente de $\vec{r}$, também $s=0$. A região de interesse, para sistemas reais, é para valores $0 \leq s \leq 3$ e $0 \leq r_{s} / a_{0} \leq 10$. A parte do termo de troca domina no limite de altas densidades, com $F_{x c}\left(r_{s}, \zeta, s\right) \longrightarrow F_{x}\left(r_{s}, \zeta\right)$ a medida que $r_{s} \longrightarrow 0$. A não localidade do termo de troca é dominante para a densidade dos elétrons de valência $\left(1 \leq r_{s} / a_{0} \leq 10\right)$ e, no limite de baixas densidades, a correlação é tão forte se comparada com a troca que a não localidade do termo de correlação é dominante. A aproximação GGA-PBE retém as características corretas da LSDA e as combina com as características mais importantes, energeticamente, da não localidade corrigida pelo gradiente. 


\subsection{O Método APW}

Dentre os métodos existentes para resolver as equações de KS encontramos o método APW+lo (Augmented Plane Waves plus local orbital) [14], no qual está baseado o código WIEN2k [17], utilizado neste trabalho.

As funções de base mais comuns para se determinar a função de onda periódica de um elétron num sólido são as ondas planas. Mas essa base não é conveniente para descrever as variações rápidas que as funções de onda do elétron possuem em regiões próximas aos núcleos atômicos. A fim de superar esta dificuldade pode-se eliminar a presença destas oscilações através do método de pseudopotenciais ou tomando um conjunto misto de funções de base. Os métodos FP-LAPW (Full-Potential Linear Augmented Plane Waves) e APW+lo (Augmented Plane Waves plus local orbitals) são exemplos de métodos que utilizam base mista e foram construídos a partir do método APW, originalmente proposto por Slater [15], em 1937, o qual leva em conta o fato da função, que descreve o potencial, ser do tipo atômica nas regiões próximas ao núcleo atômico e praticamente constante na região inter-atômica.

\subsubsection{Noções Preliminares - Método APW}

A essência do método APW, proposto por Slater, é considerar que perto dos núcleos atômicos as funções de onda e o potencial são similares aos de um átomo ou seja, variam fortemente. Na região entre os átomos, entretanto, tanto a função de onda como o potencial são mais suaves. Assim, neste método, o potencial é do tipo muffin-tin e é definido a partir de uma divisão da célula de Wigner-Seitz em duas regiões distintas, onde uma região esférica ao redor dos átomos é nomeada região I ou atômica e a região intersticial é nomeada região II, como mostra a figura 2.1.

A região I, também conhecida como região atômica ou muffin-tin (MT), é uma região interior às esferas centradas nos átomos da rede, onde o potencial cristalino é considerado esfericamente simétrico em relação aos centros das esferas. Dessa forma o hamiltoniano de um elétron pode ser escrito em coordenadas esféricas e as auto-funções são da forma 


$$
\Phi_{\mathrm{I}}\left(\vec{r}_{j}\right)=\sum_{\ell, m} A_{\ell m}^{j} u_{\ell, \epsilon_{\ell}}\left(r_{j}\right) Y_{\ell m}\left(\hat{r}_{j}\right)
$$

onde $j=1,2, \ldots, N$ identifica os átomos; $\vec{r}_{j}=\vec{r}-\vec{R}_{j}$ é o vetor radial a partir do centro da esfera de raio $R ; \hat{r}_{j}$ identifica as coordenadas angulares $\left(\theta_{j}, \varphi_{j}\right)$ dos harmônicos esféricos $Y_{\ell m}\left(\theta_{j}, \varphi_{j}\right) ; u_{\ell, \epsilon_{\ell}}\left(r_{j}\right)$ é a solução da parte radial da equação de Schrödinger para a energia $\epsilon_{\ell}$ dentro de cada esfera $j$ :

$$
\left\{-\frac{d^{2}}{d r^{2}}+\frac{\ell(\ell+1)}{r^{2}}+V(r)-\epsilon_{\ell}\right\} r u_{\ell}(r)=0 .
$$

Região II: é a região intersticial onde o potencial é constante e, portanto, a solução da equação é da forma

$$
\Phi_{\mathrm{II}}\left(\vec{k}_{n}, \vec{r}_{j}\right)=\Omega^{-1 / 2}\left[e^{i \vec{k}_{n} \cdot \vec{r}}\right]=\Omega^{-1 / 2} 4 \pi e^{i \vec{k}_{n} \cdot \vec{r}_{j}} \sum_{\ell, m} i^{\ell} \mathrm{j}_{\ell}\left(k_{n}, r_{j}\right) Y_{\ell m}^{*}\left(\hat{k}_{n}\right) Y_{\ell m}\left(\hat{r}_{j}\right)
$$

onde $\vec{r}=\vec{\rho}_{j}+\vec{r}_{j}$, com $\vec{r}_{j}$ sendo o vetor que localiza o $j$-ésimo átomo; $\vec{k}_{n}=\vec{k}+\vec{G}_{n}$, com $\vec{k}$ pertencente à primeira zona de Brillouin e $\vec{G}_{n}$ são vetores de translação da rede recíproca; $\mathrm{j}_{\ell}(\mathrm{x})$ são as funções esféricas de Bessel.

Os coeficientes $A_{\ell m}^{j}$ na equação (2.44) são obtidos impondo-se que a função da região I se ajusta de maneira contínua com a onda plana definida na região II,

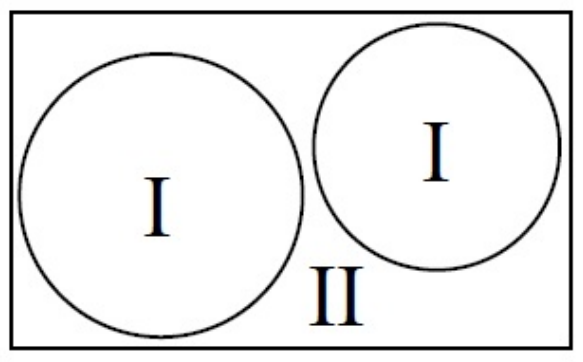

Figura 2.1: Partição da célula primitiva, onde a região I compreende as esferas atômicas e a região II é a região intersticial. 
equação (2.46), para $\vec{r}_{j}=\vec{R}_{j}$, onde $R_{j}$ é o raio da $j$-ésima esfera. Desse modo, a expressão para os coeficientes é:

$$
A_{\ell m}^{j}=4 \pi e^{i \vec{k}_{n} \cdot \vec{r}_{j}} i^{\ell} \frac{\mathrm{j}_{\ell}\left(k R_{j}\right)}{u_{\ell, E_{\ell}}\left(R_{j}\right)} Y_{\ell m}^{*}(\hat{k})
$$

Com isto, cada onda plana definida na região II é aumentada por funções atômicas dentro de cada esfera. Em termos desta base APW, uma solução do problema cristalino é construída pela combinação linear $\Psi(\vec{r})=\sum_{i} C_{i} \psi_{i}^{\mathrm{APW}}(\vec{r})$, onde os coeficientes $C_{i}$ são determinados por um processo variacional, o que nos leva ao sistema de equações $\sum_{j}\left\langle\psi_{i}|H-\varepsilon| \psi_{j}\right\rangle=0$, que admite solução não trivial se $\operatorname{det}\left[\left\langle\psi_{i}|H-\varepsilon| \psi_{j}\right\rangle\right]=0$. Usualmente, o que se faz dentro deste método, é escolher arbitrariamente um valor para $\varepsilon$, definindo o conjunto de funções de base $\psi$ com o qual calculamos o determinante. Se este não se anular para este valor de $\varepsilon$, o processo deve ser repetido até se obter o valor correto que anula o determinante e este será, então, o autovalor procurado. Este processo é conhecido como método de procura dos zeros do determinante e demanda um grande esforço computacional. Para agilizar o processo de busca dos autovalores de energia $\varepsilon$ que anulam o determinante, Andersen propôs em 1975 a linearização da base APW [14, 29, 30]. Essa linearização permitiu a associação das vantagens do método APW com uma solução computacional mais viável da equação secular. Neste método a partição do espaço cristalino é a mesma que no método APW porém, dentro da esfera atômica, as funções de base são linearizadas.

Apesar de o método APW, com ou sem a linearização, permitir a obtenção da solução da estrutura de faixas para uma grande classe de materiais, sofre com a restrição de trabalhar com potenciais muffin-tin. Este tipo de potencial descreve muito bem certos casos específicos de materiais, como sistemas de alta coordenação, tais como metais que apresentam estrutura cristalina cúbica de faces centradas ou estrutura cristalina hexagonal compacta (hcp - hexagonal close-packed). É porém uma aproximação ruim para descrever o potencial de sólidos que apresentam ligações com caráter covalente ou que tenham estruturas cristalinas abertas ou em camadas. Este problema foi sanado através da proposta feita por A. Freeman 
et. al. [31], que introduziu modificações na maneira de descrever o potencial, que deixou de ser do tipo muffin-tin e passou a ser sem formato. Nesta aproximação, chamada de potencial total (full-potential), tanto o potencial como a densidade de carga são desenvolvidos em harmônicos esféricos dentro de cada esfera atômica e em séries de Fourier na região intersticial:

$$
\begin{aligned}
& \vec{r} \in \mathbf{I}\left\{\begin{array}{l}
V(\vec{r})=\sum_{\ell m} V_{\ell m}(r) Y_{\ell m}(\hat{r}), \\
\rho(\vec{r})=\sum_{\ell m} \rho_{\ell m}(r) Y_{\ell m}(\hat{r})
\end{array}\right. \\
& \vec{r} \in \mathbf{I I}\left\{\begin{array}{l}
V(\vec{r})=\sum_{\vec{k}} V_{\vec{k}}(\vec{r}) e^{i \vec{k} \cdot \vec{r}} \\
\rho(\vec{r})=\sum_{\vec{k}} \rho_{\vec{k}}(\vec{r}) e^{i \vec{k} \cdot \vec{r}}
\end{array}\right.
\end{aligned}
$$

Os métodos que utilizam esquemas chamados full-potential (FP), onde a forma do potencial não sofre aproximações, são altamente convenientes e, associados aos processos de linearização, permite a associação das vantagens do método APW com uma solução computacional mais viável da equação secular, levando aos métodos FP-LAPW e APW+lo, descritos a seguir.

\subsubsection{Método FP-LAPW}

No método FP-LAPW, além de se assumir a continuidade da função de onda no contorno das esferas atômicas, assume-se também que a função deva ser suave, ou seja, que a derivada da função também seja contínua. Assim, dentro das esferas atômicas, a parte radial das funções de base são linearizadas pela adição de uma segunda parcela que depende da derivada parcial da função radial em relação à energia, $\dot{u}_{\epsilon_{\ell 1}}^{j}(r)$, ou seja,

$$
\dot{u}_{\epsilon_{\ell 1}}^{j}(r)=\left[\frac{\partial u_{\ell}(r)}{\partial \epsilon}\right]_{\epsilon=\epsilon_{\ell 1}},
$$

solução da equação

$$
\left\{-\frac{d^{2}}{d r^{2}}+\frac{\ell(\ell+1)}{r^{2}}+V(r)-\epsilon_{\ell}\right\} r \dot{u}_{\ell}(r)=r u_{\ell}(r) .
$$


Deste modo, a base mista LAPW fica:

$$
\phi_{\vec{k}_{n}}(\vec{r})= \begin{cases}\sum_{\ell m}\left[A_{\ell m}^{j} u_{\ell}\left(r_{j}, \epsilon_{\ell}\right)+B_{\ell m}^{j} \dot{u}_{\ell}\left(r_{j}, \epsilon_{\ell 1}\right)\right] Y_{\ell m}\left(\hat{r}_{j}\right) & r_{j} \in \mathrm{I} \\ \Omega^{-1 / 2}\left[e^{i \vec{k}_{n}} \cdot \vec{r}\right] & r \in \mathrm{II}\end{cases}
$$

Os coeficientes $A_{\ell m}^{j}$ e $B_{\ell m}^{j}$ são determinados impondo-se a continuidade das funções de base sobre as superfícies das esferas atômicas, assim como de suas derivadas parciais radiais. As LAPW's fornecem uma base suficientemente flexível para se descrever corretamente as autofunções com auto-energias $\epsilon_{\ell}$ próximas à energia de linearização $\epsilon_{\ell 1}$. Neste caso, toma-se um valor fixo para $\epsilon_{\ell 1}$ e os autovalores da energia são obtidos por uma simples diagonalização. No entanto, apesar de a utilização das LAPW's agilizar o processo de obtenção das auto-energias do determinante, elas não servem para tratar estados que possuam energias que se encontram longe da energia de linearização, tais como os chamados estados de semi-caroço. Assim, estes estados, quando apresentam um número quântico secundário $(\ell)$ igual aos de estados de valência, têm sua energia de linearização igual aos de valência, apesar de possuírem autovalores muito diferentes. A linearização também não é suficientemente precisa nos casos de materiais que tenham faixas de valência largas e quando são formados por elementos que têm função de onda com grande variação dentro da esfera atômica (tal como aquelas associadas aos estados $d$ e $f$ ). Para melhorar os resultados provenientes da linearização, Singh introduziu os chamados orbitais locais (local orbitals - LO's) [14], onde o conjunto de funções de base é aumentado para certos valores de $\ell$ e as funções de base para estes orbitais é escrita como

$\varphi_{L O}(\vec{r})=\left\{\begin{array}{lr}{\left[A_{\ell m}^{j, L O} u_{\ell}\left(r_{j}, \epsilon_{\ell 1}\right)+B_{\ell m}^{j, L O} \dot{u}_{\ell}\left(r_{j}, \epsilon_{\ell 1}\right)+C_{\ell m}^{j, L O} u_{\ell}\left(r_{j}, \epsilon_{\ell 2}\right)\right] Y_{\ell m}\left(\hat{r}_{j}\right)} & r_{j} \in \mathrm{I} \\ 0 & r \in \mathrm{II}\end{array}\right.$

Um LO é construído pela função radial LAPW na energia $\epsilon_{\ell 1}$ e uma outra função radial $u_{\ell}\left(r_{j}, \epsilon_{\ell 2}\right)$ relativa a uma segunda energia $\epsilon_{\ell 2}$, distante de $\epsilon_{\ell 1}$ e esco- 
lhida para melhorar a linearização. Os três coeficientes $A_{\ell m}^{j, L O}, B_{\ell m}^{j, L O}$ e $C_{\ell m}^{j, L O}$ são determinados impondo-se que os LO's sejam nulos, com derivada nula, no contorno da esfera atômica, além de serem normalizados dentro delas. A introdução dos LO's melhora o processo de linearização mais do que métodos alternativos, como os métodos que contenham segundas e terceiras derivadas da função radial, em relação à energia, em suas bases [14]. Neste método, é conveniente diferenciar três tipos de estados eletrônicos, normalmente chamados de estados de caroço, de semi-caroço e de valência. Por exemplo, o mercúrio tem a configuração eletrônica [Xe $] 4 f^{14} 5 d^{10} 6 s^{2}$. Os estados eletrônicos com a configuração do átomo de Xe são considerados de caroço; os estados $4 f$ como de semi-caroço e os estados $5 d$ e $6 s$ como de valência. Podemos, então, separar os níveis de energia e encontrar as energias de linearização, em três espécies de estados:

Estados de Caroço: estados que possuem densidades eletrônicas totalmente confinadas nas esferas atômicas, apresentando, geralmente, energias atômicas abaixo de -6,0 Ry. Os orbitais atômicos destes estados são calculados autoconsistentemente no potencial cristalino usando-se um código computacional atômico totalmente relativístico [14], substituindo-se as equações para a função radial e para sua derivada pelas correspondentes equações de Dirac.

Estados de Semi-Caroço: estados que não possuem as cargas eletrônicas totalmente confinadas na esfera atômica, mas uma pequena porcentagem está fora dela. Geralmente possuem valores de energia entre $-1,0$ e -6,0 Ry. O melhor modo de tratar estes estados é através de orbitais locais (LO), onde, como exposto, uma extensão da base LAPW usual é utilizada. Os orbitais destes estados são calculados autoconsistentemente no potencial cristalino resolvendo as equações de KS dentro do esquema escalar relativístico [14], com a base LAPW + LO, permitindo, ainda introduzir acoplamento spin-órbita por um tratamento variacional.

Estados de Valência: estados mais altos ocupados que apresentam uma quantidade significativa de carga eletrônica fora da esfera atômica, possuindo, em geral, valores de energia acima de -1,0 Ry. Os orbitais destes estados são calculados autoconsistentemente, no potencial cristalino, resolvendo classicamente as equações 
de KS na região intersticial e no esquema escalar relativístico na região atômica, permitindo, ainda, introduzir acoplamento spin-órbita por um tratamento variacional [14].

Os parâmetros básicos que determinam a qualidade do cálculo quando se utiliza o esquema LAPW são: o momento angular máximo $\ell_{\text {máx }}$ que se toma na expansão em harmônicos esféricos dentro das esferas e o parâmetro de corte $K_{\text {máx }}$ (máximo valor dos vetores de translação no espaço recíproco) nas ondas planas definidas na região intersticial. Sabe-se que $\ell_{\text {máx }}$ permite a representação de funções com um máximo de $2 \ell_{\text {máx }}$ nodos ao longo da circunferência da esfera de raio $r_{j}$, ou seja, na distância $2 \pi r_{j}$ e portanto tem-se $\ell_{\text {máx }} /\left(\pi r_{j}\right)$ nodos por $a_{B}$ (raio de Bohr). Por outro lado, $K_{\text {máx }}$ corresponde à onda plana com $K_{\text {máx }} / \pi$ nodos por $a_{B}$. Igualando estas duas condições tem-se que um bom critério para a escolha destas duas grandezas é aquele para o qual $r_{j} K_{\text {máx }}$ é da ordem de $\ell_{\text {máx }}$. Na prática, os valores típicos de $r_{j} K_{\text {máx }}$ estão na faixa de valores entre 6,5-8,5. Usualmente, este parâmetro de convergência é rotulado por $R_{M T} K_{\text {máx }}=R K$, e está relacionado com o valor máximo do número de ondas planas utilizadas no desenvolvimento do potencial e da densidade para descrever a região II. Entretanto, deve-se ter em mente que o valor conveniente para este parâmetro deve ser tal que esteja em uma faixa dentro da qual a energia total do sistema esteja convergida, dentro de um critério préestabelecido.

\subsubsection{Método APW+lo}

Recentemente, Sjöstedt et. al. [32] introduziram uma modificação no método FPLAPW introduzindo uma base denominada APW+lo. Neste método a base APW das equações (2.44) e (2.46) é obtida para uma energia fixa e sua flexibilidade é introduzida com a inclusão de outro tipo de orbitais locais (agora especificado por lo's), combinando as soluções radiais $u$ e $\dot{u}$ da seguinte forma

$$
\phi_{\ell m}^{l o}(\vec{r})= \begin{cases}{\left[a_{\ell m}^{l o} u_{\ell}\left(r_{j}, \epsilon_{\ell}\right)+b_{\ell m}^{l o} \dot{u}_{\ell}\left(r_{j}, \epsilon_{\ell}\right)\right] Y_{\ell m}(\hat{r})} & \vec{r}_{j} \in \mathrm{I} \\ 0 & \vec{r} \in \mathrm{II}\end{cases}
$$


Os lo's são resolvidos para a mesma energia fixa das APW's correspondentes. Os dois coeficientes são determinados pela normalização e pela condição de que os lo's sejam nulos na superfície das esferas. Os dois conjuntos de base, APW+lo e LAPW, consistem das mesmas funções $u$ e $\dot{u}$, só que é mais eficiente introduzir soluções radiais extras, tais como as $\dot{u}$, via orbitais locais (APW+lo) do que nas funções de base ordinárias (LAPW), pois no conjunto LAPW é necessário imporse mais restrições na base o que, em consequência, necessita um maior número de funções de base. No método APW+lo o termo que contém a derivada da função radial é somente incluído para alguns lo's e não para todas as ondas planas, como no LAPW. Não é óbvio que a linearização da base APW+lo seja, em todos os casos, mais precisa que no esquema LAPW. No entanto, ambas as bases, na prática, convergem para a mesma energia total e mesmos autovalores de $\mathrm{KS}$, só que a base APW+lo converge mais rapidamente e frequentemente de maneira mais sistemática e suave para o valor final que a base LAPW. Como a base APW+lo é menor que a LAPW, este método necessita de tempo de computação menor e usa menos memória que o LAPW, tornando viável cálculos de superfícies, adsorção de moléculas em superfícies e de cristais com estruturas abertas.

O melhor esquema para se obter a melhor solução é a utilização de uma base mista, utilizando APW+lo para os estados que apresentam difícil convergência, tais como os estados $d$ e $f$, ou para átomos que necessitem de pequenas esferas atômicas, e em LAPW+LO para todos outros tipos de átomos.

\subsubsection{Efeitos Relativísticos no WIEN2k}

Para elementos da tabela periódica com número atômico alto ou para elétrons confinados perto do núcleo, os efeitos relativísticos se tornam importantes, devido a alta energia cinética nessas condições. Dessa forma, no método APW+lo ou LAPW, podemos ignorar efeitos relativísticos na região intersticial (região II da figura 2.1) e incorporar correções relativísticas apenas nas regiões atômicas, próximas do núcleo (região I da figura 2.1). Dessa forma, devemos substituir as equações (2.45) e (2.51) pelas equações radiais de Dirac correspondentes, para incorporar efeitos re- 
lativísticos. Koeling e Harmon [33] propuseram um método para se resolver a equação de Dirac em um potencial esfericamente simétrico, inicialmente ignorando efeitos de acoplamento spin-órbita, a chamada aproximação escalar-relativística, os quais podem ser incorporados posteriormente através de um segundo processo variacional. A hamiltoniana relativística de Dirac fornece uma descrição quantummecânica dos elétrons, consistente com a teoria da relatividade especial, e é dada por

$$
H_{D}=c \vec{\alpha} \cdot \vec{p}+\beta m c^{2}+q V
$$

onde $c$ é a velocidade da luz, $\vec{p}$ é o operador momento, $V$ é o potencial externo, $q$ e $m$ são, respectivamente, a carga e a massa de repouso do elétron, $\vec{\alpha}$ é escrita como

$$
\vec{\alpha}=\left[\begin{array}{lr}
\mathbf{0} & \sigma_{\mathbf{k}} \\
\sigma_{\mathbf{k}} & \mathbf{0}
\end{array}\right]
$$

com $\sigma_{k}$ representando as matrizes de Pauli e $\beta$ é dada por

$$
\beta=\left[\begin{array}{rr}
1 & 0 \\
0 & -1
\end{array}\right]
$$

Tanto a hamiltoniana de Dirac quanto as funções de onda são objetos quadridimensionais. As funções de onda, soluções da equação de Dirac $\left(H_{D} \Phi_{\kappa \mu}=E \Phi_{\kappa \mu}\right)$, podem ser escritas na forma:

$$
\Phi_{\kappa \mu}=\left[\begin{array}{c}
g_{\kappa} \chi_{\kappa \mu} \\
-i f_{\kappa} \sigma_{r} \chi_{\kappa \mu}
\end{array}\right],
$$

onde $\kappa$ é o número quântico relativístico dado por $\kappa=-s\left(j+\frac{1}{2}\right)$, com $j=\ell+\frac{s}{2}$ e $s= \pm 1 . \chi_{\kappa \mu}$ é um spinor de duas componentes e a coordenada radial foi omitida. Substituindo a função de onda, dada na expressão (2.58), na equação de Dirac, tem-se para a parte radial o sistema de equações diferenciais 


$$
\begin{aligned}
\frac{d g_{\kappa}}{d r} & =-\frac{\kappa+1}{r} g_{\kappa}+2 M c f_{\kappa} \\
\frac{d f_{\kappa}}{d r} & =\frac{1}{c}(V-E) g_{\kappa}+\frac{\kappa-1}{r} f_{\kappa}
\end{aligned}
$$

onde

$$
M=m+\frac{1}{2 c^{2}}(E-V)
$$

Substituindo a pequena componente $f_{\kappa}$ da equação (2.59) na equação (2.60), obtémse a equação diferencial para a grande componente $g_{\kappa}$, dada por

$-\frac{1}{2 M}\left[\frac{d^{2} g_{\kappa}}{d r^{2}}+\frac{2}{r} \frac{d g_{\kappa}}{d r}-\frac{\ell(\ell+1)}{r^{2}} g_{\kappa}\right]-\frac{d V}{d r} \frac{d g_{\kappa}}{d r} \frac{1}{4 M^{2} c^{2}}+V g_{\kappa}-\frac{\kappa-1}{r} \frac{d V}{d r} \frac{g_{\kappa}}{4 M^{2} c^{2}}=E g_{\kappa}$

Para os estados de caroço, a equação (2.62) é resolvida e a solução radial é tomada como base na expansão escrita na equação (2.44). O último termo do primeiro membro da equação (2.62) descreve o acoplamento spin-órbita. Este é o único termo que depende do sinal de $\kappa$, para um dado valor de $\ell$. Ao realizar uma média sobre $j$ na equação para $\kappa=\ell\left(j=\ell-\frac{1}{2}\right)$ e $\kappa=-(l+1)\left(j=\ell-\frac{1}{2}\right)$, a única alteração que obtemos na equação (2.62) é a ausência do termo de acoplamento spin-órbita. Dessa forma obtêm-se uma equação na qual $j$ e $s$ estão desacoplados, permitindo que o spin volte a ser um bom número quântico. Esta é a aproximação escalar-relativística. Para os estados de valência, mas dentro da região atômica, a equação é resolvida dentro dessa aproximação, na qual o termo de acoplamento spin-órbita é ignorado. Entretanto, mesmo assim, não é fácil resolver a equação (2.62). Para resolvê-la, Koeling e Harmon [33] definiram uma nova função:

$$
\phi_{\kappa}=\frac{1}{2 M c} \frac{d g_{\kappa}}{d r}
$$


que permite que a expressão (2.59) possa ser escrita como

$$
f_{\kappa}=\phi_{\kappa}+\frac{1}{2 M c r}(\kappa+1) g_{\kappa} .
$$

Utilizando a equação (2.63) na equação (2.62) e ignorando o termo de acoplamento spin-órbita, tem-se

$$
\frac{d \phi_{\ell}}{d r}=-\frac{2}{r} \phi_{\ell}+\left[\frac{\ell(\ell+1)}{2 M c r}+\frac{1}{c}(V-E)\right] g_{\ell}
$$

onde o índice $\kappa$ foi substituído por $\ell$, pois não há mais dependência em $j$. Utilizando a equação (2.64), podemos substituir a pequena componente $f_{\kappa}$ na equação (2.58) e, utilizando coeficientes de Clebsch-Gordan apropriados, re-escrever a função de onda em termos apenas dos números quânticos $(\ell m s)$, conhecidos da teoria não relativística, obtendo-se

$$
\Phi_{\ell m s}=\left[\begin{array}{c}
g_{\ell} Y_{\ell m} \chi_{s} \\
\frac{i}{2 M c} \sigma_{r}\left(-\frac{d g_{\ell}}{d r}+\frac{1}{r} g_{\ell} \sigma \cdot L\right) Y_{\ell m} \chi_{s}
\end{array}\right]
$$

onde $\chi_{s}$ é o spinor não relativístico (representado pelas matrizes de Pauli). Definindo $P_{\ell}=r g_{\ell}$ e $Q_{\ell}=r c g_{\ell}$, as equações radiais escalar-relativísticas se tornam:

$$
\begin{aligned}
\frac{d P_{\ell}}{d r} & =2 M Q_{\ell}+\frac{1}{r} P_{\ell} \\
\frac{d Q_{\ell}}{d r} & =-\frac{1}{r} Q_{\ell}+\left[\frac{\ell(\ell+1)}{2 M r^{2}}+\left(V+E_{\ell}\right)\right] P_{\ell},
\end{aligned}
$$

que podem ser resolvidas numericamente, com a condição de contorno:

$$
\lim _{r \rightarrow 0} \frac{Q}{P}=c \frac{\left[\ell(\ell+1)+1-(2 Z / c)^{2}\right]^{1 / 2}-1}{2 Z / c} .
$$


A obtenção de $\mathrm{P}_{\ell}$ e $\mathrm{Q}_{\ell}$, as pequena e grande componentes da parte radial da equação de Dirac, permite que $f_{\ell}$ e $g_{\ell}$ possam ser calculadas, pelas próprias definições de $\mathrm{P}_{\ell}, \mathrm{Q}_{\ell}$ e $\phi_{\ell}$. Na normalização, tanto a grande como a pequena componente devem ser levadas em consideração de modo que a expressão $f_{\ell}^{2}+g_{\ell}^{2}$ é utilizada, ao invés de $u^{2}$ na equação (2.45). Entrementes, na fronteira entre a região atômica e a região intersticial, onde utiliza-se um tratamento não relativístico, a continuidade da função de onda e de sua derivada se faz apenas com a grande componente, por uma questão de consistência, sendo que e a pequena componente é considerada nula.

\subsection{O Processo Autoconsistente}

Para o estudo da estrutura eletrônica de um dado sistema de muitos corpos, é preciso resolver as equações de Kohn-Sham em um processo cíclico. Para iniciar o processo, uma densidade de carga tentativa é escrita para o sistema. A partir deste "chute" inicial obtém-se o primeiro potencial de Kohn-Sham. Com este potencial a equação de Kohn-Sham pode ser resolvida e a função de onda de uma única partícula determinada. Utiliza-se esta função de onda para a construção de uma nova densidade de carga, a qual determina um novo potencial de Kohn-Sham e assim por diante. O resultado final convergido é então obtido após várias iterações, obedecendo critérios de convergência pré-determinados. Este processo cíclico de refinamento da densidade de carga, a partir de várias iterações, é denominado processo auto-consistente. Atualmente este procedimento é largamente utilizado em cálculos de primeiros princípios e implementados em códigos computacionais, que utilizam a teoria DFT, e o WIEN2k [17] está entre eles. As relaxações estruturais dos sistemas foram obtidas utilizando-se o processo de optimização de geometria de acordo com o esquema dinâmico de Newton com amortecimento (damped Newton dynamics scheme), através da equação

$$
R_{m}^{\tau+1}=R_{m}^{\tau}+\eta\left(R_{m}^{\tau}-R_{m}^{\tau-1}\right)+\delta_{m} F_{m}^{\tau}
$$


onde $R_{m}^{\tau}$ é a coordenada e $F_{m}^{\tau}$ a força resultante em cada átomo, no passo $\tau$, que é utilizada em conexão com os cálculos das forças de Hellman-Feynman e Pulay. Para cada nova posição calculada com essa equação, um novo ciclo eletrônico autoconsistente é executado. Esta minimização de geometria é efetuada até que as forças nos átomos atinjam valores menores que $1 \mathrm{mRy} / \mathrm{u}$.a..

\subsection{Esquema da Supercélula}

A periodicidade de sistemas cristalinos implica que as propriedades do cristal também sejam periódicas. Pode-se então realizar os cálculos de estrutura eletrônica dentro de apenas um período do cristal, ou seja, pode-se considerar apenas os átomos dentro de uma célula primitiva que, repetida no espaço através de vetores de translação, reproduz todo o cristal. Entretanto, em sistemas não periódicos não se tem como definir uma célula unitária periódica, pela própria natureza do sistema. A presença de uma impureza e/ou defeito, em um cristal, quebra a simetria translacional, tornando-o um sistema aperiódico. Em sistemas aperiódicos não podemos definir uma célula unitária periódica. No entanto, podemos ainda usar métodos de cálculos de estrutura de faixas utilizando o tratamento de supercélulas, selecionando uma região de interesse que é repetida periodicamente no espaço. Em princípio, somente no limite de uma supercélula infinitamente grande é que os resultados obtidos, com este processo de cálculo, convergiriam para as propriedades do sistema aperiódico. Quando a aperiodicidade for local, como no caso de impurezas profundas em semicondutores, o método da supercélula é conveniente e tem sido amplamente utilizado. Desse modo, a energia de um cristal infinito contendo uma certa concentração de defeitos é substituída pela energia, por supercélula, de um cristal contendo uma distribuição periódica de impurezas. Esse esquema prático foi proposto em 1972 por Debrotvorskii et al. [34] para o estudo de impurezas profundas em nitretos de boro e mais tarde explicado detalhadamente por Evarestov et al. [35]. Este método consiste em se aumentar a célula primitiva, através de uma transformação linear dos vetores de translação da rede, formando assim uma célula aumentada, contendo $\mathrm{N}$ células primitivas, que é considerada como a unidade de 
repetição. Consequentemente a primeira zona de Brillouin (ZB) da supercélula é menor que da célula primitiva. Na representação do cristal através do esquema de supercélula, contendo somente átomos hospedeiros, o número de estados do cristal é mantido, apesar de suas classificações poderem ser diferentes e dependerem do tipo de rede escolhido para representar a supercélula. Assim, para diferentes tipos de redes de supercélula, os estados do cristal estarão diretamente relacionados com aqueles da célula primitiva, pois um único ponto $\vec{k}$ na ZB da supercélula deve ser equivalente a $\mathrm{N}$ pontos $\vec{k}$ na ZB da célula primitiva. Por exemplo, o espectro de níveis de energia calculados em um único ponto $\Gamma(\vec{k}=0)$ da supercélula será equivalente a se considerar $\mathrm{N}$ pontos na ZB da célula primitiva.

No estudo dos efeitos causados por impurezas e/ou defeitos em estruturas cristalinas, a supercélula do cristal perfeito deve ser escolhida com o propósito de evitar, neste tipo de simulação, uma grande dispersão nos níveis de energia da impureza, que indicaria a existência de interação entre impurezas em supercélulas adjacentes. Desse modo, é essencial a inclusão de um número suficientemente grande de átomos do cristal (hospedeiro) nesta célula artificialmente aumentada. As relaxações e distorções iônicas também podem ficar restringidas por causa de uma escolha inadequada do tamanho da supercélula.

Na simulação de defeitos profundos e situações similares, a supercélula deve representar uma quantidade do cristal suficientemente grande de forma que suas imagens, replicadas no espaço, não permitam a interação entre defeitos. Portanto a técnica de cálculo com supercélulas é bastante útil no estudo de sistemas onde defeitos e/ou impurezas são introduzidos. Variando o seu tamanho é possível simular, por exemplo, o comportamento de alguma propriedade física em função da concentração ou até mesmo da posição de uma impureza ou defeito. 


\section{Capítulo 3}

\section{Cristal de $\mathrm{ZrO}_{2}$}

\subsection{Introdução}

A zircônia $\left(\mathrm{ZrO}_{2}\right)$ é um material que possui excelentes propriedades elétricas e mecânicas, possibilitando muitas aplicações tecnológicas. Sua grande condutividade iônica, devido a vacâncias de oxigênio, em altas temperaturas, quando dopada com cálcio e ítrio [36], e sua alta dureza às fraturas, faz com que a zircônia seja utilizada como eletrólito em células e sensores de oxigênio [2,7]. A maioria das aplicações do $\mathrm{ZrO}_{2}$ são baseadas nas propriedades de suas fases tetragonal e cúbica, as quais são menos estáveis, a temperatura ambiente, que a fase monoclínica. No entanto, a zircônia pode ser estabilizada nestas outras duas fases, a temperatura ambiente, com a adição de dopantes, tais como ítrio, cálcio e cério [6, 36]. Nanopartículas de $\mathrm{ZrO}_{2}$, abaixo de um certo tamanho crítico, também podem se estabilizar nas fases cúbica e tetragonal, mas o mecanismo pelo qual isso ocorre e o valor desse tamanho crítico ainda é um problema em aberto [36].

As propriedades físicas e químicas do $\mathrm{ZrO}_{2}$ são similares às do $\mathrm{HfO}_{2}$, já que os átomos de háfnio e zircônio apresentam propriedades químicas parecidas [37] e ambos materiais aparecem juntos na natureza, sendo que sua separação é muito complicada. Esses dois compostos apresentam as mesmas fases cristalinas, tanto a pressão ambiente como a altas pressões, e sempre contêm impurezas, ou seja, o $\mathrm{HfO}_{2}$ sempre tem impurezas de $\mathrm{Zr}$ e o $\mathrm{ZrO}_{2}$ sempre tem impurezas de $\mathrm{Hf}$, as quais 
são nativas.

A zircônia pura e natural possui 3 fases estáveis, dependendo da temperatura: monoclínica para $\mathrm{T}<1473 \mathrm{~K}$, tetragonal simples para $1473 \mathrm{~K}<\mathrm{T}<2553 \mathrm{~K}$ e cúbica de faces centradas para $\mathrm{T}>2553 \mathrm{~K}$. Como dito anteriormente, pode-se obter a zircônia em condições metaestáveis, a temperatura ambiente, nas fases cúbica e tetragonal com a adição de dopantes, como ítrio, cálcio, magnésio e cério. O estudo teórico das propriedades físicas dos sistemas propostos, através de simulações computacionais de primeiros princípios e utilizando, quando necessário, o esquema da supercélula, exige que os sistemas a serem estudados, em suas estruturas cristalinas perfeitas, estejam bem descritos em termos de suas propriedades eletrônicas e estruturais. Neste contexto, torna-se importante e fundamental um estudo detalhado destas propriedades, as quais são obtidas com a simulação do material através de sua célula primitiva e da supercélula perfeita, composta somente de átomos hospedeiros. Neste capítulo apresentamos as propriedades da zircônia nas fases cúbica e tetragonal, assim como em uma fase tetragonal de corpo centrado, pois, como mostraremos, esta fase é equivalente à estrutura cúbica de face centrada com uma pequena distorção na direção $\hat{k}$, sendo que este tipo de distorção já foi observada experimentalmente [2].

\subsection{Cristais Perfeitos de Zircônia}

As propriedades físicas dos sistemas estudados foram obtidas dentro da teoria do funcional da densidade (DFT) com aproximação GGA (Generalized Gradient Aproximation), devida a Perdew, Burke e Ernzerhof [16] para o termo de trocacorrelação, utilizando o método APW+lo no qual está baseado o código computacional WIEN2k [17].

As iterações autoconsistentes foram consideradas convergidas quando ambas, a energia total e a carga total dentro das esferas, apresentavam, entre duas iterações consecutivas, diferença de valores menores do que $10^{-4} \mathrm{eV}$ por célula primitiva e $10^{-5}$ cargas eletrônicas por átomo, respectivamente. A integração na primeira Zona de Brillouin da célula primitiva foi efetuada utilizando-se uma rede de $8 \times$ 
$8 \times 8$ pontos $k$ de Monkhorst-Pack [38], os quais se reduzem, na primeira Zona de Brillouin (BZ) irredutível, a 29 pontos.

\subsection{1 $\quad \mathrm{ZrO}_{2}$ Cúbico}

\section{Propriedades Estruturais}

A fase cúbica da zircônia possui estrutura cúbica de faces centradas (FCC), pertence ao grupo espacial Fm3m, cujos vetores primitivos são:

$$
\left\{\begin{array}{l}
\vec{a}_{1}=\frac{a}{2}(\hat{\imath}+\hat{\jmath}) \\
\vec{a}_{2}=\frac{a}{2}(\hat{\jmath}+\hat{k}) \\
\vec{a}_{3}=\frac{a}{2}(\hat{\imath}+\hat{k})
\end{array}\right.
$$

A célula primitiva da zircônia cúbica possui uma base de três átomos, um átomo de zircônio e dois átomos de oxigênio, colocados nas posições dadas na tabela 3.1, de modo que cada átomo de zircônio possui 8 átomos de oxigênio como primeiros vizinhos na rede, enquanto que cada átomo de oxigênio possui 4 átomos de zircônio como primeiros vizinhos na rede. Uma representação do arranjo dos átomos na célula cúbica da zircônia está mostrada na figura 4.1.

Tabela 3.1: Posições dos átomos de Zr e O na estrutura cúbica de face centrada do $\mathrm{ZrO}_{2}$.

\begin{tabular}{||c|c||}
\hline \hline Átomo & Posição \\
\hline \hline $\mathrm{Zr}_{1}$ & $(0,0,0)$ \\
\hline $\mathrm{O}_{1}$ & $(a / 4, a / 4, a / 4)$ \\
\hline $\mathrm{O}_{2}$ & $(a / 4, a / 4,3 a / 4)$ \\
\hline \hline
\end{tabular}

Para obter as propriedades do cristal, utilizando o método APW+lo, devemos escolher o raio das esferas que representam as regiões atômicas. Escolhemos, para 


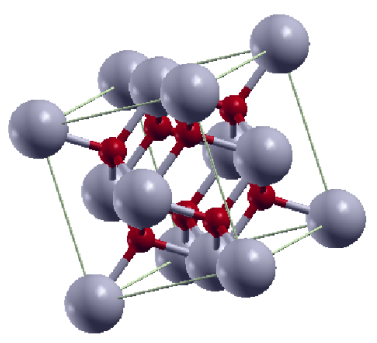

Figura 3.1: Estrutura cristalina da zircônia cúbica, onde as esferas maiores (cinzas) representam os átomos de $\mathrm{Zr}$ e as menores (vermelhas) os átomos de oxigênio.

descrever as regiões atômicas referentes aos átomos de Zr e O, esferas não superpostas e não tocantes, com raios $\mathrm{r}_{\mathrm{Zr}}=1,95$ u.a. e $\mathrm{r}_{\mathrm{O}}=1,73$ u.a., os quais permitem tratar relaxações atômicas da rede cristalina sem que haja superposição das esferas, pois é recomendável que os raios sejam parecidos para todos os elementos na célula primitiva, caso contrário pode ocorrer uma discrepância no número de bases utilizadas para cada átomo [39]. É recomendável também que os raios sejam os mesmos em todos os cálculos, apesar de teoricamente o valor desse raio não interferir na convergência final. Durante a otimização da estrutura, para se obter o volume (parâmetro de rede) correspondente à mínima energia do sistema, é feita uma variação no volume, aumentando e reduzindo a constante de rede. Se for utilizado o maior raio possível para as esferas, tal procedimento pode provocar a superposição das esferas. Outro parâmetro muito importante é o valor de $R K_{\text {máx }}=R K$, que determina o número de funções de base que serão utilizadas na região intersticial, conforme descrito no capítulo anterior. Se o valor deste parâmetro for muito pequeno, poucas funções são usadas e o programa fica mais rápido, mas não tão preciso. Se o seu valor for grande ocorre o oposto, o programa fica mais preciso, porém mais lento, pois o tamanho da matriz a ser resolvida é maior. Fizemos um estudo do comportamento da variação da energia total em função da variação do valor de $R K$. A figura 3.2 mostra o gráfico da energia total em função de $R K$, variando o valor desse parâmetro de 5 até 10, onde foi adotado o valor zero para a energia total mais baixa obtida. Deste gráfico podemos observar que o valor 


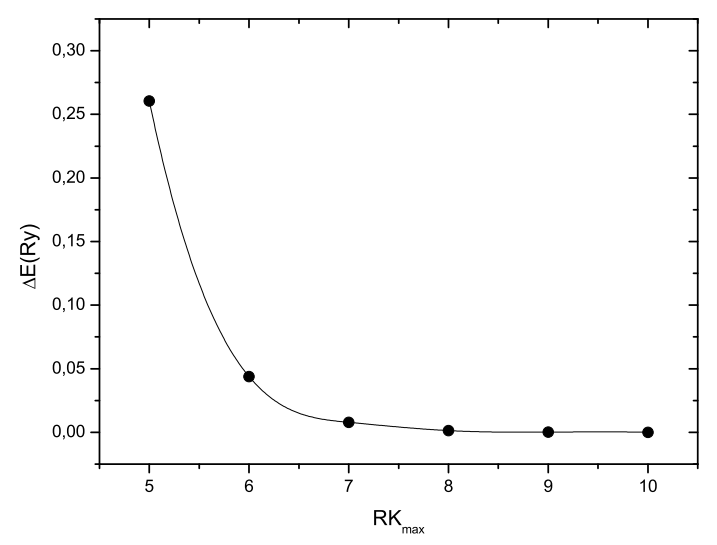

Figura 3.2: Convergência na variação da energia total em função do parâmetro $R K_{\text {máx }}$ para a zircônia cúbica, onde o valor nulo para a energia foi adotado ser o mais baixo obtido.

da energia total do sistema, obtido com $R K=7$, difere de menos de $10 \mathrm{meV}$ do valor convergido, obtido com $R K=10$. Deste estudo percebe-se que para o valor $R K=7$ a energia já está convergida, sendo, portanto, o valor que utilizaremos para obter as propriedades do material.

Adotando o valor $R K=7$, calculamos o valor do parâmetro de rede teórico do cristal, valor este para o qual o valor da energia é a mínima. A determinação do parâmetro de rede teórico e do módulo de compressibilidade volumétrica (bulk modulus), dado por

$$
B_{0}=\left[V \frac{\partial^{2} E}{\partial V^{2}}\right]_{V=V_{0}}
$$

foi efetuada através do ajuste da curva de energia total em função do volume da célula primitiva, pela equação de estado de Murnaghan [40], dada por

$$
E_{t o t}(V)=V\left(\frac{B_{0}}{B_{0}^{\prime}}\right)\left[\left(\frac{1}{B_{0}^{\prime}-1}\right)\left(\frac{V_{0}}{V}\right)^{B_{0}^{\prime}}+1\right]+E_{t o t}\left(V_{0}\right)-\left(\frac{B_{0} V_{0}}{B_{0}^{\prime}-1}\right)
$$

onde $V_{0}$ é o volume de equilíbrio, $B_{0}$ é o bulk modulus e $B_{0}^{\prime}$ é a derivada do bulk modulus em relação à pressão. Pela equação de estado de Murnaghan, dada pela 
expressão (3.3), percebe-se que $E_{t o t}(V)>E_{t o t}\left(V_{0}\right)$ sempre, para todo $V_{0}$. Assim, para o valor mínimo da energia total pode-se encontrar o volume de equilíbrio do sistema, $V_{0}$, e com esse valor do volume calcular a constante de rede. Para a estrutura cristalina de zircônia, cúbica de face centrada, tem-se que $a=\sqrt[3]{4 V_{0}}$. Já que o volume depende apenas de um parâmetro, pode-se variar apenas este para calcular a variação da energia total do sistema em função do volume. Realizando estes cálculos da energia total, variando o volume da célula primitiva, obteve-se a curva apresentada na figura 3.3. Deste gráfico extraiu-se que a energia mínima

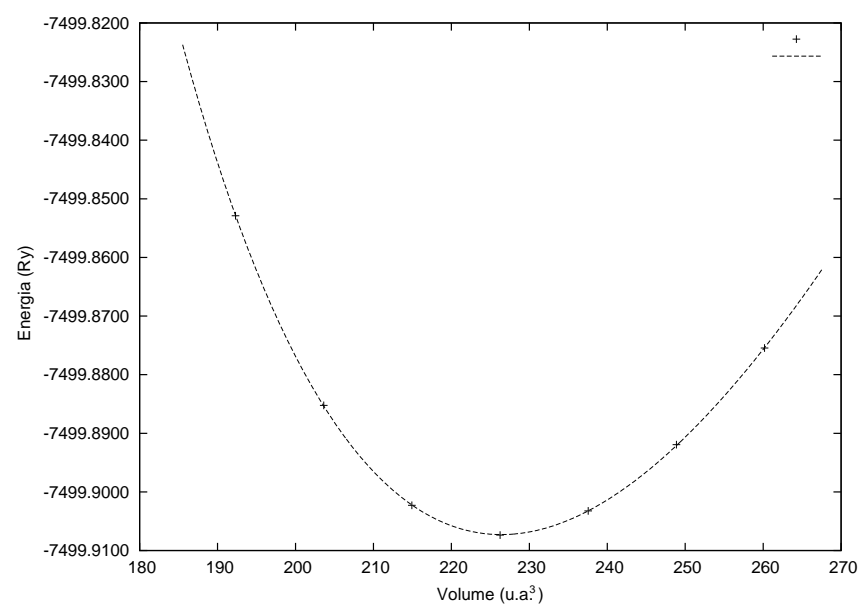

Figura 3.3: Energia total versus volume da célula primitiva para o $\mathrm{ZrO}_{2}$ cúbico.

do sistema é obtida para o volume $\mathrm{V}_{0}=226,3872$ (u.a.) ${ }^{3}$ e assim, o parâmetro de rede teórico obtido é $a=\sqrt[3]{4(226,3872)}=9,675$ u.a. $=5,12 \AA$. Este resultado está de acordo com resultados teóricos obtidos anteriormente com diversos métodos teóricos [3] e com resultados experimentais [5,41,42] como mostrado na tabela 3.2. Também, através da equação de estado de Murnaghan, obteve-se o valor para o bulk modulus de $B_{0}=234 \mathrm{GPa}, 21 \%$ maior que o valor experimental.

Para calcular a energia de coesão, os valores das energias atômicas dos átomos de Zr e O foram obtidos através do modelo do átomo na caixa, onde utilizamos uma rede de Bravais cúbica simples contendo ou o átomo de $\mathrm{Zr}$ ou o de $\mathrm{O}$, como 
Tabela 3.2: Valores teóricos e experimentais para o parâmetro de rede $a$, bulk modulus $B_{0}$, gap de energia $\mathrm{E}_{g}$, energia de coesão $\mathrm{E}_{c}$ e entalpia de formação $\Delta_{\mathrm{f}} \mathrm{H}$ do $\mathrm{ZrO}_{2}$ cúbico. O parâmetro de rede está dado em u.a., o bulk modulus em GPa, as energias e a entalpia em eV.

\begin{tabular}{||l|c|c|c|c|c||}
\hline \hline & $a$ & $B_{0}$ & $\mathrm{E}_{g}$ & $\mathrm{E}_{c}$ & $\Delta_{\mathrm{f}} \mathrm{H}$ \\
\hline \hline Teórico & 9,675 & 234 & 3,33 & $-24,33\left[-26,18^{(a)}\right]$ & $-9,94$ \\
\hline Exp. & $9,611^{(b)}$ & $194^{(b)}$ & $4,6-6,1^{(c)}$ & - & - \\
\hline \hline
\end{tabular}
(a) Ref. [43]
(b) Ref. [5]
(c) Ref. $[44,45]$

base, com parâmetro de rede $a=12,0$ u.a. para a célula. Os valores obtidos para as energias totais dos átomos, neste caso, não diferem muito daqueles obtidos pelos cálculos atômicos relativísticos. O valor calculado para a energia de coesão é $11 \%$ menor que o valor encontrado em um cálculo de pseudopotencial [43]. A entalpia de formação da $\mathrm{ZrO}_{2}$ cúbica foi obtida utilizando-se a equação (A.7) do apêndice A. Com o valor teórico do parâmetro de rede $a$, obtivemos as distâncias entre vizinhos mais próximos na rede do $\mathrm{ZrO}_{2}$ cúbico, as quais estão mostradas na tabela 3.3.

Tabela 3.3: Distâncias entre os vizinhos mais próximos para o cristal de $\mathrm{ZrO}_{2}$ cúbico, onde cada átomo de zircônio possui, como primeiros vizinhos, 8 átomos de oxigênio e cada átomo de oxigênio possui, como primeiros vizinhos, 4 átomos de zircônio.

\begin{tabular}{||l|c||}
\hline \hline & Distância $(\AA)$ \\
\hline \hline$d\left(\mathrm{Zr}_{1}, \mathrm{O}_{1}\right)$ & 2,217 \\
\hline $\mathrm{d}\left(\mathrm{O}_{1}, \mathrm{O}_{2}\right)$ & 2,560 \\
\hline $\mathrm{d}\left(\mathrm{O}_{1}, \mathrm{O}_{1}\right)=\mathrm{d}\left(\mathrm{O}_{2}, \mathrm{O}_{2}\right)$ & 3,620 \\
\hline \hline
\end{tabular}

Comparando nossos resultados, apresentados na tabela 3.2, com os dados experimentais, podemos concluir que as propriedades estruturais do c- $\mathrm{ZrO}_{2}$ estão muito bem descritas pelo método utilizado. 


\section{Propriedades Eletrônicas}

A primeira zona de Brillouin do $\mathrm{ZrO}_{2}$ cúbico é o poliedro de 14 faces da rede FCC, conforme mostra a figura 3.4, onde estão destacados os pontos e as direções de alta simetria. Com os valores otimizados da constante de rede, calculou-se a estrutura

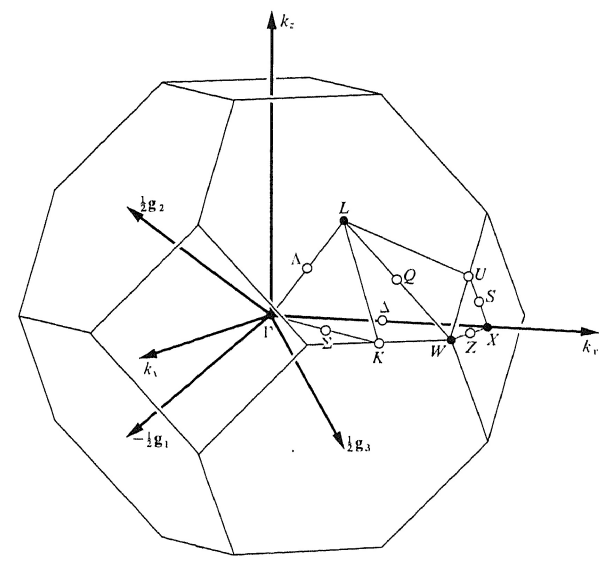

Figura 3.4: Primeira zona de Brillouin da rede cúbica de face centrada do c- $\mathrm{ZrO}_{2}$, mostrando os pontos e as direções de alta simetria

de bandas do material, nas direções de alta simetria da primeira zona de Brillouin, que está mostrada na figura 3.5, onde o zero de energia foi deslocado para o topo da banda de valência $\left(E_{v}\right)$. A figura mostra, também, a densidade de estados total (TDOS) e as densidades de estados projetadas nos átomos de $\mathrm{Zr}$ e $\mathrm{O}$ da zircônia cúbica. A estrutura de bandas do c- $\mathrm{ZrO}_{2}$ mostra que a banda de valência é estreita, com aproximadamente 6,0 eV de largura, e que o gap é indireto e na direção $\mathrm{X} \rightarrow \Gamma$, de valor $E_{g}=3,33 \mathrm{eV}$. Este valor é compatível com o calculado por Kobayashi et. al. [46], mas é cerca de $41 \%$ menor que o valor experimental obtido por French et. al. [44], de acordo com os valores mostrados na tabela 3.2. O valor subestimado para a largura da faixa de energia proibida de transição indireta é esperado, pois é calculado como a diferença entre o autovalor do estado mais alto ocupado, que define o valor da energia do topo da faixa de valência, e o autovalor do estado mais baixo desocupado, que define o valor da energia do fundo da faixa de condução, 


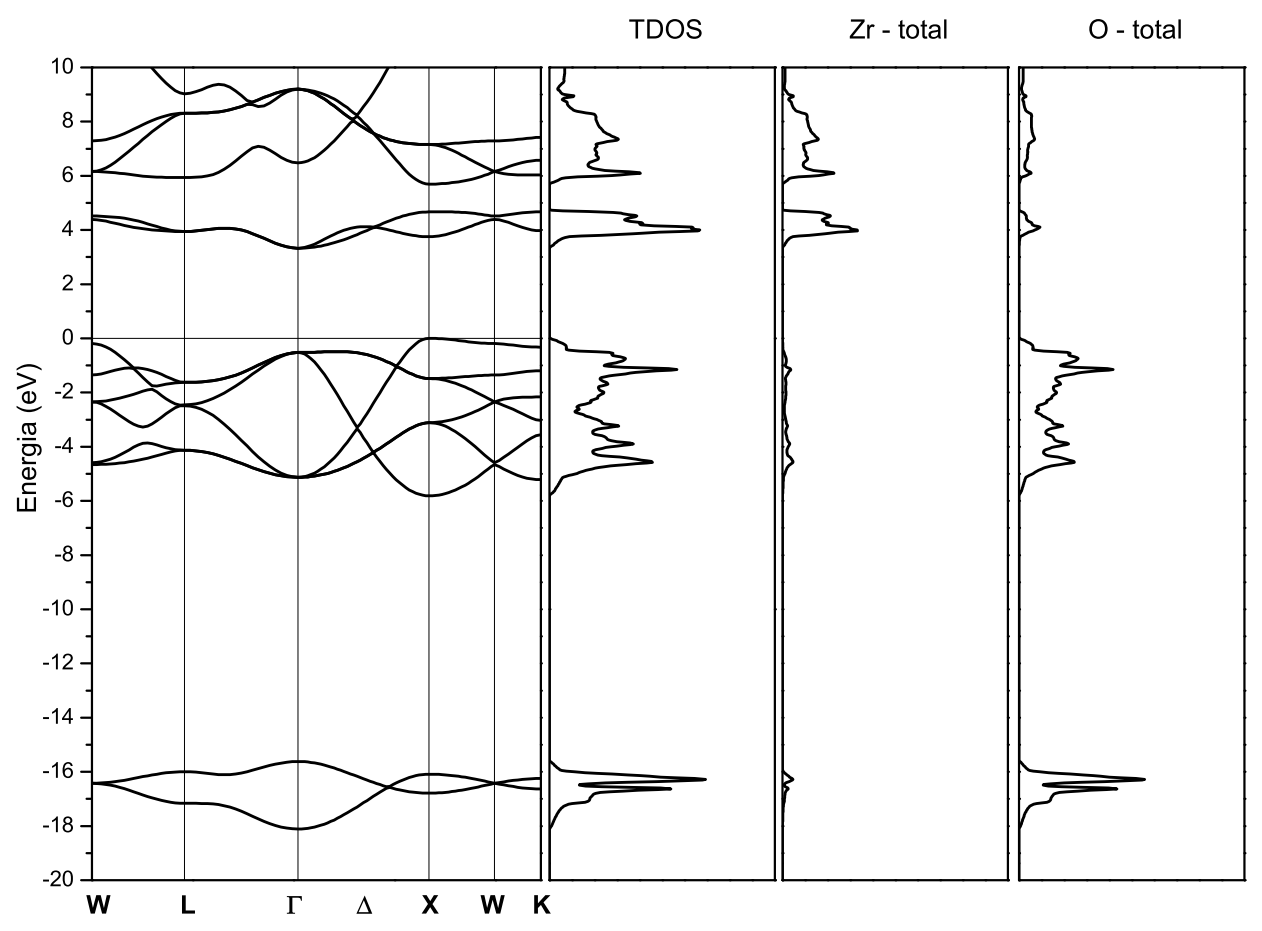

Figura 3.5: Estrutura de bandas, densidade de estados total (TDOS) e projetadas nos átomos de $\mathrm{Zr}$ (Zr-total) e $\mathrm{O}$ (O-total) do $\mathrm{ZrO}_{2}$ cúbico.

pois os cálculos foram efetuados dentro do formalismo do funcional da densidade, desenvolvido para descrever a energia total do estado fundamental dos sistemas e, portanto, não descreve corretamente os autovalores dos estados excitados, como os que definem a banda de condução.

Comparando a TDOS com as densidades de estados projetadas nos átomos, percebemos que os estados característicos do átomo de zircônio compõem, predominantemente, o fundo da banda de condução, que são estados com caráter $s$ e $d$ do zircônio. Os estados característicos dos átomos de oxigênio predominam na faixa estreita de energia em aproximadamente $E_{v}-16,5 \mathrm{eV}$, com caráter $s$, assim como compõem a banda de valência do material, composto primordialmente pelos estados $p$ do $\mathrm{O}$, no intervalo de energia $-6,0 \leq E \leq E_{v}(\mathrm{eV})$. O átomo de zircônio tem 4 
elétrons na camada de valência, com a configuração $4 d^{2} 5 s^{2}$ e o átomo de oxigênio 6 elétrons na valência, com configuração $2 s^{2} 2 p^{4}$. Dessa forma, os elétrons da camada de valência do átomo de zircônio são praticamente doados para os dois átomos de oxigênio, ficando na configuração iônica $\mathrm{Zr}^{4+}$, completando as camadas de valência dos átomos de oxigênio, que ficam na configuração iônica $\mathrm{O}^{2-}$. No entanto, a ligação não é totalmente iônica, apresentando um pequeno caráter covalente. Isso pode ser observado na distribuição eletrônica do sistema, mostrada na figura 3.6, que representa a densidade eletrônica de valência do material, calculada em um plano (110), mostrando que a ligação entre os átomos é mais iônica do que covalente.

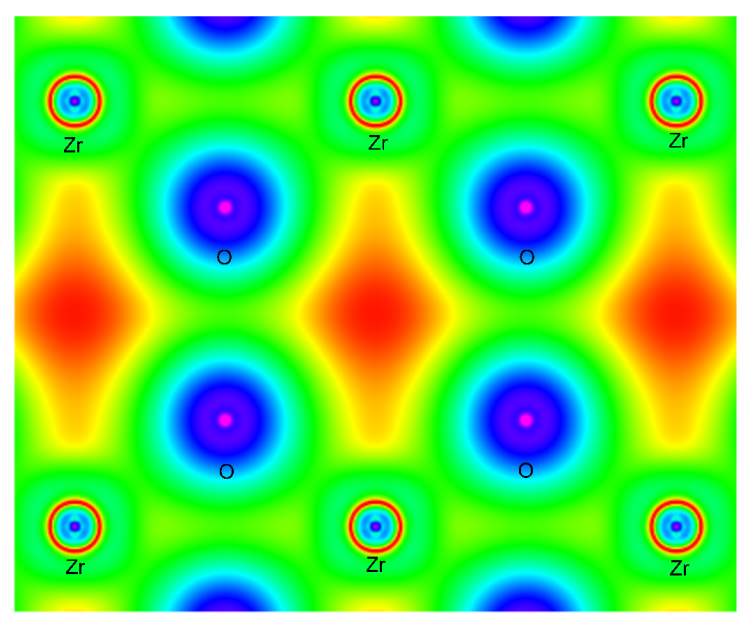

Figura 3.6: Densidade eletrônica do $\mathrm{ZrO}_{2}$ cúbico, no plano (110), onde o esquema de cores segue o arco-íris, variando do violeta (alta densidade) para o vermelho (baixa densidade).

De nossos resultados podemos concluir que as propriedades eletrônicas do $\mathrm{ZrO}_{2}$ cúbico estão muito bem descritas pelo método utilizado. 


\subsection{2 $\quad \mathrm{ZrO}_{2}$ Tetragonal}

\section{Propriedades Estruturais}

A estrutura cristalina tetragonal do $\mathrm{ZrO}_{2}$ pertence ao grupo espacial $\mathrm{P} 42 / \mathrm{nmc}$. Os vetores primitivos da rede tetragonal são:

$$
\left\{\begin{array}{l}
\vec{a}_{1}=a \hat{\imath} \\
\vec{a}_{2}=a \hat{\jmath} \\
\vec{a}_{3}=c \hat{k}
\end{array}\right.
$$

onde $a$ e $c$ são os parâmetros da rede tetragonal. Esta rede pode ser construída, em relação à estrutura cúbica, através de uma distorção de pares alternados de átomos de oxigênio, por uma quantidade adimensional $d_{z}=\Delta c / c$. Dessa forma obtém-se que a base é composta por 6 átomos na célula tetragonal primitiva, compreendendo dois átomos de Zr e quatro átomos de $\mathrm{O}$, nas posições dadas na tabela 3.4, onde z é um parâmetro interno, de modo que cada átomo de zircônio possui 8 átomos de oxigênio mais próximos na rede, quatro a quatro a uma mesma distância (número de coordenação 2), enquanto que cada átomo de oxigênio possui 4 átomos de zircônio como primeiros vizinhos na rede, também com número de coordenação 2.

Tabela 3.4: Posições dos átomos de $\mathrm{Zr}$ e $\mathrm{O}$ na estrutura tetragonal primitiva do $\mathrm{ZrO}_{2}$.

\begin{tabular}{||c|c||}
\hline \hline Átomo & Posição \\
\hline \hline $\mathrm{Zr}_{1}$ & $(0,0,0)$ \\
\hline $\mathrm{Zr}_{2}$ & $(a / 2, a / 2, c / 2)$ \\
\hline $\mathrm{O}_{1}$ & $(0, a / 2, z c)$ \\
\hline $\mathrm{O}_{2}$ & $(0, a / 2,(z+1 / 2) c)$ \\
\hline $\mathrm{O}_{3}$ & $(a / 2,0,(-z+1 / 2) c)$ \\
\hline $\mathrm{O}_{4}$ & $(a / 2,0,-z c)$ \\
\hline \hline
\end{tabular}


Uma representação do arranjo dos átomos na célula tetragonal da zircônia está mostrada na figura 3.7. Nesta estrutura, a zircônia $\left(\mathrm{t}-\mathrm{ZrO}_{2}\right)$ é estável apenas entre

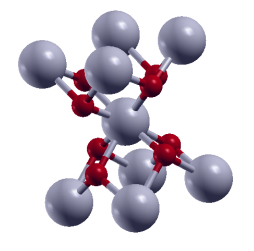

Figura 3.7: Estrutura cristalina da zircônia tetragonal, onde as esferas maiores (cinzas) representam os átomos de Zr e as menores (vermelhas) os átomos de oxigênio.

as temperaturas de $1400 \mathrm{~K}$ e $2650 \mathrm{~K}$, mas pode ser mantida estável na temperatura ambiente com a adição de dopantes, como o ítrio e o cério [2,5]. Para os cálculos das propriedades eletrônicas e estruturais do t- $\mathrm{ZrO}_{2}$ utilizou-se, para descrever as regiões atômicas referentes aos átomos de $\mathrm{Zr}$ e O, esferas não superpostas e não tocantes, com raios $\mathrm{r}_{\mathrm{Zr}}=1,83$ u.a. e $\mathrm{r}_{\mathrm{O}}=1,62$ u.a., os quais permitem tratar relaxações atômicas da rede cristalina sem que haja superposição das esferas. Da mesma forma que para a estrutura cúbica, fez-se um estudo da energia total do sistema em função da variação do valor do parâmetro $R K$. A figura 3.8 mostra o gráfico da energia total em função de $R K$, variando seu valor de 5 até 10, onde foi adotado o valor zero para a energia total mais baixa obtida. Deste gráfico podemos observar que o valor da energia total do sistema, obtido com $R K=7$, difere de menos que $20 \mathrm{meV}$ do valor convergido, obtido com $R K=10$. Deste estudo percebe-se que para o valor $R K=7$ a energia já está convergida, sendo, portanto, o valor que utilizaremos para obter as propriedades do material. A otimização da estrutura tetragonal do $\mathrm{ZrO}_{2}$, para obter-se os parâmetros de rede $a$ e $c$ teóricos, assim como o parâmetro $z$ interno, é feita de uma maneira diferente daquela da estrutura cúbica. Neste caso, como o volume da célula depende de dois parâmetros ( $c$ e $a$ ), além de de um parâmetro interno $z$, a minimização é realizada em duas etapas, primeiro calculando a energia total do sistema, mantendo-se constante a 
relação $c / a$ e variando o volume da célula primitiva. A figura 3.9 mostra uma curva de energia total em função da variação do volume, para um valor fixo de $c / a$, como exemplo. O valor do volume encontrado, que dá a energia mínima do sistema, é então mantido fixo, variando-se a relação $c / a$. Uma curva da energia total do sistema em função da variação da relação $c / a$, para um valor fixo do volume, está mostrada na figura 3.10. Além disso, a cada passo, é necessário efetuar-se uma relaxação iônica, que consiste em uma minimização das forças que aparecem em cada átomo da estrutura, calculadas de acordo com o teorema de Hellmann-Feymann e com as correções de Pulay [47,48]. Estes dois processos são repetidos várias vezes, até obter-se o volume que dá a energia mínima do sistema. Terminado o processo de procura da energia mínima do sistema, encontrou-se para o volume mínimo o valor $V_{0}=467,8474$ (u.a.) ${ }^{3}$, com $c / a=1,45$, a partir dos quais foram obtidos os valores para os parâmetros de rede, obtendo-se $a=6,860$ u.a. e $c=9,940$ u.a., enquanto que o valor obtido para o parâmetro interno foi $z=0,306$. Estes valores estão em excelente acordo com os resultados teóricos calculados por Fadda et. al. [5] e compatíveis com os valores experimentais [41,49].

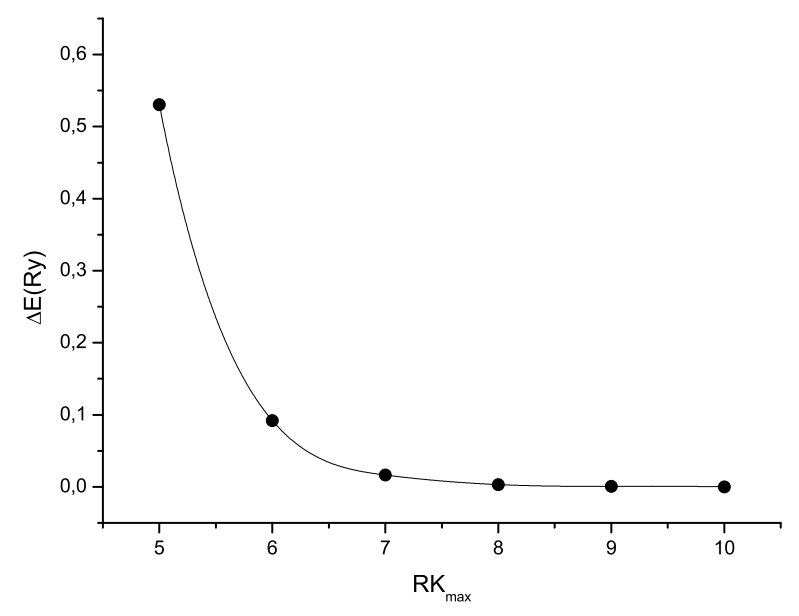

Figura 3.8: Convergência da energia total em função do parâmetro $R K_{\text {máx }}$ para a zircônia tetragonal. 


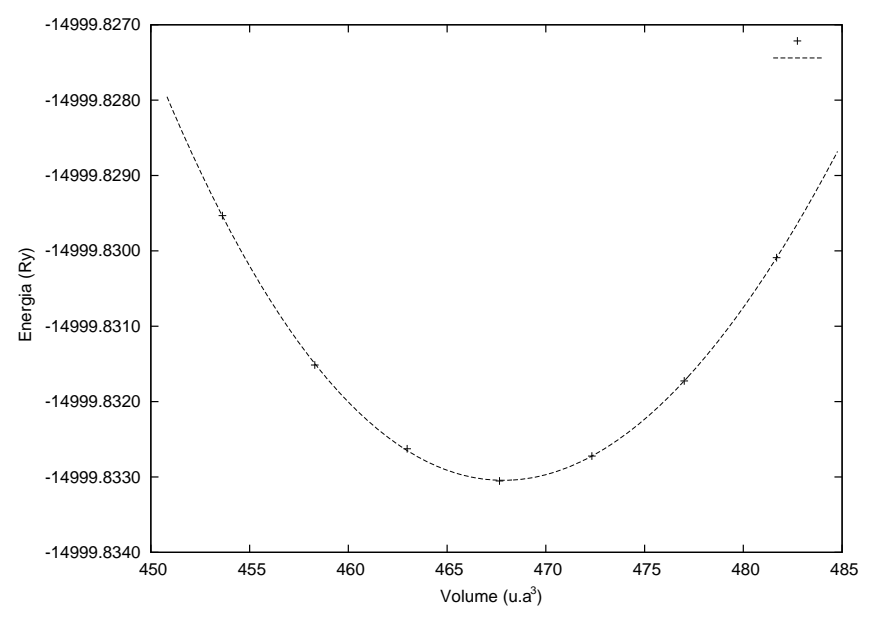

Figura 3.9: Energia total em função da variação do volume da célula primitiva da zircônia tetragonal, mantendo-se fixo o valor da relação $c / a$.

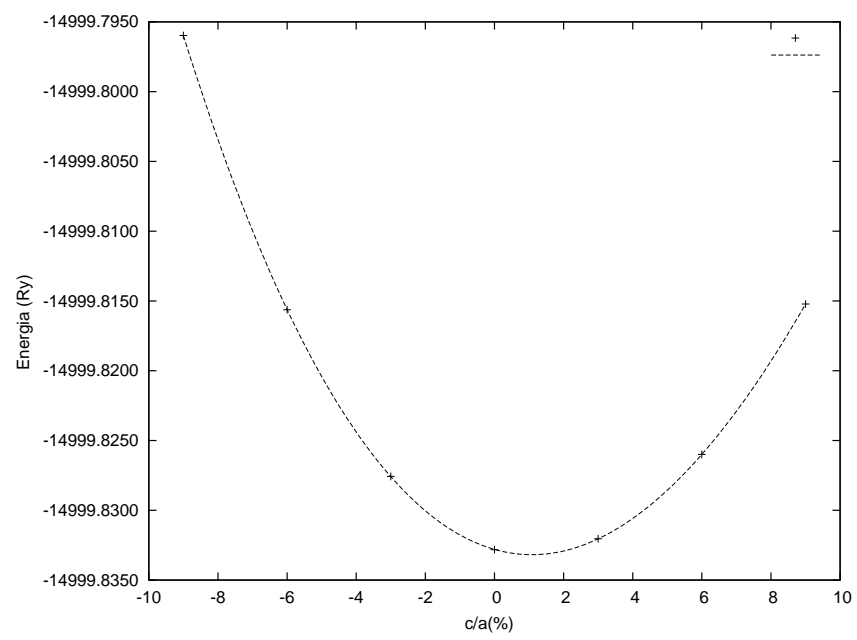

Figura 3.10: Energia total em função da variação da relação $c / a$, para um valor fixo do volume, para a célula primitiva da zircônia tetragonal.

Para esta estrutura, através da equação de Murnaghan, calculou-se o bulk modulus do material, obtendo-se o valor de $225 \mathrm{GPa}$, o qual é $24 \%$ maior que o valor 
experimental de $183 \mathrm{GPa}$ [41], mas compatível com os valores calculados por outros métodos. A tabela 3.5 resume os resultados teóricos obtidos neste trabalho, para as propriedades do $\mathrm{t}-\mathrm{ZrO}_{2}$, juntamente com valores experimentais.

Tabela 3.5: Valores teóricos e experimentais para os parâmetros de rede $a$ e $c$, parâmetro interno $z$, bulk modulus $B_{0}$, gap de energia $\mathrm{E}_{g}$, energia de coesão $\mathrm{E}_{c} \mathrm{e}$ entalpia de formação $\Delta_{\mathrm{f}} \mathrm{H}$ do $\mathrm{ZrO}_{2}$ tetragonal. Os parâmetros de rede estão dados em u.a., o bulk modulus em GPa, as energias e a entalpia em eV.

\begin{tabular}{||l|c|c|c|c|c|c|c||}
\hline \hline & $a$ & $c$ & $z$ & $B_{0}$ & $\mathrm{E}_{g}$ & $\mathrm{E}_{c}$ & $\Delta_{\mathrm{f}} \mathrm{H}$ \\
\hline \hline Teórico & 6,860 & 9,940 & 0,306 & 225 & 4,04 & $-24,45\left[-26,29^{(a)}\right]$ & $-10,06$ \\
\hline Exp. & $6,813^{(b)}$ & $9,788^{(b)}$ & $0,307^{(c)}$ & $183^{(b)}$ & $5,78-6,62^{(d)}$ & - & - \\
\hline \hline
\end{tabular}
(a) Ref. [42]
(b) Ref. [41]
(c) Ref. [49]
(d) Ref. [44]

Observa-se que a constante de rede $c$ é $1 \%$ maior que o valor experimental, o que condiz com o fato da aproximação GGA superestimar a constante de rede. O valor calculado para a energia de coesão é, como no caso do material cúbico, 11\% menor que o valor obtido por cálculos de psedopotencial. Vale ressaltar, entretanto, que ao compararmos os valores das energias de coesão do $\mathrm{ZrO}_{2}$ nas estruturas cúbica (tabela 3.2) e tetragonal (tabela 3.5), encontramos, de acordo com os dados de outro resultado teórico, que a estrutura tetragonal é mais estável que a estrutura cúbica, pois sua energia de coesão é menor. A entalpia de formação da $\mathrm{ZrO}_{2}$ tetragonal primitiva foi obtida através da equação (A.7) do apêndice A. Com os valores teóricos dos parâmetros de rede e do parâmetro interno $z$, obtivemos as distâncias entre vizinhos mais próximos na rede do $\mathrm{ZrO}_{2}$ tetragonal, onde cada átomo de $\mathrm{Zr}$ possui 8 átomos de oxigênio como vizinhos mais próximos, divididos em duas esferas de coordenação, e cada átomo de oxigênio possui 4 átomos de Zr como primeiros vizinhos, divididos também em duas esferas de coordenação. Estas distâncias estão mostradas na tabela 3.6.

Desta análise podemos concluir que as propriedades estruturais do t- $\mathrm{ZrO}_{2}$ estão muito bem descritas pelo método utilizado. 
Tabela 3.6: Distâncias entre os vizinhos mais próximos no cristal de $\mathrm{ZrO}_{2}$ tetragonal. Cada átomo de Zr possui 8 átomos de oxigênio como vizinhos mais próximos, divididos em duas esferas de coordenação e cada átomo de oxigênio possui 4 átomos de zircônio como primeiros vizinhos, divididos em duas esferas de coordenação.

\begin{tabular}{||c|c||}
\hline \hline & Distância $(\AA)$ \\
\hline \hline $\mathrm{d}\left(\mathrm{Zr}_{1}, \mathrm{O}_{1}\right)=\mathrm{d}\left(\mathrm{Zr}_{2}, \mathrm{O}_{1}\right)$ & 2,081 \\
\hline $\mathrm{d}\left(\mathrm{Zr}_{1}, \mathrm{O}_{2}\right)=\mathrm{d}\left(\mathrm{Zr}_{2}, \mathrm{O}_{2}\right)$ & 2,428 \\
\hline $\mathrm{d}\left(\mathrm{O}_{1}, \mathrm{O}_{2}\right)=\mathrm{d}\left(\mathrm{O}_{3}, \mathrm{O}_{4}\right)$ & 2,630 \\
\hline $\mathrm{d}\left(\mathrm{O}_{1}, \mathrm{O}_{3}\right)=\mathrm{d}\left(\mathrm{O}_{2}, \mathrm{O}_{4}\right)$ & 2,635 \\
\hline $\mathrm{d}\left(\mathrm{O}_{1}, \mathrm{O}_{4}\right)=\mathrm{d}\left(\mathrm{O}_{2}, \mathrm{O}_{3}\right)$ & 3,275 \\
\hline $\mathrm{d}\left(\mathrm{O}_{1}, \mathrm{O}_{1}\right)=\mathrm{d}\left(\mathrm{O}_{2}, \mathrm{O}_{2}\right)=\mathrm{d}\left(\mathrm{O}_{3}, \mathrm{O}_{3}\right)=\mathrm{d}\left(\mathrm{O}_{4}, \mathrm{O}_{4}\right)$ & 3,630 \\
\hline \hline
\end{tabular}

\section{Propriedades Eletrônicas}

Com os parâmetros de rede e interno otimizados, obtivemos a estrutura de bandas do material nas direções de alta simetria da primeira zona de Brillouin do $\mathrm{ZrO}_{2}$ tetragonal, que é um paralelepípedo, como mostra a figura 3.11, onde estão destacados os pontos e as direções de alta simetria da zona. A estrutura de bandas da fase tetragonal do $\mathrm{ZrO}_{2}$, juntamente com as densidades de estados total e projetadas nos átomos de Zr e O, está mostrada na figura 3.12.

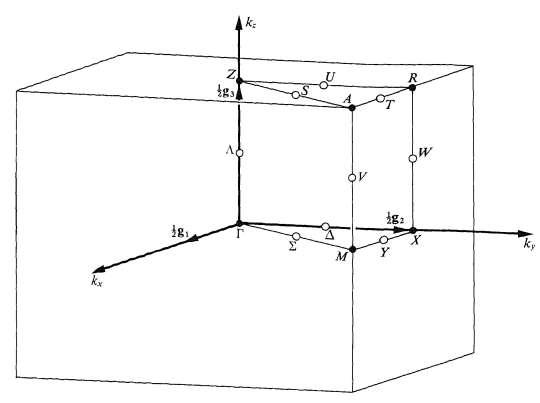

Figura 3.11: Primeira zona de Brillouin da fase tetragonal do $\mathrm{ZrO}_{2}$, destacando os pontos e as direções de alta simetria. 


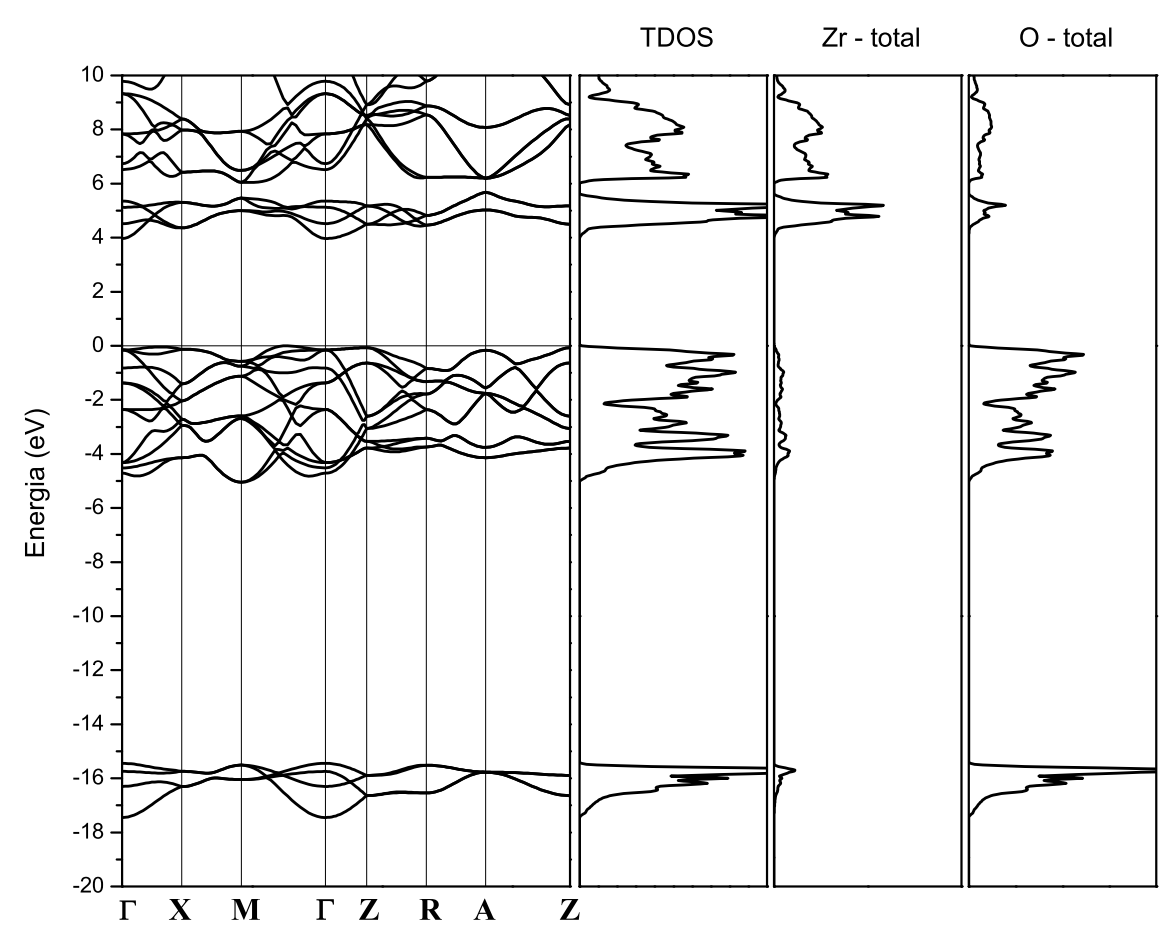

Figura 3.12: Estrutura de bandas e densidades de estados total (TDOS) e projetadas nos átomos de $\mathrm{Zr}$ (Zr-total) e $\mathrm{O}$ (O-total) do $\mathrm{ZrO}_{2}$ tetragonal.

O gap de energia obtido é indireto, na direção $Z \rightarrow \Gamma$, e seu valor é de 4,04 $\mathrm{eV}$, subestimado em relação ao valor experimental, como esperado. Percebe-se que a densidade de estados da zircônia tetragonal tem as mesmas características daquelas apresentadas pela zircônia cúbica, com os estados $s$ e $d$ característicos dos átomos de zircônio compondo o fundo da banda de condução e os estados $p$ dos átomos de oxigênio compondo a banda de valência do material. Os estados $s$ característicos dos átomos de oxigênio compõem uma banda estreita e profunda em aproximadamente $E_{v}-17,0 \mathrm{eV}$. Como analisado anteriormente para a estrutura cúbica da zircônia, na estrutura tetragonal as ligações entre os átomos é predominantemente de caráter iônico, podendo ser atribuída a uma interação entre a $\mathrm{Zr}^{4+} \mathrm{e}$ os dois átomos de $\mathrm{O}^{2-}$. Esta característica é evidenciada pela densidade eletrônica 
mostrada na figura 3.13, no plano (011) da zircônia tetragonal.

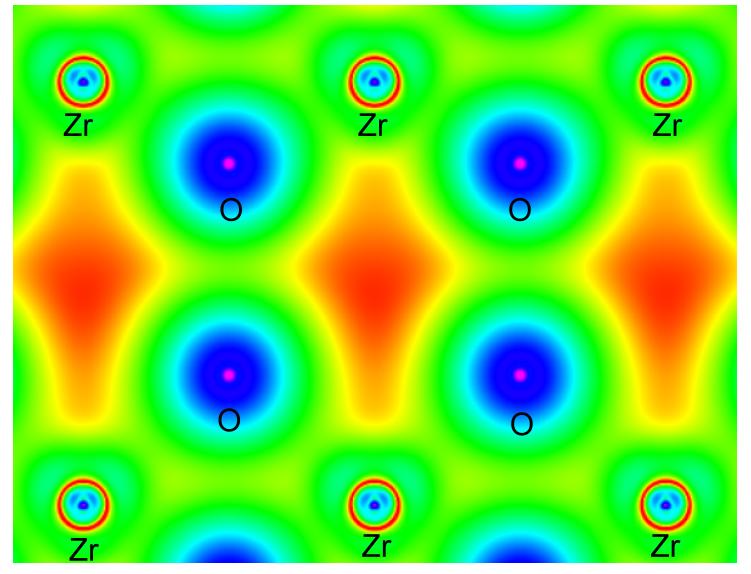

Figura 3.13: Densidade eletrônica, no plano (011), do $\mathrm{ZrO}_{2}$ tetragonal, onde o esquema de cores segue o arco-íris, variando do violeta (alta densidade) para o vermelho (baixa densidade).

Nossos resultados indicam que as propriedades eletrônicas e estruturais do $\mathrm{ZrO}_{2}$ tetragonal estão muito bem descritas pelo método utilizado.

\subsubsection{Cristal de $\mathrm{ZrO}_{2}$ Tetragonal de Corpo Centrado}

L. Acuña et. al. [2] mediram os parâmetros de rede de pós nanocristalinos de zircônia, estabilizados na temperatura ambiente, e encontraram os valores $a=$ 9,623 u.a. e $c=9,796$ u.a., resultando em uma relação $c / a=1,02$. Valores de $c / a$ próximos a este são também apresentados por Zavodinsky et. al. [50]. Estes parâmetros de rede são muito diferentes e não compatíveis com os valores da $\mathrm{ZrO}_{2}$ tetragonal, calculadas no capítulo anterior e obtidas experimentalmente para temperaturas entre $1400 \mathrm{~K}$ e $2650 \mathrm{~K}$. Estes resultados podem indicar que as estruturas estabilizadas nestes pós nanocristalinos estariam relacionadas com o $\mathrm{ZrO}_{2}$ em uma rede cúbica de face centrada com uma pequena distorção para fora na direção $\hat{k}$ ou em uma rede tetragonal com uma relaxação para dentro na direção $\hat{k}$ e no plano basal. Se a primeira hipótese for levada em consideração, poderíamos descrevê-la como uma rede tetragonal de faces centradas, com parâmetros de rede 
$a=b \neq c$. Entretanto, esta rede é equivalente à rede de Bravais tetragonal de corpo centrado com parâmetros $a^{\prime}=b^{\prime}=a \sin \left(45^{\circ}\right)$ e $c^{\prime}=c$, onde $a$ e $c$ seriam as constantes de rede da estrutura tetragonal de faces centradas (que não é uma das 14 redes de Bravais), enquanto que $a^{\prime}, b^{\prime}$ e $c^{\prime}$ são as constantes de rede da estrutura tetragonal de corpo centrado. A figura 3.14 mostra a equivalência entre estes dois tipos de rede.

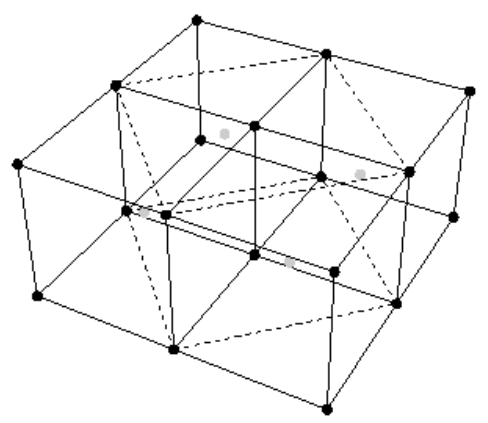

Figura 3.14: Equivalência entre uma rede tetragonal de face centrada e uma tetragonal de corpo centrado.

A zircônia descrita como uma rede de Bravais tetragonal de corpo centrado (TCC) apresenta o grupo espacial $\mathrm{I} / \mathrm{mmm}$, cujos vetores primitivos são

$$
\left\{\begin{array}{r}
\vec{a}_{1}=\frac{a^{\prime}}{2}(\hat{\imath}+\hat{\jmath})-\frac{c^{\prime}}{2} \hat{k} \\
\vec{a}_{2}=\frac{a^{\prime}}{2}(\hat{\imath}-\hat{\jmath})+\frac{c^{\prime}}{2} \hat{k} \\
\vec{a}_{3}=\frac{a^{\prime}}{2}(-\hat{\imath}+\hat{\jmath})+\frac{c^{\prime}}{2} \hat{k}
\end{array}\right.
$$

e a base é composta por três átomos, um átomo de zircônio e dois átomos de oxigênio, cujas posições estão dadas na tabela 3.7.

Portanto, se interpretarmos as constantes de rede citadas na referência [2] como as de uma rede cúbica de face centrada com uma pequena distorção na direção $\hat{k}$, obtemos uma rede tetragonal de corpo centrado com $a=6,804$ u.a e $c=9,796$ u.a., 
Tabela 3.7: Posições dos átomos de Zr e O na estrutura tetragonal de corpo centrado.

\begin{tabular}{||c|c||}
\hline \hline Átomo & Posição \\
\hline \hline $\mathrm{Zr}_{1}$ & $(0,0,0)$ \\
\hline $\mathrm{O}_{1}$ & $\left(0, a^{\prime} / 2, c^{\prime} / 4\right)$ \\
\hline $\mathrm{O}_{2}$ & $\left(a^{\prime} / 2,0, c^{\prime} / 4\right)$ \\
\hline \hline
\end{tabular}

cuja relação $c / a=1,44$ está bem próxima do valor teórico do $\mathrm{ZrO}_{2}$ com rede de Bravais tetragonal simples (TP), mostrado na seção anterior, grupo espacial $\mathrm{P} 4_{2} / \mathrm{nmc}$, com uma base de seis átomos nas posições dadas pela tabela 3.4. Assim, os parâmetros experimentais poderiam estar associados a nanocristais com rede tetragonal primitiva, com uma pequena distorção para dentro na direção $\hat{k}$ e no plano basal, e uma grande modificação no parâmetro interno $z$, que determina as posições dos átomos de oxigênio. Se assumirmos $z=0,25$ na rede TP descrita na seção anterior, os átomos de oxigênio se tornam equivalentes dois a dois e ela se transforma na rede tetragonal de corpo centrado obtida da rede cúbica de face centrada distorcida na direção $\hat{k}$ (tetragonal de corpo centrado). O parâmetro $z$ medido experimentalmente para o pó nanocristalino, no trabalho de L. Acuña et. al. [2], foi $z=0,222$. Ao impormos este valor de $z$ nas estruturas descritas pelas redes TP e TCC, ambas continuam apresentando as mesmas distâncias entre os átomos de Zr com seus oito átomos vizinhos de oxigênio, como demonstrado no apêndice $\mathrm{B}$, onde

$$
\begin{gathered}
d_{1}\left(\mathrm{Zr}_{2}, \mathrm{O}_{1}\right)=d_{1}\left(\mathrm{Zr}_{2}, \mathrm{O}_{4}\right)=\sqrt{\frac{a^{\prime 2}}{4}+\left(z c^{\prime}\right)^{2}}=2,135 \AA \\
d_{2}\left(\mathrm{Zr}_{2}, \mathrm{O}_{3}\right)=d_{2}\left(\mathrm{Zr}_{2}, \mathrm{O}_{2}\right)=\sqrt{\frac{a^{\prime 2}}{4}+\left(\frac{1}{2}-z\right)^{2} c^{\prime 2}}=2,304 \AA
\end{gathered}
$$

As distâncias estão calculadas em relação ao átomo de zircônio na posição 
$(a / 2, a / 2, c / 2)$ da estrutura tetragonal primitiva, que pode ser obtido na estrutura de corpo centrado através dos vetores de translação da rede, equação 3.5, e as posições dos átomos de oxigênio estão nas tabelas 3.7 para a estrutura de corpo centrado e 3.4 para a estrutura tetragonal primitiva. Entretanto, as redes não são equivalentes, pois apesar de as distâncias serem iguais, as estruturas configuracionais dos oito átomos de oxigênio ao redor de um átomo de Zr não são iguais, como mostra a figura 3.15 .

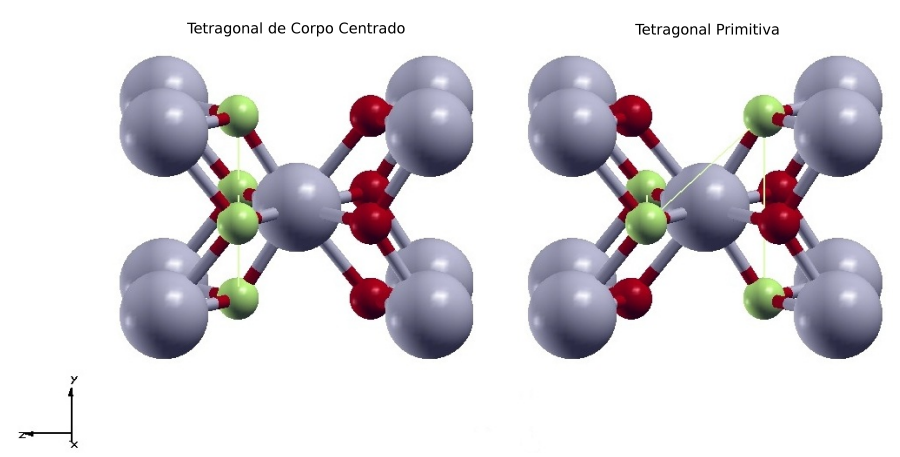

Figura 3.15: Configuração estrutural da zircônia tetragonal, mostrando a configuração atômica dos oito átomos de oxigênio ao redor de um átomo de zircônio. Esquerda: corpo centrado; Direita: primitiva. As esferas verdes e vermelhas representam os átomos de oxigênio distantes $2,135 \AA$ e 2,304 $\AA$ do átomo central de Zr, respectivamente.

Nesta figura as esferas verdes e vermelhas representam átomos de oxigênio, sendo que aqueles destacados em verde distam 2,135 ̊ do átomo de Zr central, enquanto que aqueles destacados em vermelho distam 2,304 $\AA$ do átomo de $\mathrm{Zr}$ central. Observa-se, na figura à esquerda, que no caso da rede TCC, os átomos de oxigênio mais próximos localizam-se à esquerda, ou de um mesmo lado, do átomo de zircônio, enquanto que no caso da rede TP, na figura à direita, os átomos de oxigênio aparecem alternados em relação ao átomo de Zr central. Utilizando os valores experimentais, calculou-se as distâncias entre os átomos nesta estrutura de corpo centrado, conforme mostra a tabela 3.8 .

Efetuando-se um ciclo auto-consistente na estrutura TCC, aparecem forças nos 
Tabela 3.8: Distâncias entre os vizinhos mais próximos no cristal de $\mathrm{ZrO}_{2}$ tetragonal de corpo centrado. Cada átomo de Zr possui 8 átomos de oxigênio como vizinhos mais próximos, divididos em duas esferas de coordenação e cada átomo de oxigênio possui 4 átomos de zircônio como primeiros vizinhos, divididos em duas esferas de coordenação.

\begin{tabular}{||c|r||}
\hline \hline & Distância $(\AA)$ \\
\hline \hline$d\left(\mathrm{Zr}_{1}, \mathrm{O}_{1}\right)$ & 2,137 \\
\hline $\mathrm{d}\left(\mathrm{Zr}_{1}, \mathrm{O}_{2}\right)$ & 2,306 \\
\hline $\mathrm{d}\left(\mathrm{O}_{1}, \mathrm{O}_{2}\right)$ & 2,546 \\
\hline $\mathrm{d}\left(\mathrm{O}_{1}, \mathrm{O}_{1}\right)=\mathrm{d}\left(\mathrm{O}_{2}, \mathrm{O}_{2}\right)$ & 3,601 \\
\hline \hline
\end{tabular}

átomos de oxigênio, na direção $\hat{k}$. Relaxando-se estes átomos na direção das forças, os átomos de oxigênio tendem a voltar para a posição com $z=0,25$. Neste caso as duas estruturas são equivalentes, com os oito átomos de oxigênio à uma mesma distância do átomo de Zr primeiro vizinho.

Para obtermos as propriedades eletrônicas da estrutura com rede TCC, precisamos saber qual é a primeira zona de Brillouin do $\mathrm{ZrO}_{2}$ tetragonal de corpo centrado. Ela é um paralelepípedo truncado, como mostra a figura 3.16, onde estão destacados os pontos e as direções de alta simetria.

A estrutura de bandas da fase tetragonal de corpo centrado do $\mathrm{ZrO}_{2}$, juntamente com as densidades de estados total e projetadas nos átomos de Zr e O, está mostrada na figura 3.17 .

O gap de energia obtido é indireto e igual a $3,28 \mathrm{eV}$, na direção $\mathrm{X} \rightarrow \Gamma$. Os gaps de energia obtidos para as estruturas tetragonal primitiva e cúbica de face centrada foram, respectivamente, 4,04 eV e 3,33 eV. Portanto, o gap da fase TCC é mais semelhante ao obtido para a fase cúbica do que aquele obtido para a fase TP. A densidade de estados da zircônia tetragonal de corpo centrado apresenta as mesmas características daquelas apresentadas pela zircônia nas outras duas fases estudadas anteriormente, com os orbitais $s$ e $d$ característicos dos átomos de zircônio compondo os estados que descrevem o fundo da banda de condução e os orbitais 


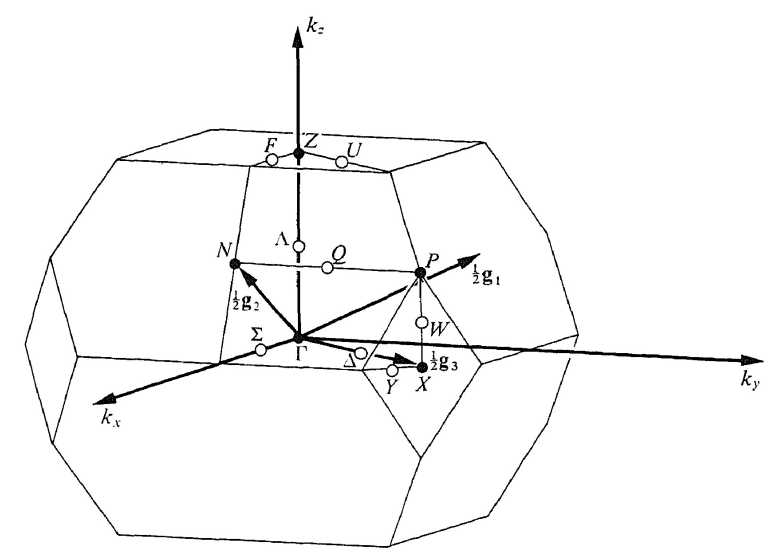

Figura 3.16: Primeira zona de Brillouin da fase tetragonal de corpo centrado do $\mathrm{ZrO}_{2}$, destacando os pontos e as direções de alta simetria.

$p$ dos átomos de oxigênio compondo os estados da banda de valência do material. Os estados $s$ característicos dos átomos de oxigênio compõem uma banda estreita e profunda em aproximadamente $E_{v}-17,0 \mathrm{eV}$. Como analisado anteriormente para as estruturas cúbica e TP da zircônia, na estrutura TCC as ligações entre os átomos é predominantemente de caráter iônico, podendo ser atribuída a uma interação entre a $\mathrm{Zr}^{4+}$ e os dois átomos de $\mathrm{O}^{2-}$. Esta característica é evidenciada pela densidade eletrônica mostrada na figura 3.18, no plano (011) da zircônia tetragonal de corpo centrado.

Tabela 3.9: Valores utilizados para as constantes de rede $a$ e $c$ e para o parâmetro interno $z$, e valores obtidos para o gap de energia $\mathrm{E}_{g}$ e para a energia de coesão $\mathrm{E}_{c}$ para o $\mathrm{ZrO}_{2}$ tetragonal de corpo centrado. Os parâmetros de rede e as energias estão dados em u.a. e eV, respectivamente.

\begin{tabular}{||l|c|c|c|c|c|c|c||}
\hline \hline & $a$ & $c$ & $z$ & $c / a$ & $\mathrm{E}_{g}$ & $\mathrm{E}_{c}$ & $\Delta_{\mathrm{f}} \mathrm{H}$ \\
\hline \hline Teórico & 6,804 & 9,796 & 0,222 & 1,44 & 3,28 & $-24,23$ & $-9,85$ \\
\hline Exp. $^{(a)}$ & 6,804 & 9,796 & 0,222 & 1,44 & - & - & - \\
\hline \hline
\end{tabular}

(a) Ref. [2] 


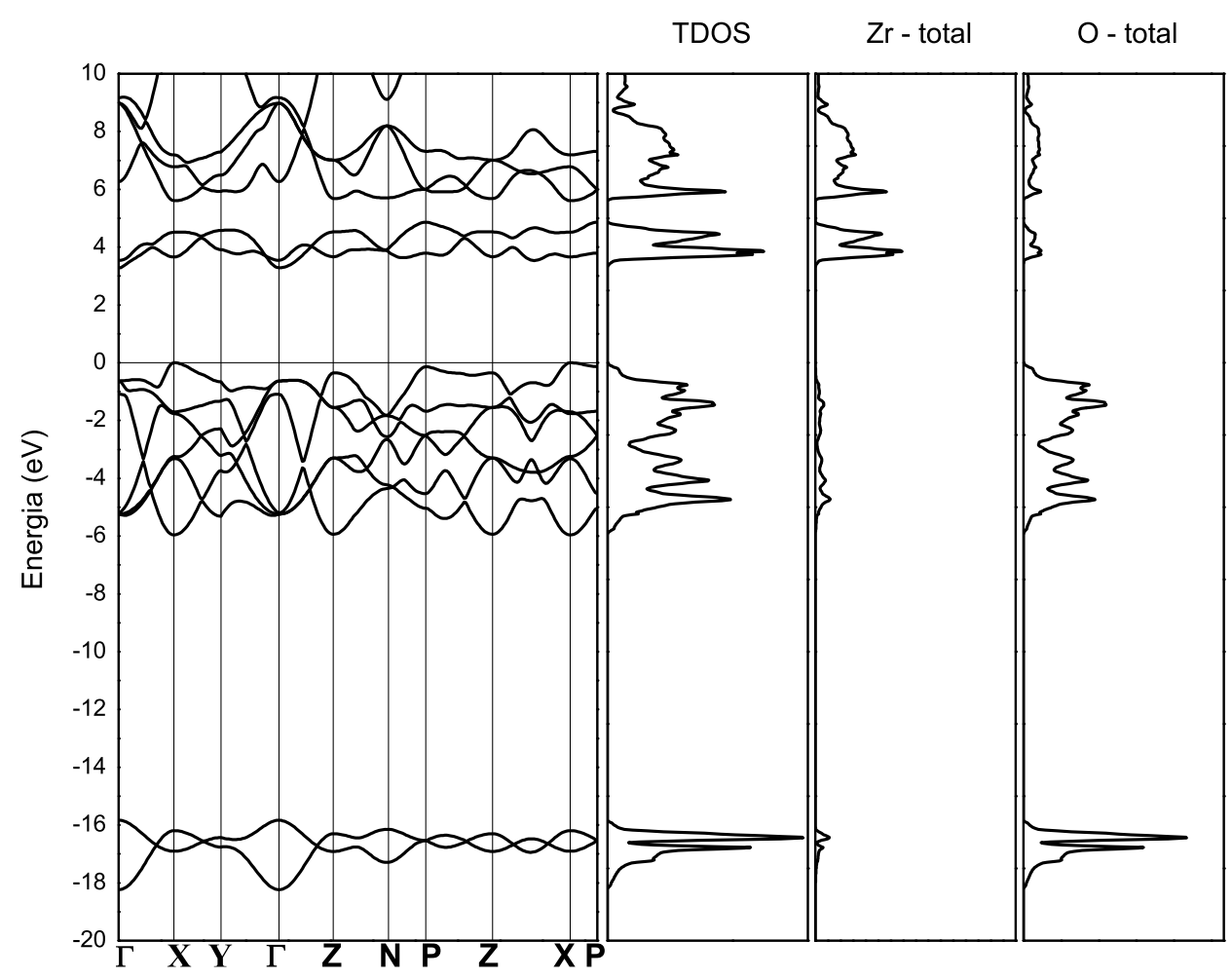

Figura 3.17: Estrutura de bandas e densidades de estados total (TDOS) e projetadas nos átomos de $\mathrm{Zr}$ (Zr-total) e $\mathrm{O}$ (O-total) do $\mathrm{ZrO}_{2}$ tetragonal de corpo centrado.

Calculamos a entalpia de formação da $\mathrm{ZrO}_{2}$ tetragonal de corpo centrado, de acordo com a equação (A.7) do apêndice A, e obtivemos $\Delta_{\mathrm{f}} \mathrm{H}^{\mathrm{TCC}-\mathrm{ZrO}_{2}}=-10,05 \mathrm{eV}$. Propomos, baseados neste estudo, que devido a pressões internas nos nanocristais, a estrutura estabilizada é quase cúbica, mas pode ser descrita tanto como uma distorção na estrutura cúbica de face centrada, como na estrutura tetragonal primitiva da zircônia. De qualquer modo, esta nova estrutura quase cúbica pode ter uma célula primitiva, tanto tetragonal primitiva como tetragonal de corpo centrado. Não existem diferenças estruturais que possam diferenciá-las e, ainda, nas duas es- 


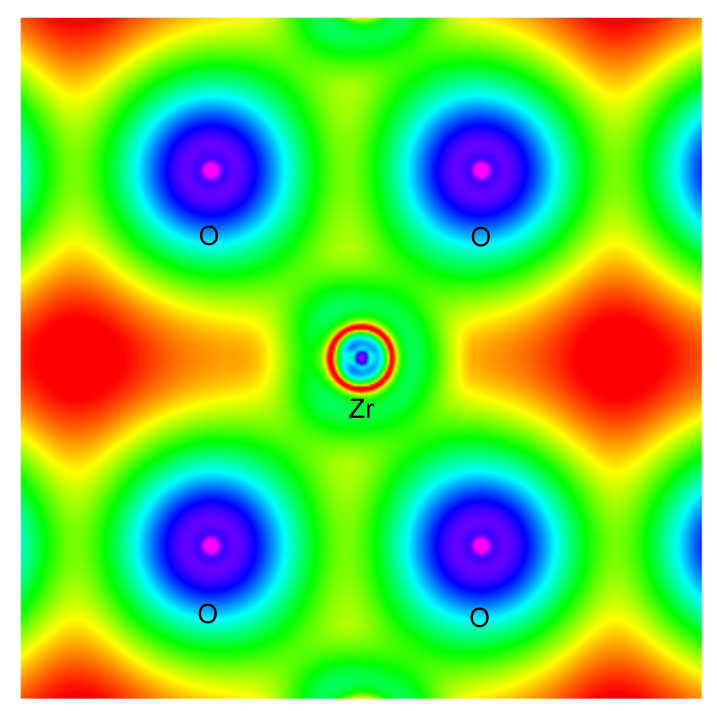

Figura 3.18: Densidade eletrônica, no plano (011), do $\mathrm{ZrO}_{2}$ tetragonal de corpo centrado, onde o esquema de cores segue o arco-íris, variando do violeta (alta densidade) para o vermelho (baixa densidade).

truturas os átomos de Zr apresentam os oito vizinhos de oxigênio divididos em dois diferentes tipos, cada tipo com quatro átomos. A diferenciação entre essas duas estruturas só seria possível através de medidas experimentais que caracterizassem a estrutura local do sistema. Experimentos deste tipo foram realizados [2], entretanto a análise destas medidas foram feitas considerando apenas a rede TP. Com isso, para se ajustar corretamente os dados experimentais foi necessário supor três diferentes distâncias entre os átomos de zircônio e oxigênio. Como mostrado nas tabelas 3.9 e 3.5, os parâmetros de rede experimentais e teóricos são muito próximos, mas as distâncias entre primeiros vizinhos teóricos e experimentais da rede TP são bem diferentes. Essa diferença se dá principalmente pelo parâmetro interno z. O valor teórico deste parâmetro é $z=0,306$ enquanto que o valor medido em [2] é $z=0,222$. Assim sendo, para que a estrutura vista experimentalmente seja a TP, seria necessário uma grande distorção nos átomos de oxigênio. Entretanto, em uma estrutura TCC, obtida com uma pequena distorção do parâmetro de rede na direção $\hat{k}$, o parâmetro interno ideal seria $z=0,25$. Valor este muito mais próximo 
de 0,222, ou seja, é necessária distorção muito menor na rede TCC para ajustar a estrutura teórica à estrutura experimental. Propomos então que a análise dos resultados de difração de raio-X e EXAFS considerem também a possibilidade da existência de estruturas cristalinas tetragonais de corpo centrado.

\subsection{Supercélulas de $\mathrm{ZrO}_{2}$}

O esquema de supercélula é adequado para se estudar defeitos profundos em materias. Entretanto, é preciso que a supercélula composta somente de átomos hospedeiros represente adequadamente o material, para ser usada como referência no estudo desses defeitos. Nesta seção, construímos supercélulas para descrever a zircônia nas fases cúbica e tetragonal para obter suas propriedades, antes de iniciar os estudos de defeitos nos materiais.

\subsubsection{Supercélula da Zircônia Cúbica}

Para o estudo de defeitos na zircônia cúbica, construiu-se, primeiramente, uma supercélula cúbica de faces centradas, com parâmetro de rede $3 a$, onde $a$ é parâmetro de rede da célula primitiva. Esta supercélula contém 81 átomos hospedeiros, sendo 27 átomos de Zr e 54 átomos de O. A figura 3.19 mostra uma representação cúbica desta supercélula. Determinamos, com isso, a estrutura de bandas desta supercélula, nas direções de alta simetria da primeira zona de Brillouin, mostrada

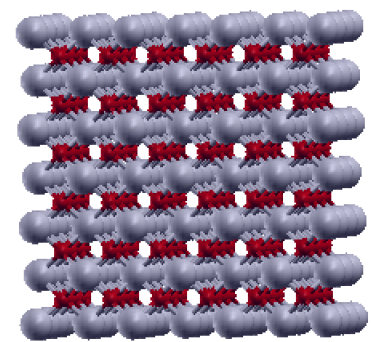

Figura 3.19: Supercélula do $\mathrm{ZrO}_{2}$ cúbico, mostrando a célula primitida repetida 3 vezes no espaço. 


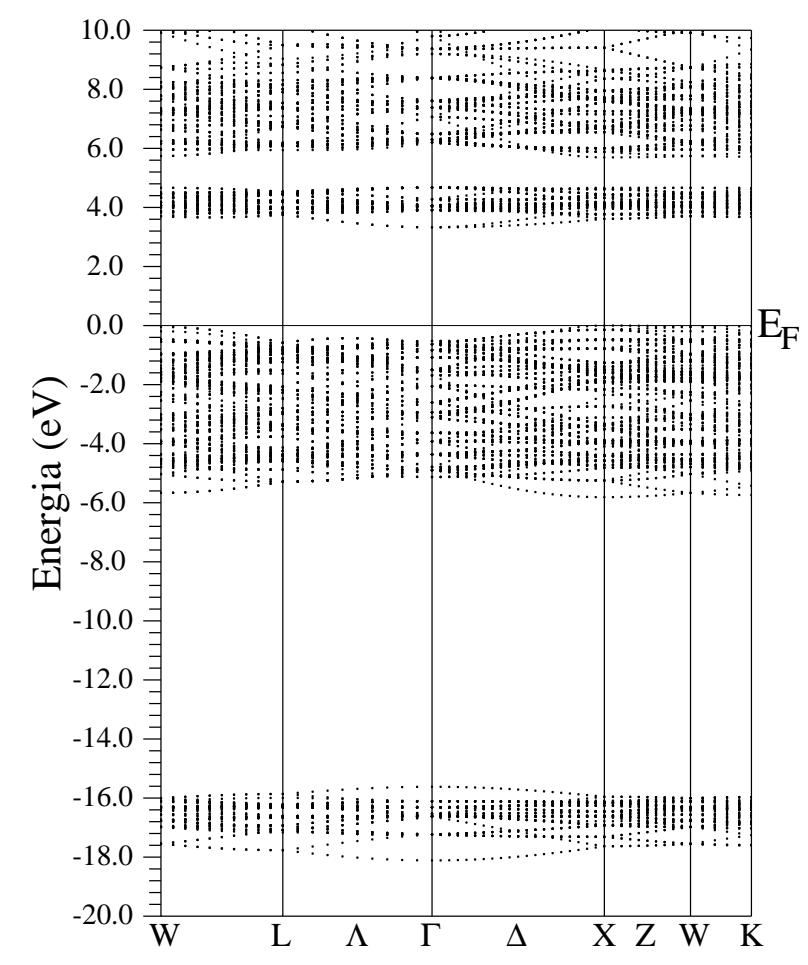

Figura 3.20: Estrutura de bandas da supercélula cúbica de faces centradas do $\mathrm{ZrO}_{2}$, com 81 átomos, em direções de alta simetria da zona de Brillouin.

na figura 3.20. Pela estrutura de bandas da supercélula percebe-se que esta estrutura apresenta um gap indireto, mesmo após o rebatimento dos pontos da zona de Brillouin da célula primitiva para os da supercélula, e que as faixas de energia são compostas de modo equivalente às da célula primitiva. Conclui-se que a supercélula representa corretamente o material e pode ser usada para se estudar as propriedades físicas de defeitos e impurezas.

\subsubsection{Supercélula da Zircônia Tetragonal}

A supercélula tetragonal, para descrever a zircônia tetragonal, foi construída com parâmetros de rede $3 a, 3 a$ e $2 c$, onde $a$ e $c$ são os parâmetros de rede da célula 
primitiva. Esta repetição faz com que a supercélula seja aproximadamente cúbica, de modo que quando da introdução de defeitos, as distâncias entre eles e suas imagens sejam praticamente as mesmas nas três direções. Esta supercélula contém 108 átomos hospedeiros, sendo 36 átomos de Zr e 72 átomos de O. A figura 3.21 mostra uma representação desta supercélula. Determinamos a estrutura de bandas desta supercélula, nas direções de alta simetria da primeira zona de Brillouin, mostrada na figura 3.22.

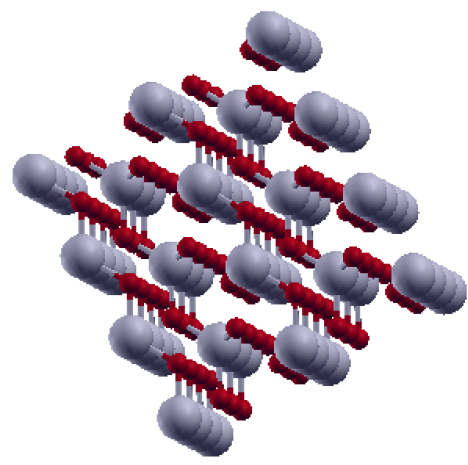

Figura 3.21: Supercélula do $\mathrm{ZrO}_{2}$ tetragonal, mostrando a célula primitida repetida no espaço.

Da mesma forma que para a supercélula representando a zircônia cúbica, a largura das faixas de energia são as mesmas que da célula primitiva e o sistema apresenta um gap indireto, mesmo após o rebatimento dos pontos da zona de Brillouin da célula primitiva para os da supercélula. Conclui-se, portanto, que a supercélula representa corretamente o material e pode ser usada para se estudar as propriedades físicas de defeitos e impurezas. 


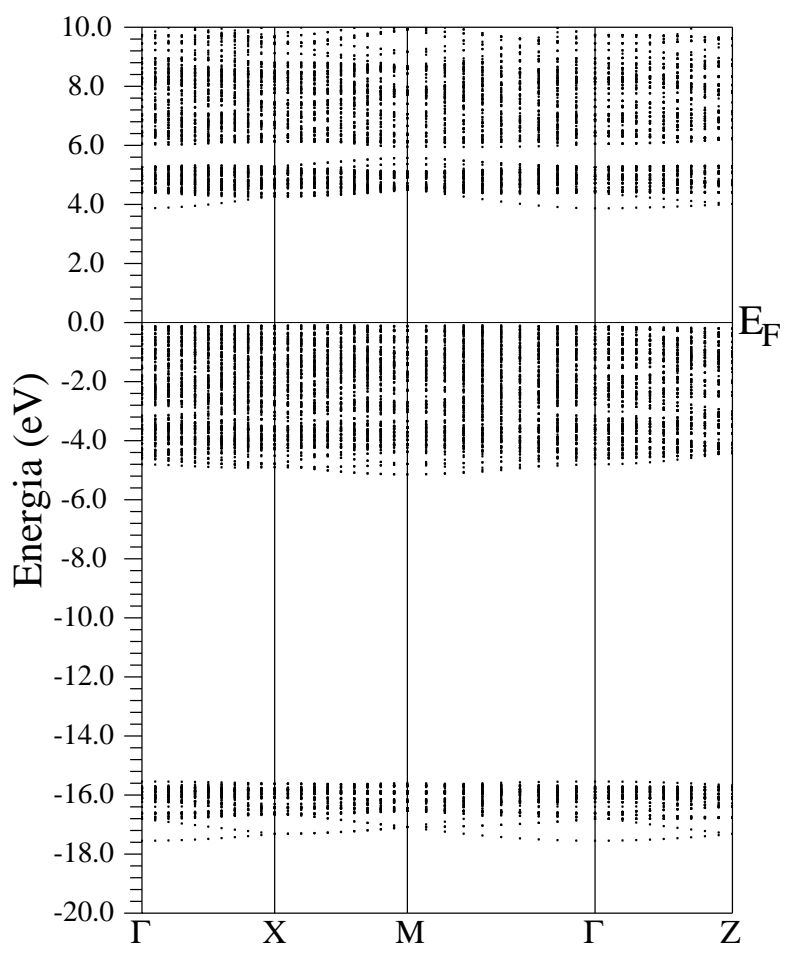

Figura 3.22: Estrutura de bandas da supercélula do $\mathrm{ZrO}_{2}$ tetragonal. 


\section{Capítulo 4}

\section{Defeitos e Impurezas no Cristal de $\mathrm{ZrO}_{2}$}

\subsection{Introdução}

A zircônia tem sido um material muito estudado recentemente mas, apesar de existirem vários estudos sobre a zircônia utilizando diferentes técnicas experimentais, poucos estudos teóricos têm sido realizados. Como descrito anteriormente, a fase estável da zircônia, a temperatura ambiente, é a monoclínica. Entretanto é possível estabilizar a zircônia na fase tetragonal, ou quase cúbica, a temperatura ambiente, através de processos que geram pós nanocristalinos. Quando os grãos destes pós forem menores que um certo tamanho crítico, a estrutura apresentada é quase cúbica. O tamanho crítico e o mecanismo pelo qual ocorre a estabilização da zircônia na fase tetragonal, quase cúbica, ainda não foram estabelecidos. Artigos recentes sugerem que esta estabilização estrutural é obtida para um tamanho de nanocristal de até $5 \mathrm{~nm}$ [36], mas há registros de partículas com até $40 \mathrm{~nm}$ estabilizadas na fase tetragonal [2].

Muito tem se falado sobre o papel das vacâncias de oxigênio na estabilização da estrutura, já que estas sempre estão presentes nas nanopartículas [36], mas poucos estudos de primeiros princípios foram realizados. Assim, o estudo da estrutura cristalina e da ordem atômica local podem ser vitais para o entendimento desses 
mecanismos. Ainda não se sabe como se comporta a estrutura local da zircônia quando presentes impurezas e defeitos. Alguns trabalhos sugerem um número de coordenação igual a 8 para o Zr na zircônia tetragonal, indicando que os átomos de oxigênio primeiros vizinhos da zircônia estão todos a uma mesma distância do Zr, mas Vlaic et.al. [1] propuseram um modelo de coordenação da forma $4+2+2$ para a estrutura local da zircônia. Entretanto, vários outros modelos foram propostos e ainda não há consenso entre eles. Outro ponto importante a ser destacado é como as vacâncias de oxigênio influenciam nas propriedades eletrônicas e estruturais do material. Como elas estão sempre presentes nas amostras, é importante saber como as características do material são influenciadas por sua presença. Essas vacâncias são impurezas profundas e podem introduzir níveis de energia na região do gap do material, modificando diversas propriedades eletrônicas e ópticas. Apesar desse fato consolidado, existe pouco estudo nessa direção.

Do ponto de vista tecnológico, o maior interesse está nas fases cúbica e tetragonal da zircônia. Entretanto, ela se apresenta nessas fases apenas a altas temperaturas. É possível, também, estabilizar a zircônia na fase tetragonal com a adição de dopantes, entre eles, o mais utilizado é o cério. Apesar de existirem muitos estudos experimentais sobre o sistema $\mathrm{ZrO}_{2}: \mathrm{Ce}_{\mathrm{Zr}}$, poucos estudos teóricos foram efetuados para descrever a zircônia dopada dessa forma.

O objetivo deste capítulo é estudar o efeito de vacâncias de oxigênio e de dopantes de Ce no cristal de zircônia, verificando as mudanças nas propriedades eletrônicas e estruturais causadas por eles.

\subsection{Vacância de Oxigênio: $V_{O}$}

Utilizando a supercélula cúbica com 81 átomos, sendo 27 átomos de zircônio e 54 átomos de oxigênio, apresentada no capítulo anterior, calculou-se o efeito de uma vacância de oxigênio na estrutura eletrônica do material. A simulação deste defeito foi feita retirando-se um átomo de oxigênio da supercélula. Os raios das regiões atômicas foram mantidos os mesmos utilizados para estudar a célula primitiva. O valor do parâmetro $R K$, que define o número de ondas planas utilizado na expansão 
do potencial na região intersticial foi $R K_{\text {máx }}=7$, valor este obtido nos testes de convergência realizados na célula primitiva, como descrito no capítulo anterior. A integração na zona de Brillouin foi efetuada somente no ponto $\Gamma$, o qual representa 27 pontos na célula primitiva.

As relaxações da estrutura foram feitas utilizando-se o método de amortecimento de Newton, como descrito no capítulo 2. Observamos que ao retirarmos o átomo de oxigênio, para simular a vacância, a distância entre o átomo de zircônio e a posição da vacância de oxigênio ideal, diminui. Esta diminuição é de $0,4 \%$. Ao mesmo tempo, o átomo de zircônio se aproxima de 3,44\% dos átomos de oxigênio, quebrando a simetria cúbica e apresentando 3 diferentes tipos de distância dos átomos de oxigênio. Assim, a remoção de um átomo de oxigênio perturba a região próxima ao sítio vacante, causando relaxações e modificando a posição de equilíbrio dos átomos na região do defeito. Essa pertubação quebra a simetria original do sistema, fazendo com que, ao invés de 8 átomos primeiros vizinhos, a esfera de coordenação do $\mathrm{Zr}$ ao redor da vacância tenha uma configuração $1+3+3+\mathrm{V}_{\mathrm{O}}$. A tabela 4.1 mostra a relação entre as distâncias dos primeiros vizinhos do oxigênio na supercélula pura e para o centro $\mathrm{ZrO}_{2}: \mathrm{V}_{\mathrm{O}}$, onde $\mathrm{Zr}_{1}$ indica o átomo de zircônio primeiro vizinho da vacância e $\mathrm{O}_{1}$ e $\mathrm{O}_{2}$ indicam os átomos de oxigênio primeiros e segundos vizinhos da vacância, respectivamente. Os terceiros vizinhos são muito pouco modificados pela presença da vacância, não sendo mostrados.

A vacância de oxigênio apresenta uma configuração eletrônica de camada fechada ( $\mathrm{S}=0$ ), deslocando os níveis de energia, quando comparada com a supercélula pura, além de introduzir um nível de energia na estrutura de bandas do material. Para se comparar a estrutura de bandas da supercélula com o defeito de vacância de oxigênio com a supercélula que descreve o cristal puro é necessário nivelar as energias de referência das duas, já que a vacância desloca todos os níveis de energia. Como a vacância é um defeito local, ela não deve alterar a estrutura de bandas do material e nem os níveis de energia associados aos átomos distantes da região do defeito. Dessa forma comparou-se o nível de energia relacionado com um átomo localizado longe do sítio vacante com o mesmo nível de energia relacionado com um 
Tabela 4.1: Distâncias, em Å, dos átomos próximos da vacância de oxigênio no centro $\mathrm{ZrO}_{2}: \mathrm{V}_{\mathrm{O}}$ cúbico e dos átomos próximos ao sítio de oxigênio no cristal perfeito, antes da retirada do átomo para simular a vacância de oxigênio. $\mathrm{Zr}_{1}$ indica o átomo de zircônio primeiro vizinho do sítio vacante e $\mathrm{O}_{1}$ e $\mathrm{O}_{2}$ indicam os átomos de oxigênio primeiros e segundos vizinhos da vacância, respectivamente.

\begin{tabular}{||c|c|c||}
\hline \hline & $\mathrm{ZrO}_{2}: \mathrm{V}_{\mathrm{O}}$ & $\mathrm{ZrO}_{2}$ \\
\hline \hline $\mathrm{d}\left(\mathrm{Zr}_{1}, \mathrm{~V}_{\mathrm{O}}\right)$ & 2,208 & 2,217 \\
$\mathrm{~d}\left(\mathrm{O}_{1}, \mathrm{~V}_{\mathrm{O}}\right)$ & 2,472 & 2,560 \\
$\mathrm{~d}\left(\mathrm{O}_{2}, \mathrm{~V}_{\mathrm{O}}\right)$ & 3,624 & 3,620 \\
$\mathrm{~d}\left(\mathrm{Zr}_{1}, \mathrm{O}_{1}\right)$ & 2,164 & 2,217 \\
$\mathrm{~d}\left(\mathrm{Zr}_{1}, \mathrm{O}_{2}\right)$ & 2,232 & 2,217 \\
$\mathrm{~d}\left(\mathrm{O}_{1}, \mathrm{O}_{2}\right)$ & 2,572 & 2,560 \\
\hline \hline
\end{tabular}

átomo na mesma posição na supercélula que descreve o cristal puro. Verificando a diferença entre esses níves calculou-se um fator $\delta$, que representa a diferença entre os níveis de energia das duas supercélulas. Com esse fator calculou-se a posição do nível de energia criado pela vacância, relativamente à supercélula pura. Depois do alinhamento das bandas, obtivemos que o nível de energia introduzido pelo centro $\mathrm{V}_{\mathrm{O}}$ está em $E_{v}+2,81 \mathrm{eV}$, onde $E_{v}$ representa o topo da banda de valência. Como o valor do gap é de $3,33 \mathrm{eV}$, concluímos que o nível de energia introduzido por este defeito se encontra dentro do gap do material, o qual pode ser observado na figura 4.1, que apresenta a estrutura de bandas do sistema $\mathrm{c}-\mathrm{ZrO}_{2}: \mathrm{V}_{\mathrm{O}}$.

Analizando a composição do sistema sem defeitos do ponto de vista da ionicidade dos átomos constituintes, podemos dizer que o átomo de Zr encontra-se no estado de carga $\mathrm{Zr}^{4+}$ e o de oxigênio no estado $\mathrm{O}^{2-}$. Neste modelo o átomo de zircônio doa quatro elétrons para os átomos de $\mathrm{O}$, dois para cada um, para formar a unidade $\mathrm{ZrO}_{2}$ do cristal. Os estados $s$ e $d$ do átomo de $\mathrm{Zr}$, desocupados e com características deslocalizadas, contribuem para a formação dos estados que compõem o fundo da banda de condução. Quando um átomo de oxigênio é retirado do sistema, ou seja, quando a vacância de oxigênio neutra é formada, o átomo de 


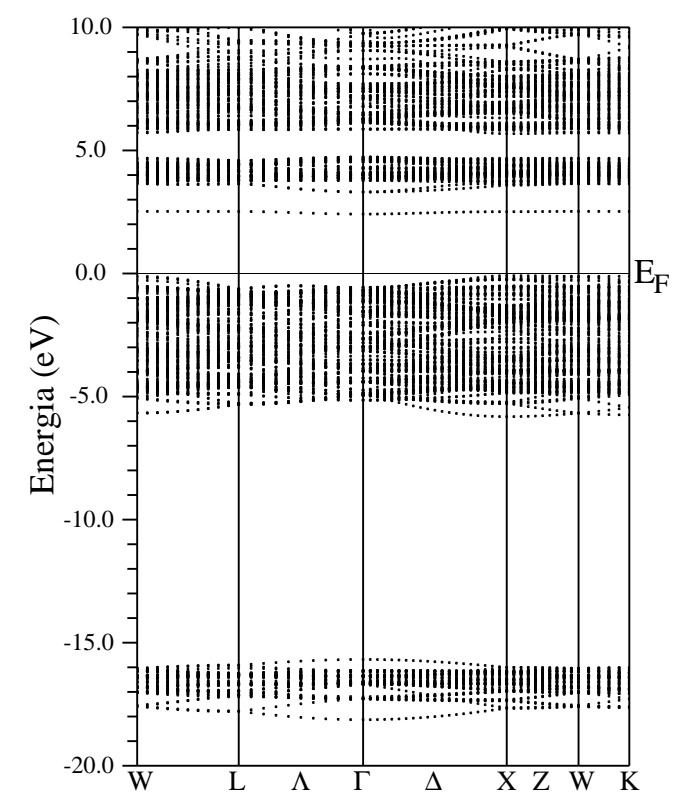

Figura 4.1: Estrutura de bandas do sistema c- $\mathrm{ZrO}_{2}: \mathrm{V}_{\mathrm{O}}$.

zircônio, vizinho à vacância, doa só dois elétrons e os outros dois elétrons restantes ficam localizados na sua vizinhança e, energeticamente, localizados no nível de defeito introduzido no gap, que tem caráter de orbital $d$ do Zr. A figura 4.2 mostra a densidade eletrônica do nível de energia de defeito, localizado no gap do material, no plano (110), que compreende 2 átomos de zircônio primeiros vizinhos da vacância de oxigênio. Calculou-se a energia de formação de uma vacância de oxigênio no estado de carga neutro, no cristal de $\mathrm{ZrO}_{2}$, como descrito no apêndice A, e o valor encontrado foi de $4,33 \mathrm{eV}$.

Como descrito no capítulo anterior, de maneira a explicar resultados experimentais obtidos por EXAFS (Extended X-ray Absorption Fine Structure), L. Acuña et. al. [2] adotaram um modelo para número de coordenação do $\mathrm{ZrO} 2_{2}$ composto por três diferentes distâncias entre um átomo de zircônio e seus átomos vizinhos de oxigênio. Como mostrado na tabela 4.1, a presença de uma vacância de oxigênio 


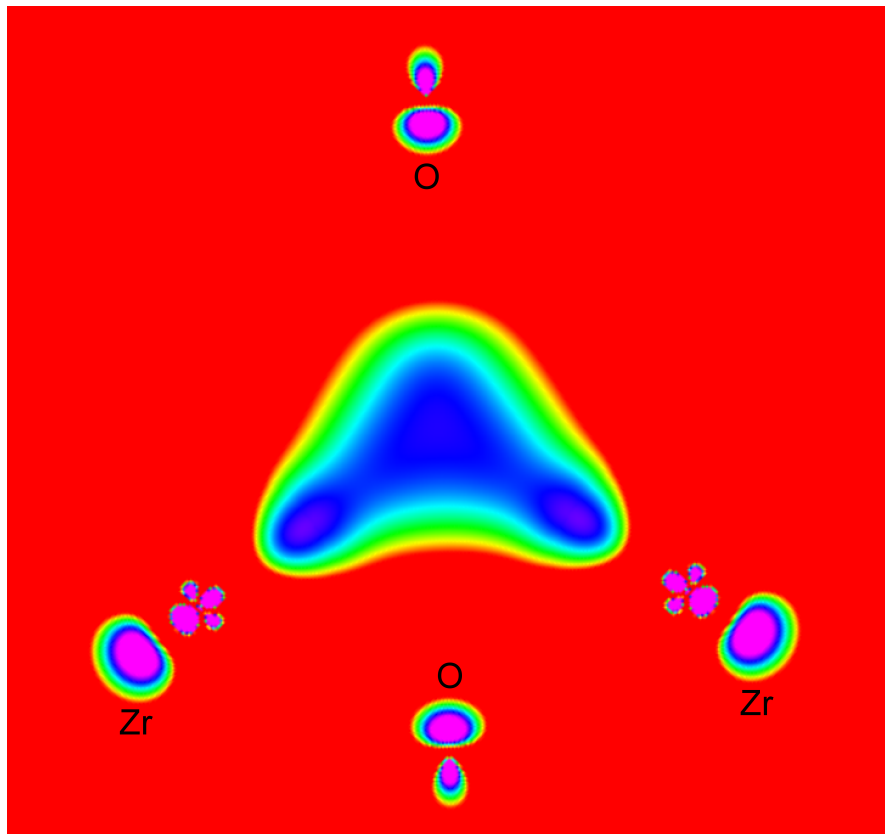

Figura 4.2: Densidade eletrônica, no plano (110), do nível de energia introduzido no gap do c- $\mathrm{ZrO}_{2}$, pela vacância de oxigênio, mostrando a localização da distribuição eletrônica nos átomos de Zr e seu caráter $d$. O esquema de cores segue o arco-íris, variando do violeta (alta densidade) para o vermelho (baixa densidade).

quebra a simetria local do sistema e faz com que existam três diferentes distâncias entre um átomo de Zr e os átomos primeiros vizinhos de oxigênio. Dessa forma, uma possível explicação para os dados experimentais obtidos por estes autores é a presença de vacâncias de oxigênio nas amostras, pois elas sempre estão presentes em qualquer nanopartícula de $\mathrm{ZrO}_{2}$ [36].

\subsection{Impureza substitucional de $\mathrm{Ce}: \mathrm{ZrO}_{2}: \mathrm{Ce}_{\mathrm{Zr}}$}

A simulação do centro de impureza substitucional de Ce foi efetuada substituindose o átomo de zircônio, $\mathrm{Z}=40$ e configuração eletrônica $[\mathrm{Kr}] 4 d^{2} 5 s^{2}$, por um átomo de cério, $\mathrm{Z}=58$ e configuração eletrônica [Xe] $4 f^{2} 5 d^{0} 6 s^{2}$, na supercélula cúbica com 81 átomos. Os raios das regiões atômicas foram mantidos os mesmos utilizados para estudar a célula primitiva, onde $r_{\mathrm{Ce}}=r_{\mathrm{Zr}}$. Utilizamos $R K_{\text {máx }}=7$ e a integração na 
zona de Brillouin foi efetuada somente no ponto $\Gamma$. A substituição perturba a região próxima ao sítio do Ce, causando relaxações e modificando a posição de equilíbrio dos átomos na região do defeito. As forças geradas nos átomos são simétricas de modo que as relaxações são do tipo respiratórias, para fora, em relação as posições no cristal perfeito. As relaxações estruturais foram efetuadas utilizandose o método de amortecimento de Newton, descrito no capítulo 2. A tabela 4.2 mostra as distâncias entre o átomo de zircônio e seus vizinhos, no cristal puro, e as distâncias entre a impureza substitucional de Ce e seus vizinhos.

Tabela 4.2: Distâncias, em $\AA$, dos átomos ao redor da impureza substitucional de $\mathrm{Ce}$, no sítio do $\mathrm{Zr}$, no $\mathrm{ZrO}_{2}$ cúbico, assim como dos átomos próximos ao sítio do átomo de Zr no cristal perfeito, antes da substituição do átomo de Zr pelo de Ce. $\mathrm{O}_{1}$ e $\mathrm{O}_{2}$ indicam os átomos de oxigênio primeiros e segundos vizinhos da impureza de $\mathrm{Ce}$, respectivamente, e $\mathrm{Zr}_{1}$ indica os átomos de zircônio primeiros vizinhos da impureza.

\begin{tabular}{||c|c|c||}
\hline \hline & $\mathrm{ZrO}_{2}: \mathrm{Ce}_{\mathrm{Zr}}$ & $\mathrm{ZrO}_{2}$ \\
\hline \hline $\mathrm{d}\left(\mathrm{O}_{1}, \mathrm{Ce}\right)$ & 2,299 & 2,217 \\
$\mathrm{~d}\left(\mathrm{Zr}_{1}, \mathrm{Ce}\right)$ & 3,642 & 3,620 \\
$\mathrm{~d}\left(\mathrm{O}_{2}, \mathrm{Ce}\right)$ & 4,256 & 4,245 \\
$\mathrm{~d}\left(\mathrm{Zr}_{1}, \mathrm{O}_{1}\right)$ & 2,209 & 2,217 \\
$\mathrm{~d}\left(\mathrm{Zr}_{1}, \mathrm{O}_{2}\right)$ & 2,224 & 2,217 \\
$\mathrm{~d}\left(\mathrm{O}_{1}, \mathrm{O}_{2}\right)$ & 2,526 & 2,560 \\
\hline \hline
\end{tabular}

A distância entre a impureza e os átomos de oxigênio primeiros vizinhos aumenta da ordem de 4\%, em relação à distância no cristal perfeito. O valor de 2,299 $\AA$ é $3 \%$ menor que a distância entre Ce e $\mathrm{O}$ no cristal de $\mathrm{CeO}_{2}$, cuja estrutura cristalina mais estável é cúbica de faces centradas. Destes resultados, percebemos que a introdução do cério modifica, de modo acentuado, a posição dos primeiros vizinhos, provocando uma relaxação para fora, quando comparamos as distâncias entre a impureza de cério e seus oito átomos primeiros vizinhos de oxigênio com as distâncias do átomo de zircônio, que foi substituído pela impureza na supercélula, 
e os seus oito átomos primeiros vizinhos de oxigênio. Quando comparamos as distâncias dos segundos, terceiros e quartos vizinhos da impureza e do átomo de Zr no cristal perfeito, percebemos que os deslocamentos dos átomos diminuem, em relação a suas posições ideais. Isso é um indício de que o átomo de cério altera apenas localmente a configuração estrutural da zircônia. Calculou-se a energia de formação da impureza de $\mathrm{Ce}$, no estado de carga neutro, no cristal de $\mathrm{ZrO}_{2}$, como descrito no apêndice A, e o valor encontrado foi de $0,68 \mathrm{eV}$. Este pequeno valor indica que a formação deste centro é muito favorável.

A densidade eletrônica de valência da impureza de Ce substitucional no sítio do $\mathrm{Zr}$ no c- $\mathrm{ZrO}_{2}$, no plano de uma das faces do cubo, está mostrada na figura 4.3.

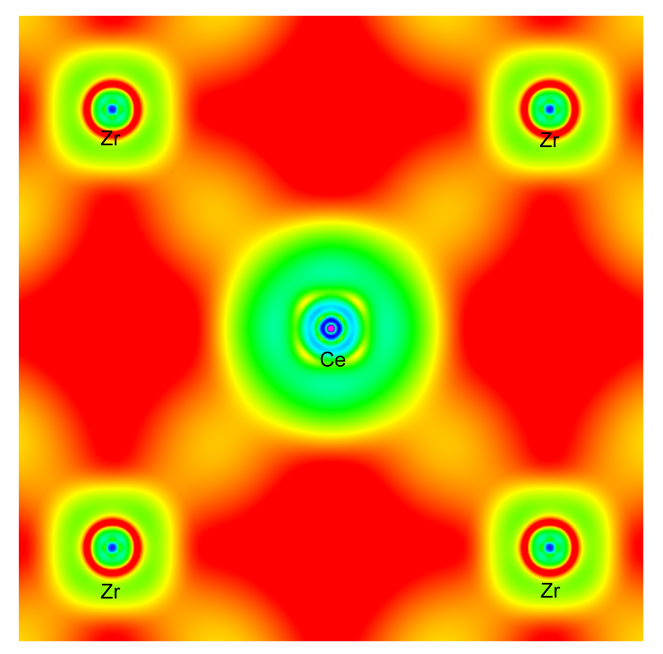

Figura 4.3: Densidade eletrônica de valência, no plano (100), da impureza de Ce substitucional no sítio do $\mathrm{Zr}$ no $\mathrm{c}-\mathrm{ZrO}_{2}$. O esquema de cores segue o arco-íris, variando do violeta (alta densidade) para o vermelho (baixa densidade).

No centro da figura está o átomo de cério, rodeado pelos átomos de Zr segundos vizinhos da impureza. A figura mostra uma densidade eletrônica praticamente nula na região intersticial, entre a impureza e os átomos de zircônio. Obtivemos, também, a densidade eletrônica no plano (110), mostrada na figura 4.4. No centro da figura está o átomo de cério rodeado pelos átomos de oxigênio primeiros vizinhos. Podemos perceber, pela distribuição de carga, que a ligação entre eles é iônica, com um pequeno caráter covalente, maior que o caráter covalente na ligação Zr-O. 


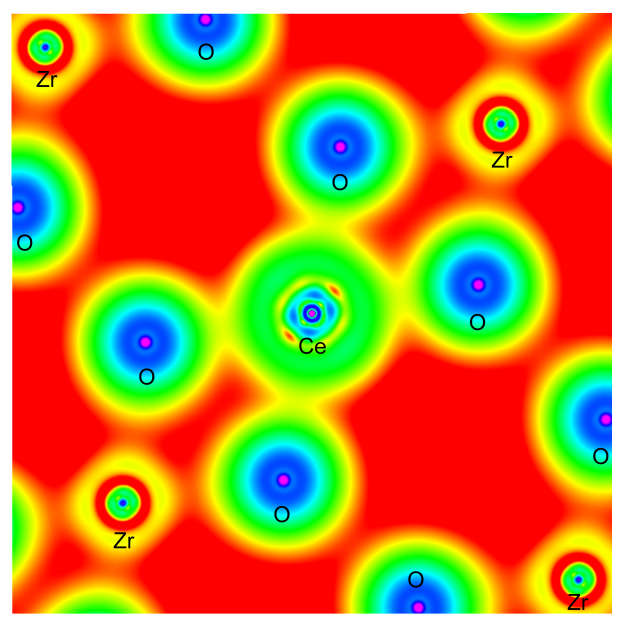

Figura 4.4: Densidade eletrônica de valência, no plano (110), da impureza de Ce substitucional no sítio do $\mathrm{Zr}$ no c- $\mathrm{ZrO}_{2}$. O esquema de cores segue o arco-íris, variando do violeta (alta densidade) para o vermelho (baixa densidade).

Analisando a composição do sistema do ponto de vista da ionicidade dos átomos constituintes, como o átomo de cério e o de zircônio são isovalentes, ao substituirmos um átomo de Zr por um de Ce, a impureza encontra-se no estado de carga $\mathrm{Ce}^{4+}$ e os átomos de oxigênio vizinhos no estado $\mathrm{O}^{2-}$. Assim, a impureza faz um papel semelhante ao de um átomo de $\mathrm{Zr}$, doando quatro elétrons para os átomos de $\mathrm{O}$, dois para cada um, para formar a unidade $\mathrm{CeO}_{2}$ na região do defeito.

Nossos resultados da estrutura eletrônica do centro $\mathrm{ZrO}_{2}$ : $\mathrm{Ce}_{\mathrm{Zr}}$ mostram que ele apresenta configuração de camada fechada $(\mathrm{S}=0)$. Para se comparar a estrutura de bandas da supercélula com a impureza de Ce com a supercélula que descreve o cristal puro é necessário nivelar as energias de referência das duas, já que a impureza perturba os níveis de energia. Como esta impureza tem características de um defeito profundo, ela não deve alterar a estrutura de bandas do material e nem os níveis de energia associados aos átomos distantes da região do defeito. Dessa forma comparou-se o nível de energia relacionado com um átomo localizado longe do sítio substituído com o mesmo nível de energia relacionado com um átomo na mesma posição na supercélula que descreve o cristal puro. Verificada a diferença entre esses níves calculou-se um fator $\delta$, que representa a diferença entre os níveis 
de energia das duas supercélulas. Depois do alinhamento das bandas, obtivemos a estrutura de bandas do material com a impureza isolada de Ce substituindo um átomo de Zr, que está mostrada na figura 4.5.

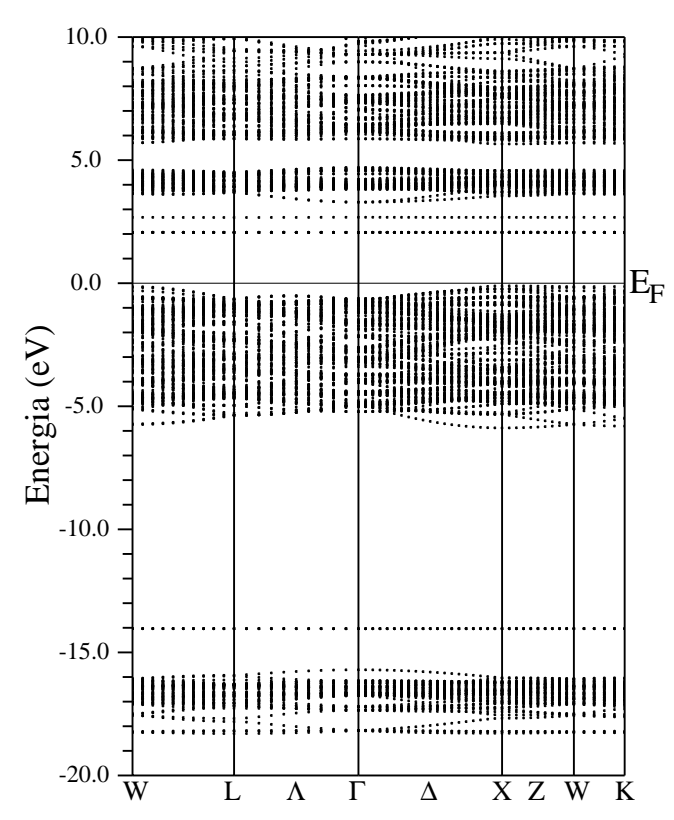

Figura 4.5: Estrutura de bandas do centro $\mathrm{ZrO}_{2}: \mathrm{Ce}_{\mathrm{Zr}}$.

Podemos observar que o defeito acrescenta níveis de energia no interior do gap, próximos ao seu topo, um nível de energia hiper-profundo, em $E_{v}-14,0 \mathrm{eV}$, localizado entre a banda de valência do material e a banda formada pelos orbitais $2 s$ dos átomos de oxigênio, assim como uma banda estreita, ressonante com os estados $2 s$ dos átomos de oxigênio, em aproximadamente $E_{v}-19,0 \mathrm{eV}$. A figura 4.6 apresenta a densidade de estados total da célula unitária, onde estão destacados os níveis de energia relacionados à impureza, ou seja, que apresentam porcentagem de carga dentro da esfera de cério.

Os níveis de energia desocupados e localizados no gap do material estão relacionados aos orbitais $f$ do Ce, os quais se desdobram, devido ao campo cristalino, em dois níveis de energia, um com degenerescência $12\left(t_{1}+t_{2}\right)$ e outro duplamente 


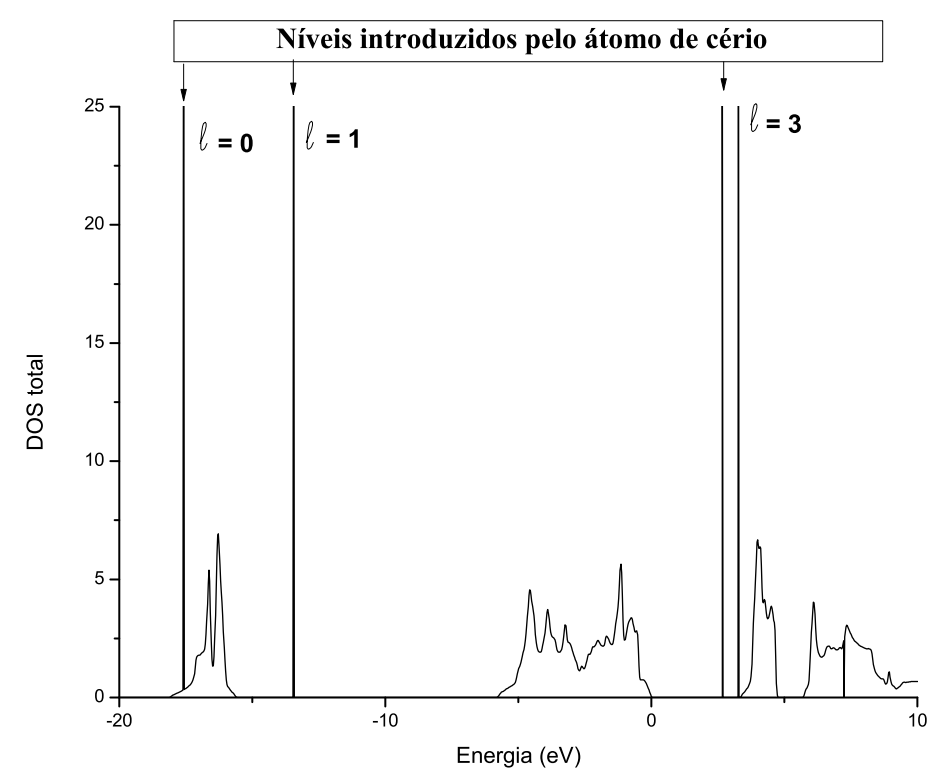

Figura 4.6: Densidade de estados do cristal de $\mathrm{ZrO}_{2}$ mostrando os níveis de energia introduzidos pelo átomo de cério.

degenerado $\left(\mathrm{a}_{1}\right)$. A porcentagem de carga com caráter $f$ dentro da esfera de Ce, para destes estados, é de aproximadamente 86\%, indicando que eles são estados altamente localizados na impureza. Apesar de não termos utilizado nenhum tipo de correção para descrever os níveis $f$ do Ce, os quais são fortemente correlacionados, acreditamos que ao utilizarmos o formalismo GGA+U o nível de defeito, introduzido no gap pela impureza de Ce, passe a ser ressonante na banda de condução. Isto porque a essência deste formalismo consiste na separação do espaço total variacional em dois [51,52], de modo que um dos subespaços descreve os orbitais localizados $f$ através da interação coulombiana on-site do tipo Hubbard, que é inserida na Hamiltoniana do sistema, e o outro subespaço descreve todos os outros estados para o qual a aproximação GGA é suficiente para descrever as interações. No momento, este formalismo está sendo aplicado para este sistema para averi- 
guarmos se nossa suposição está correta. Se sim, o resultado explicaria porque as impurezas de Ce estabilizam o $\mathrm{ZrO}_{2}$ nas estruturas tetragonal e quase cúbica, pois não introduzem níveis de energia no gap do material, tem uma energia de formação muito pequena e aumentam as distâncias de ligação entre os átomos, favorecendo a estrutura cúbica. 


\section{Capítulo 5}

\section{Conclusão}

Neste trabalho foram estudadas as propriedades físicas de cristais cúbicos e tetragonais de $\mathrm{ZrO}_{2}$ utilizando cálculos ab initio baseados na teoria do funcional da densidade. As propriedades estruturais e eletrônicas destes sistemas estão em acordo com valores experimentais. Medidas experimentais dos parâmetros de rede de pós nanocristalinos de zircônia, estabilizados na temperatura ambiente, mostram uma relação $c / a=1,02$. Este resultado pode indicar que as estruturas estabilizadas nestes pós nanocristalinos estariam relacionadas com o $\mathrm{ZrO}_{2}$ em uma rede cúbica de face centrada com uma pequena distorção para fora na direção $\hat{k}$ ou em uma rede tetragonal com uma relaxação para dentro na direção $\hat{k}$ e no plano basal. Levando em conta a primeira hipótese, podemos descrever estes cristais como uma rede tetragonal de faces centradas, com parâmetros de rede $a=b \neq c$. Entretanto, esta rede é equivalente à rede de Bravais tetragonal de corpo centrado com parâmetros $a^{\prime}=b^{\prime}=a \sin \left(45^{\circ}\right)$ e $c^{\prime}=c$, onde $a$ e $c$ seriam as constantes de rede da estrutura tetragonal de faces centradas (que não é uma das 14 redes de Bravais), enquanto que $a^{\prime}, b^{\prime}$ e $c^{\prime}$ são as constantes de rede da estrutura com rede de Bravais tetragonal de corpo centrado. Por outro lado, podemos assumir que os parâmetros experimentais estejam associados a nanocristais com rede tetragonal primitiva, com uma pequena distorção para dentro na direção $\hat{k}$ e no plano basal, e uma grande modificação no parâmetro interno z, que determina as posições dos átomos de oxigênio. Dos nossos resultados da zircônia nas estruturas cúbica, tetragonal primitiva e tetragonal de 
corpo centrado, propomos que, devido a pressões internas nos nanocristais, a estrutura estabilizada é quase cúbica, mas pode ser descrita tanto como uma distorção na estrutura cúbica de face centrada, como na estrutura tetragonal primitiva da zircônia. De qualquer modo, esta nova estrutura quase cúbica pode ter uma célula primitiva, tanto tetragonal primitiva como tetragonal de corpo centrado. Não existem diferenças estruturais que possam diferenciá-las e, ainda, nas duas estruturas os átomos de Zr apresentam os oito vizinhos de oxigênio divididos em dois diferentes tipos, cada tipo com quatro átomos. Propomos então que a análise dos resultados de difração de raio-X e EXAFS considerem também a possibilidade da existência de estruturas cristalinas tetragonais de corpo centrado. Como tem sido reportado que em nanopartículas de $\mathrm{ZrO}_{2}$ sempre estão presentes vacâncias de oxigênio, estudamos as modificações causadas nas propriedades do material pela introdução deste tipo de defeito. Verificou-se que a ausência de um átomo de oxigênio introduz um nível de energia localizado no interior do gap do material com característica $d$ do átomo de zircônio, além de pertubar a estrutura local da zircônia, ficando cada átomo de zircônio com um padrão diferente de primeiros vizinhos, apresentado um padrão de coordenação 3. Nas análises dos dados experimentais obtidos por difração de raios-X e EXAFS foram utilizadas simulações onde a estrutura tetragonal cristalográfica usual foi considerada. Dessas simulações o modelo adotado para o número de coordenação do $\mathrm{ZrO}_{2}$ é composto por três diferentes distâncias entre um átomo de zircônio e seus átomos vizinhos de oxigênio. A concordância deste modelo com nossos resultados das propriedades estruturais da vacância de oxigênio sugere a existência de vacâncias de oxigênio nas nanopartículas. A análise dos resultados das propriedades estruturais, eletrônicas e energéticas da impureza substitucional de Ce em $\mathrm{ZrO}_{2}$, mostra que esta impureza não introduz níveis de energia no gap do material, tem uma energia de formação muito pequena e provoca um aumento nas distâncias de ligação Ce-O, quando comparadas com as distâncias Zr-O do cristal. Estas características, em conjunto, podem explicar porque as impurezas de Ce, em diferentes concentrações, estabilizam o $\mathrm{ZrO}_{2}$ nas estruturas tetragonal e cúbica. 


\section{Apêndice A}

\section{Energia de Formação}

O cálculo da energia de formação de um sistema cristalino contendo defeitos e/ou impurezas permite estimar quais são as condições mais favoráveis para a incorporação destes no material. A energia de formação pode ser determinada através da abundância relativa dos átomos que constituem o meio onde o material é crescido. Tal abundância está relacionada à concentração de equilíbrio $\left[\mathrm{D}_{\mathrm{i}}\right]$ de uma impureza ou defeito em um composto cristalino e é dada por :

$$
\Delta \mathrm{G}_{\mathrm{f}}=\Delta \mathrm{E}_{\mathrm{f}}+\mathrm{T} \Delta \mathrm{S}_{\mathrm{f}}+\mathrm{p} \Delta \mathrm{V}_{\mathrm{f}}
$$

Na expressão (A.1), $\Delta \mathrm{E}_{\mathrm{f}}$ é a variação da energia total, incluindo termos do potencial químico, $\Delta \mathrm{G}_{\mathrm{f}}$ é a variação da energia livre de Gibbs, T é a temperatura, $\Delta \mathrm{S}_{\mathrm{f}}$ é a variação da entropia, p é a pressão e $\Delta V_{f}$ é a variação do volume quando a impureza é introduzida no composto cristalino. Vamos nos concentrar somente na variação da energia total, uma vez que a variação do volume é praticamente nula na fase sólida e a variação da entropia é muito pequena e cancela-se quando comparamos diferentes impurezas. Assim, temos que $\Delta \mathrm{G}_{\mathrm{f}}=\Delta \mathrm{E}_{\mathrm{f}}$. A energia de formação de um defeito pode, em muitos casos, ser definida como a diferença entre as energias totais do sistema que contém a impureza e do sistema perfeito, ambos com o mesmo número total de átomos. No nosso caso, porém, por estarmos considerando impurezas que mudam a composição do material, a energia de formação da impureza é expressa, também, em termos dos potenciais químicos 
dos átomos que constituem o composto cristalino e dos átomos de impureza (X). Se o centro estiver ionizado, a energia de formação da impureza depende tanto de sua carga líquida q como da energia de Fermi $\mathrm{E}_{\mathrm{F}}$. Para uma impureza X em $\mathrm{ZrO}_{2}$ a energia de formação é dada por

$$
\mathrm{E}_{\mathrm{f}}^{\mathrm{q}}=\mathrm{E}\left[\left(\mathrm{n}_{\mathrm{Zr}}, \mathrm{n}_{\mathrm{O}}, \mathrm{n}_{\mathrm{X}}\right)^{\mathrm{q}}\right]-\mathrm{n}_{\mathrm{Zr}} \mu_{\mathrm{Zr}}-\mathrm{n}_{\mathrm{O}} \mu_{\mathrm{O}}-\mathrm{n}_{\mathrm{X}} \mu_{\mathrm{X}}+\mathrm{q}\left(\varepsilon_{\mathrm{v}}+\mathrm{E}_{\mathrm{F}}+\delta_{\mathrm{q}}\right),
$$

onde $\mathrm{E}\left[\left(\mathrm{n}_{\mathrm{Zr}}, \mathrm{n}_{\mathrm{O}}, \mathrm{n}_{\mathrm{X}}\right)^{\mathrm{q}}\right]$ é a energia total da supercélula, no estado de carga q, que contém $\mathrm{n}_{\mathrm{Zr}}$ átomos de $\mathrm{Zr}, \mathrm{n}_{\mathrm{O}}$ átomos de $\mathrm{O}$ e $\mathrm{n}_{\mathrm{X}}$ átomos de impureza, sendo $\mu_{\mathrm{Zr}}, \mu_{\mathrm{O}}$ e $\mu_{\mathrm{X}}$ seus respectivos potenciais químicos. A energia de Fermi é tomada como a energia do reservatório do qual são transferidas ou retiradas as q cargas eletrônicas e, convencionalmente, toma-se $\mathrm{E}_{\mathrm{F}}$ como sendo zero no topo da faixa de valência $\left(\varepsilon_{\mathrm{v}}\right)$, atingindo seu valor máximo no fundo da faixa de condução, ou seja, $0 \leq \mathrm{E}_{\mathrm{F}} \leq \mathrm{E}_{\mathrm{g}}$, onde $\mathrm{E}_{\mathrm{g}}$ é a largura da faixa de energia proibida do material semicondutor. Devido à esta escolha de uma referência, devemos incluir explicitamente o valor máximo da energia da banda de valência $\varepsilon_{\mathrm{v}}$, assim como um fator $\delta_{\mathrm{q}}$, que alinha o potencial de referência na supercélula com a impureza, no estado de carga q, com o potencial da supercélula que descreve o cristal perfeito.

A variação dos potenciais químicos está sujeita à limites rigorosos que podem, diretamente, estar relacionados com as condições experimentais. Os potenciais químicos do $\mathrm{Zr}$ e do $\mathrm{O}$ não são independentes. Considerando que ambas espécies estão em equilíbrio térmico com o cristal de $\mathrm{ZrO}_{2}$, seus potenciais químicos, a $\mathrm{T}=0 \mathrm{~K}$, devem obedecer

$$
\mu_{\mathrm{ZrO}_{2}}^{*}=\mu_{\mathrm{Zr}}+2 \mu_{\mathrm{O}}
$$

onde $\mu_{\mathrm{ZrO}_{2}}^{*}$ é a energia total por unidade de fórmula do $\mathrm{ZrO}_{2}$, calculada teoricamente para a estrutura optimizada. Neste caso, a condição expressa pela equação (A.3) determina, univocamente, os valores dos potenciais químicos. Com isso, uma vez fixado o valor do potencial químico de uma das espécies de átomos do $\mathrm{ZrO}_{2}$, digamos do Zr, o valor do potencial químico do oxigênio estará automaticamente determinado. Pode-se, então, tomar o potencial químico $\mu_{\mathrm{Zr}}$ do Zr como variável independente e a energia de formação de uma impureza será função deste potencial químico e da energia de Fermi $\mathrm{E}_{\mathrm{F}}$. 
Os potenciais químicos evidenciam a perda de estequiometria de um sistema e dependem de diferentes parâmetros, tais como pressões parciais e condições de crescimento do material. Os potenciais químicos do $\mathrm{Zr}$ e do $\mathrm{O}$ no cristal de $\mathrm{ZrO}_{2}$ possuem um intervalo de variação bem definido e seus valores dependem das várias fases formadas por eles. O valor máximo do potencial químico do Zr está limitado pelo seu valor $\mu_{\mathrm{Zr}}^{*}$ no cristal metálico, que é sua fase mais estável, e portanto dado por

$$
\mu_{\mathrm{Zr}}^{*}=\frac{\mathrm{E}_{\mathrm{T}}(\mathrm{Zr})}{2}
$$

onde $\mathrm{E}_{\mathrm{T}}(\mathrm{Zr})$ é a energia total do cristal de zircônio metálico, calculada com uma célula primitiva hcp. Assim, o limite para seu potencial químico, no cristal de $\mathrm{ZrO}_{2}$ é, então,

$$
\mu_{\mathrm{Zr}} \leq \mu_{\mathrm{Zr}}^{*}
$$

Da mesma forma, o valor máximo para o potencial químico do $\mathrm{O}$, no cristal de $\mathrm{ZrO}_{2}$, está limitado ao seu valor na fase de referência, que iremos tomar como a da molécula de oxigênio, e teremos

$$
\mu_{\mathrm{O}} \leq \mu_{\mathrm{O}}^{*}, \quad \text { onde } \quad \mu_{\mathrm{O}}^{*}=\frac{\mathrm{E}_{\mathrm{T}}\left(\mathrm{O}_{2}\right)}{2}
$$

A entalpia de formação do $\mathrm{ZrO}_{2}\left(\Delta_{\mathrm{f}} \mathrm{H}^{\mathrm{ZrO}_{2}}\right)$ é definida como a variação da entalpia na reação em que um mol da substância é formada a partir dos elementos em seus estados de referência, é negativa para compostos estáveis, e é dada por :

$$
\Delta_{\mathrm{f}} \mathrm{H}^{\mathrm{ZrO}}=\mu_{\mathrm{ZrO}_{2}}^{*}-\mu_{\mathrm{Zr}}^{*}-2 \mu_{\mathrm{O}}^{*}
$$

Se combinarmos as expressões das equações (A.3), (A.5), (A.6) e (A.7) teremos os seguintes intervalos para as variações dos potenciais químicos do $\mathrm{Zr}$ e do O no $\mathrm{ZrO}_{2}$, em termos da entalpia de formação do cristal de $\mathrm{ZrO}_{2}$ :

$$
\begin{aligned}
& \mu_{\mathrm{Zr}}^{*}+\left[\Delta_{\mathrm{f}} \mathrm{H}^{\mathrm{ZrO}_{2}}\right] \leq \mu_{\mathrm{Zr}} \leq \mu_{\mathrm{Zr}}^{*} \\
& \mu_{\mathrm{O}}^{*}+\frac{1}{2}\left[\Delta_{\mathrm{f}} \mathrm{H}^{\mathrm{ZrO}_{2}}\right] \leq \mu_{\mathrm{O}} \leq \mu_{\mathrm{O}}^{*} .
\end{aligned}
$$


Se introduzirmos um parâmetro $\gamma$, tal que $0 \leq \gamma \leq 1$, teremos

$$
\begin{aligned}
\mu_{\mathrm{Zr}} & =\mu_{\mathrm{Zr}}^{*}+\gamma\left[\Delta_{\mathrm{f}} \mathrm{H}^{\mathrm{ZrO}_{2}}\right] \\
\mu_{\mathrm{O}} & =\mu_{\mathrm{O}}^{*}+\frac{(1-\gamma)}{2}\left[\Delta_{\mathrm{f}} \mathrm{H}^{\mathrm{ZrO}_{2}}\right],
\end{aligned}
$$

onde, se $\gamma=0$, o valor do potencial químico do Zr será máximo $\left(\mu_{\mathrm{Zr}}=\mu_{\mathrm{Zr}}^{*}\right)$ e dizemos que a vizinhança é rica em zircônio, enquanto que, se $\gamma=1$, o valor do potencial químico do $\mathrm{O}$ será máximo $\left(\mu_{\mathrm{O}}=\mu_{\mathrm{O}}^{*}\right)$ e a vizinhança será rica em oxigênio.

\section{A.1 Energia de Formação da Vacância de Oxigê- nio: $\mathrm{ZrO}_{2}: \mathrm{V}_{\mathrm{O}}$}

Para obtermos a energia de formação da vacância de oxigênio em $\mathrm{ZrO}_{2}$, em um estado de carga q, devemos admitir que o sistema é formado em um ambiente rico em $\operatorname{Zr}(\gamma=0)$. Utilizando a equação (A.11), a energia de formação fica:

$$
\begin{aligned}
\mathrm{E}_{\mathrm{f}}\left[\left(\mathrm{ZrO}_{2}: \mathrm{V}_{\mathrm{O}}\right)^{\mathrm{q}}\right] & =\mathrm{E}\left[\left(\mathrm{ZrO}_{2}: \mathrm{V}_{\mathrm{O}}\right)^{\mathrm{q}}\right]-\mathrm{E}\left(\mathrm{ZrO}_{2}\right)+\mu_{\mathrm{O}}^{*}+ \\
& +\frac{1}{2}\left[\Delta_{\mathrm{f}} \mathrm{HrO}^{\mathrm{ZrO}_{2}}\right]+\mathrm{q}\left(\varepsilon_{\mathrm{v}}+\mathrm{E}_{\mathrm{F}}+\delta_{\mathrm{q}}\right)
\end{aligned}
$$

onde $\mathrm{E}\left[\left(\mathrm{ZrO}_{2}: \mathrm{V}_{\mathrm{O}}\right)^{\mathrm{q}}\right]$ é a energia total da supercélula com o defeito, no estado de carga q, $\mathrm{E}\left(\mathrm{ZrO}_{2}\right)$ é a energia total da supercélula perfeita, $\mu_{\mathrm{O}}^{*}$ é o valor máximo do potencial químico do $\mathrm{O}$, tomado ser a metade da energia total calculada para a molécula de oxigênio, e $\Delta_{\mathrm{f}} \mathrm{H}^{\mathrm{ZrO}_{2}}$ é o calor de formação do cristal de $\mathrm{ZrO}_{2}$, calculado pela expressão (A.7).

\section{A.2 Energia de Formação da Impureza Substitu- cional de Ce no sítio do $\mathrm{Zr}: \mathrm{ZrO}_{2}: \mathrm{Ce}_{\mathrm{Zr}}$}

Para a determinação dos limites de variação do potencial químico do dopante de Ce devemos explorar os vários compostos que a impureza pode formar devido as 


\section{A.2. ENERGIA DE FORMAÇÃO DA IMPUREZA SUBSTITUCIONAL DE CE NO SÍTIO DO Z}

suas interações com o sistema. O limite superior para o potencial químico $\mu_{\mathrm{Ce}}$ da impureza será imposto pelo potencial químico $\mu_{\mathrm{Ce}}^{*}$ do cristal metálico. Existe, ainda, a possibilidade de formação de vários compostos em equilíbrio com o cristal de $\mathrm{ZrO}_{2}$ dopado com Ce. Assumindo a possibilidade de formação do composto $\mathrm{CeO}_{2}$, cuja entalpia de formação é

$$
\Delta_{\mathrm{f}} \mathrm{H}^{\mathrm{CeO}_{2}}=\mu_{\mathrm{CeO}_{2}}^{*}-\mu_{\mathrm{Ce}}^{*}-2 \mu_{\mathrm{O}}^{*},
$$

a restrição para o limite do potencial químico do Ce fica:

$$
\mu_{\mathrm{CeO}_{2}}^{*}=\mu_{\mathrm{Ce}}+2 \mu_{\mathrm{O}} .
$$

Das equações (A.13) e (A.14) podemos obter a expressão para a variação do potencial químico do Ce no caso em que o composto que pode ser formado, em equilíbrio com o cristal de $\mathrm{ZrO}_{2}$ dopado com Ce, for o $\mathrm{CeO}_{2}$ :

$$
\mu_{\mathrm{Ce}}=\mu_{\mathrm{Ce}}^{*}+2\left(\mu_{\mathrm{O}}^{*}-\mu_{\mathrm{O}}\right)+\Delta_{\mathrm{f}} \mathrm{H}^{\mathrm{CeO}_{2}} .
$$

Substituindo nesta equação a expressão para $\left(\mu_{O}^{*}-\mu_{O}\right)$, dada pela equação (A.11), temos

$$
\mu_{\mathrm{Ce}}=\mu_{\mathrm{Ce}}^{*}-(1-\gamma)\left[\Delta_{\mathrm{f}} \mathrm{H}^{\mathrm{ZrO}}{ }_{2}\right]+\Delta_{\mathrm{f}} \mathrm{H}^{\mathrm{CeO}_{2}} .
$$

Desta espressão podemos verificar que o intervalo de variação do potencial químico do Ce é dependente das entalpias de formação dos dois compostos em equilíbrio: $\mathrm{ZrO}_{2}$ e $\mathrm{CeO}_{2}$. Como $\mu_{\mathrm{Ce}}-\mu_{\mathrm{Ce}}^{*} \leq 0$, então devemos ter que $\Delta_{\mathrm{f}} \mathrm{H}^{\mathrm{CeO}_{2}}<\Delta_{\mathrm{f}} \mathrm{H}^{\mathrm{ZrO}}$ para que a relação (A.16) seja sempre válida, tanto para $\gamma=1$ como para $\gamma=$ 0. Os valores encontrados para as entalpias de formação dos compostos $\mathrm{ZrO}_{2}$ e $\mathrm{CeO}_{2}$ foram, respectivamente, $\Delta_{\mathrm{f}} \mathrm{H}^{\mathrm{c}-\mathrm{ZrO}_{2}}=-9,94 \mathrm{eV}, \Delta_{\mathrm{f}} \mathrm{H}^{\mathrm{t}-\mathrm{ZrO}_{2}}=-10,06 \mathrm{eV}$, $\Delta_{\mathrm{f}} \mathrm{H}^{\mathrm{tcc}-\mathrm{ZrO}}=-9,85 \mathrm{eV}$ e $\Delta_{\mathrm{f}} \mathrm{H}^{\mathrm{CeO}_{2}}=-10,21 \mathrm{eV}$, mostrando que $\Delta_{\mathrm{f}} \mathrm{H}^{\mathrm{CeO}_{2}}<$ $\Delta_{\mathrm{f}} \mathrm{H}^{\mathrm{ZrO}}{ }_{2}$ e, portanto a equação (A.16) é sempre válida. Para obtermos a energia de formação da impureza de Ce no sítio de Zr, em um estado de carga q, utilizamos a equação

$$
\mathrm{E}_{\mathrm{f}}\left[\left(\mathrm{ZrO}_{2}: \mathrm{Ce}_{\mathrm{Zr}}\right)^{\mathrm{q}}\right]=\mathrm{E}\left[\left(\mathrm{ZrO}_{2}: \mathrm{Ce}_{\mathrm{Zr}}\right)^{\mathrm{q}}\right]-\mathrm{E}\left(\mathrm{ZrO}_{2}\right)+\mu_{\mathrm{Zr}}-\mu_{\mathrm{Ce}}+\mathrm{q}\left(\varepsilon_{\mathrm{v}}+\mathrm{E}_{\mathrm{F}}+\delta_{\mathrm{q}}\right),
$$


onde $\mathrm{E}\left[\left(\mathrm{ZrO}_{2}: \mathrm{Ce}_{\mathrm{Zr}}\right)^{\mathrm{q}}\right]$ é a energia total da supercélula com a impureza, no estado de carga q, E $\left(\mathrm{ZrO}_{2}\right)$ é a energia total da supercélula perfeita, $\mu_{\mathrm{Zr}}$ é o potencial

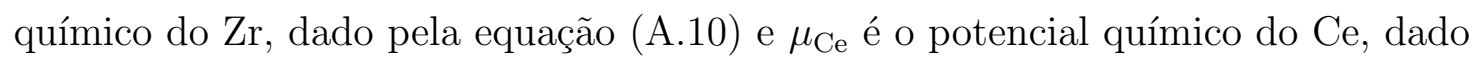
pela equação (A.16). Substituindo estas expressões, a equação (A.17) fica:

$$
\begin{aligned}
\mathrm{E}_{\mathrm{f}}\left[\left(\mathrm{ZrO}_{2}: \mathrm{Ce}_{\mathrm{Zr}}\right)^{\mathrm{q}}\right] & =\mathrm{E}\left[\left(\mathrm{ZrO}_{2}: \mathrm{Ce}_{\mathrm{Zr}}\right)-\mathrm{E}\left(\mathrm{ZrO}_{2}\right)^{\mathrm{q}}\right]+\mu_{\mathrm{Zr}}^{*}-\mu_{\mathrm{Ce}}^{*}+ \\
& +\Delta_{\mathrm{f}} \mathrm{H}^{\mathrm{ZrO}_{2}}-\Delta_{\mathrm{f}} \mathrm{H}^{\mathrm{CeO}_{2}}+\mathrm{q}\left(\varepsilon_{\mathrm{v}}+\mathrm{E}_{\mathrm{F}}+\delta_{\mathrm{q}}\right)
\end{aligned}
$$

a qual independe de $\gamma$. 


\section{Apêndice B}

\section{Cálculo da distância entre primeiros vizinhos na zircônia tetragonal}

Como mostrado no capítulo 3, as estruturas tetragonal primitiva e de corpo centrado da zircônia são muito semelhantes, sendo que as distâncias entre os primeiros vizinhos são idênticas. No caso da estrura primitiva, a célula unitária possui 6 átomos na base, cujas posições são mostradas na tabela B.1.

Tabela B.1: Posições dos átomos de Zr e O na estrutura tetragonal primitiva

\begin{tabular}{||l|c||}
\hline \hline Átomo & Posição \\
\hline \hline $\mathrm{Zr}_{1}$ & $(0,0,0)$ \\
\hline $\mathrm{Zr}_{2}$ & $(a / 2, a / 2, c / 2)$ \\
\hline $\mathrm{O}_{1}$ & $(0, a / 2, z c)$ \\
\hline $\mathrm{O}_{2}$ & $(0, a / 2,(z+1 / 2) c)$ \\
\hline $\mathrm{O}_{3}$ & $(a / 2,0,(-z+1 / 2) c)$ \\
\hline $\mathrm{O}_{4}$ & $(a / 2,0,-z c)$ \\
\hline \hline
\end{tabular}

Já a estrutura de corpo centrado possui 3 átomos na base, mostradas na tabela B.2. 
Tabela B.2: Posições dos átomos de Zr e O na estrutura tetragonal de corpo centrado

\begin{tabular}{||l|c||}
\hline \hline Átomo & Posição \\
\hline \hline $\mathrm{Zr}_{1}$ & $(0,0,0)$ \\
\hline $\mathrm{O}_{1}$ & $\left(0, a^{\prime} / 2, c^{\prime} / 4\right)$ \\
\hline $\mathrm{O}_{2}$ & $\left(a^{\prime} / 2,0, a^{\prime} / 4\right)$ \\
\hline \hline
\end{tabular}

Utilizando os vetores de translação da rede TBC, pode-se construir uma célula semelhante à estrutura primitiva. A tabela B.3 mostra uma comparação entre as posições dos átomos nas duas estruturas.

Tabela B.3: Posições dos átomos de $\mathrm{Zr}$ e $\mathrm{O}$ nas estruturas tetragonal de corpo centrado (TCC) e tetragonal primitiva (TP)

\begin{tabular}{||l|c|c||}
\hline \hline Átomo & TCC & TP \\
\hline \hline $\mathrm{Zr}_{1}$ & $(0,0,0)$ & $(0,0,0)$ \\
\hline $\mathrm{Zr}_{2}$ & $(a / 2, a / 2, c / 2)$ & $(a / 2, a 2, c / 2)$ \\
\hline $\mathrm{O}_{1}$ & $(0, a / 2, z c)$ & $(0, a / 2, z c)$ \\
\hline $\mathrm{O}_{2}$ & $(0, a / 2,(z+1 / 2) c)$ & $(0, a / 2,(z+1 / 2) c)$ \\
\hline $\mathrm{O}_{3}$ & $(a / 2,0, z c)$ & $(a / 2,0,-z c)$ \\
\hline $\mathrm{O}_{4}$ & $(a / 2,0,(z+1 / 2) c)$ & $(a / 2,0,(-z+1 / 2) c)$ \\
\hline \hline
\end{tabular}

Em ambos os casos, cada átomo de zircônio possui 8 átomos de oxigênio como primeiros vizinhos, divididos em duas esferas de coordenação, com 4 oxigênios cada. Calculando a distância entre o $\mathrm{Zr}_{2}$ e os oxigênio ao redor na estrutura TBC, tem-se:

$$
\begin{gathered}
d_{1}^{T C C}\left(Z r_{2}, O_{1}\right)=\sqrt{\left(\frac{a}{2}\right)^{2}+\left(\frac{1}{2}-z\right)^{2} c^{2}}=d_{4}^{T B C}\left(Z r_{2}, O_{4}\right) \\
d_{2}^{T C C}\left(Z r_{2}, O_{2}\right)=\sqrt{\left(\frac{a}{2}\right)^{2}+(z c)^{2}}=d_{3}^{T C C}\left(Z r_{2}, O_{3}\right)
\end{gathered}
$$




$$
\begin{gathered}
d_{3}^{T C C}\left(Z r_{2}, O_{3}\right)=\sqrt{\left(\frac{a}{2}\right)^{2}+(z c)^{2}}=d_{2}^{T C C}\left(Z r_{2}, O_{2}\right) \\
d_{4}^{T C C}\left(Z r_{2}, O_{4}\right)=\sqrt{\left(\frac{a}{2}\right)^{2}+\left(\frac{1}{2}-z\right)^{2} c^{2}}=d_{1}^{T C C}\left(Z r_{2}, O_{1}\right)
\end{gathered}
$$

Com o mesmo calculo para a estrutura TP, chega-se em

$$
\begin{gathered}
d_{1}^{T P}\left(Z r_{2}, O_{1}\right)=\sqrt{\left(\frac{a}{2}\right)^{2}+\left(\frac{1}{2}-z\right)^{2} c^{2}} \\
d_{2}^{T P}\left(Z r_{2}, O_{2}\right)=\sqrt{\left(\frac{a}{2}\right)^{2}+(z c)^{2}} \\
d_{3}^{T P}\left(Z r_{2}, O_{3}\right)=\sqrt{\left(\frac{a}{2}\right)^{2}+\left(\frac{1}{2}+z\right)^{2} c^{2}} \\
d_{4}^{T P}\left(Z r_{2}, O_{4}\right)=\sqrt{\left(\frac{a}{2}\right)^{2}+(z c)^{2}}=d_{2}^{T P}\left(Z r_{2}, O_{2}\right)
\end{gathered}
$$

Como a estrutura é periódica:

$$
\frac{1}{2}+z=\frac{1}{2}+z-1=z-\frac{1}{2}=-\left(\frac{1}{2}-z\right)
$$

Dessa forma, tem-se que:

$$
d_{3}^{T P}\left(Z r_{2}, O_{3}\right)=\sqrt{\left(\frac{a}{2}\right)^{2}+\left(\frac{1}{2}+z\right)^{2} c^{2}}=\sqrt{\left(\frac{a}{2}\right)^{2}+\left(-\left(\frac{1}{2}-z\right)\right)^{2} c^{2}}=d_{1}^{T P}\left(Z r_{2}, O_{1}\right)
$$

E portanto:

$$
\begin{aligned}
& d_{1}^{T C C}\left(Z r_{2}, O_{1}\right)=d_{1}^{T P}\left(Z r_{2}, O_{1}\right) \\
& d_{2}^{T C C}\left(Z r_{2}, O_{2}\right)=d_{2}^{T P}\left(Z r_{2}, O_{2}\right)
\end{aligned}
$$

Assim as distâncias entre os primeiros vizinhos de ambas as estruturas são iguais. 



\section{Referências Bibliográficas}

[1] G. Vlaic, R. D. Monte, P. Fornasiero, E. Fonda, J. Kaspar e M. Graziani, J. Catal. 182, 378 (1999).

[2] L. M. Acuña, D. G. Lamas, R. O. Fuentes, I. O. Fábregas, M. C. A. Fantini, A. F. Craievich e R. J. Prado, J. Appl. Cryst. 43, 227 (2010).

[3] J. C. Garcia, L. M. R. Scolfaro, A. T. Lino, V. N. Freire, G. A. Farias, C. C. Silva, H. W. Alves, S. Rodrigues e E. F. da Silva, J. Appl. Phys. 100, 104103 (2006).

[4] G. Teufer, Acta Cryst. 15, 1187 (1965).

[5] G. Fadda, L. Colombo e G. Zanzotto, Phys. Rev. B 79, 214102 (2009).

[6] I. O. Fábregas, D. G. Lamas, N. M. W. de Reca, A. F. Craievich, M. C. A. Fantini e R. J. Prado, Powder Diffraction Suppl. 23, (2008).

[7] I. O. Fábregas, D. G. Lamas, N. M. W. de Reca, M. C. A. Fantini, A. F. Craievich e R. J. Prado, J. Appl. Phys. 41, 680 (2008).

[8] M. Born e J. R. Oppenheimer, Annalen der Physik 389, 457 (1927).

[9] C. Eckart, Phys. Rev. 46, 383 (1935).

[10] P. Hohenberg e W. Kohn, Phys. Rev. 136, (1964).

[11] W. Kohn e L. J. Sham, Phys. Rev. 140, (1965).

[12] T. H. Thomas, Proc. Camb. Phil. Soc. 23, 542 (1927). 
[13] E. Fermi, Rend. Accad. Naz. Lincei. 6, 602 (1927).

[14] D. Singh e L. Nordstrom, Planewaves, Pseudopotential and the LAPW Method (Springer, ADDRESS, 2006).

[15] J. C. Slater, Phys. Rev. 51, 846 (1937).

[16] J. P. Perdew, K. Burke e M. Ernzerhof, Phys. Rev. Lett. 77, 3865 (1996).

[17] P. Blaha, K. Schwartz, P.Sorantin e S. B. Trickey, Comput. Phys. Commun. 59, 399 (1990).

[18] D. M. Ceperley e B. J. Alder, Phys. Rev. Lett. 47, 566 (1980).

[19] J. P. Perdew e A. Zunger, Phys. Rev. B 23, 5048 (1981).

[20] K. Capelle, arXiv:cond-mat/0211443v5 (2006).

[21] J. P. Perdew e Y. Wang, Phys. Rev. B 45, 13244 (1992).

[22] Y. Wang, Phys. Rev. B 43, 8911 (1991).

[23] M. Levy e J. P. Perdew, Phys. Rev. A 32, 2010 (1985).

[24] G. L. Oliver e J. P. Perdew, Phys. Rev. A 20, 397 (1979).

[25] C. Bowen, G. Sugiyama e B. J. Alder, Phys. Rev. B 50, 14838 (1994).

[26] S. Moroni, D. M. Ceperley e G. Senatore, Phys. Rev. Lett. 75, 689 (1995).

[27] G. Ortiz, Phys. Rev. B 45, 11328 (1992).

[28] E. H. Lieb e S. Oxford, Int. J. Quantum Chem. 19, 427 (1981).

[29] O. K. Andersen, Phys. Rev. B 12, 3060 (1975).

[30] D. D. Koelling e G. O. Arbman, J. Phys. F 5, 2041 (1975).

[31] H. J. F. Jansen e A. J. Freeman, Phys. Rev. B 30, 561 (1984). 
[32] E. Sjöstedt, L. Nordström e D. J. Singh, Solid State Commun. 114, 15 (2000).

[33] D. D. Koelling e B. N. Harmon, J. Phys. C 10, 3107 (1977).

[34] A. M. Dobrotvorskii e R. A. Evarestov, Phys. Stat. Sol. B 66, 83 (1974).

[35] R. A. Evarestov, M. I. Petrashen e E. M. Ledovskaya, Phys. Stat. Sol. B 68, $453(1975)$.

[36] D. M. Ramos, P. V. Suchko, J. L. Gavartin e A. L. Shluger, Phys. Rev. B 78, 235432 (2008).

[37] J. C. Garcia, Dissertação de mestrado, IFUSP, São Paulo, 2005.

[38] H. J. Monkhorst e J. P. Pack, Phys. Rev. B 13, 5188 (1976).

[39] S. Cottenier, DFT and the fammily of (L)APW methods: a step-by-step introduction (Imstituut voor kern-en Stralingsfysica, K.U. Leve, Belgium, ADDRESS, 2002).

[40] F. D. Murnaghan, Proc. Natl. Acad. Sci. 30, 244 (1944).

[41] C. J. Howard, R. J. Hill e B. E. Reichert, Acta Cryst. 116 (1988).

[42] G. Jomard, T. Petit, A. Pasturel, L. Magaud, G. Kresse e J. Hafner, Phys. Rev. B 59, 4044 (1999).

[43] F. Qunbo, W. Fuchi, Z. Huiling e Z. Feng, Molec. Sim. 34, 1099 (2008).

[44] R. H. French, S. J. Glass, F. S. Ohuchi, Y. N. Xu e W. Ching, Phys. Rev. B 49, 5133 (1994).

[45] D. W. McComb, Phys. Rev. B 54, 7094 (1996).

[46] S. Kobayashi, A. Yamasaki e T. Fujiwara, Jpn. J. App. Phys. 42, 6946 (2003).

[47] R. P. Feynman, Phys. Rev. 56, 340 (1939).

[48] R. Yu, D. Singh e H. Krakauer, Phys. Rev. B 43, 6411 (1991). 
[49] E. V. Stefanovich, A. L. Shluger e C. R. Catlow, Phys. Rev. B 49, 560 (1994).

[50] V. Zavodinsky e A. Chibisov, Phys. Sol. Stat. 48, 363 (2006).

[51] P. W. Anderson, Phys. Rev. 124, 41 (1961).

[52] J. Hubbard, Proc. R. Soc. London Ser. A 277, 237 (1964). 